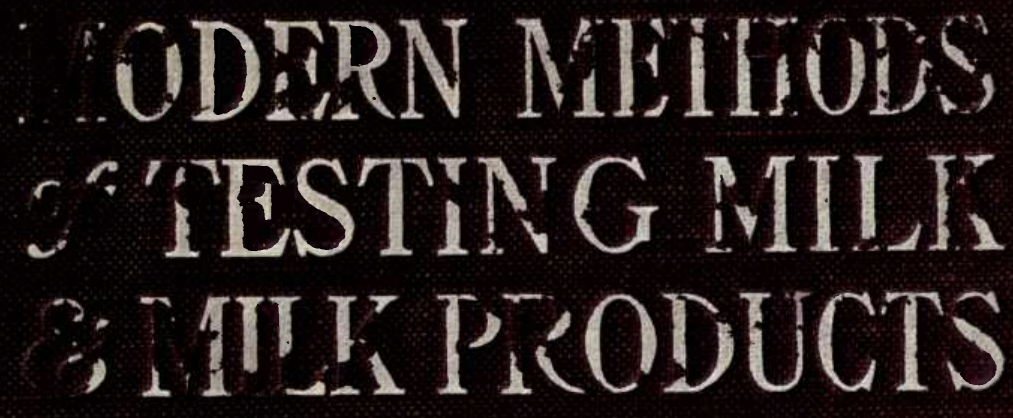

IUCIUS L.VAN STYITE, 


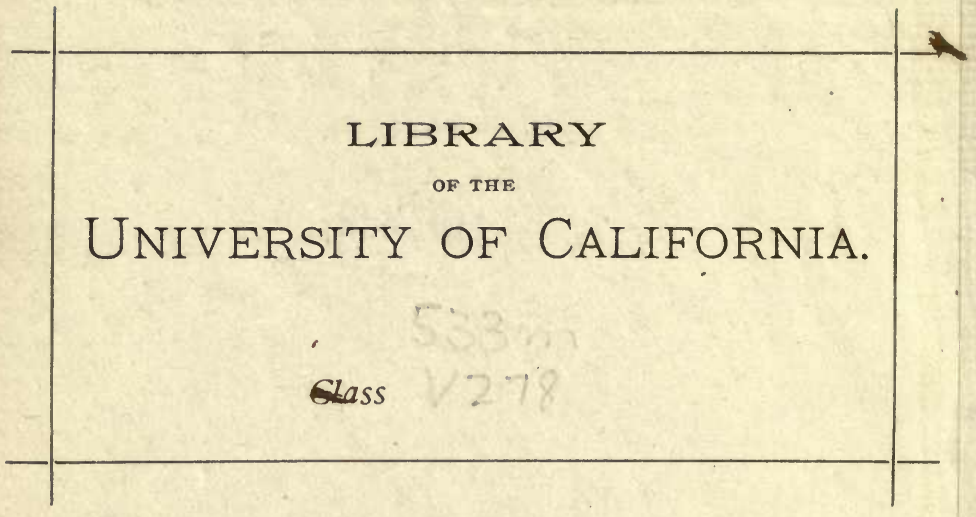






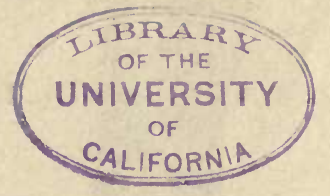

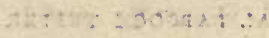




$$
\mathbb{1}
$$




\section{Modern Methods of Testing Milk and Milk Products}

A HANDBOOK PREPARED FOR THE USE OF DAIRY STUDENTS, BUTTER MAKERS, CHEESE MAKERS, PRODUCERS OF MILK, OPERATORS IN CONDENSERIES, MANAGERS OF MILK-SHIPPING STATIONS, MILKINSPECTORS, PHYSICIANS, ETC. ::: $\quad::$ :::

\section{By \\ LUCIUS L. VAN SLYKE}

Chemist of the New York Agricultural Experiment Station

ILLUST'R AT'ED

REVISED EDITION

NEW YORK

ORANGE JUDD COMPANY

LONDON

Kegan Paul, Trench, Trübner \& Co., Limited 1907

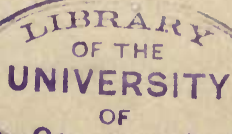




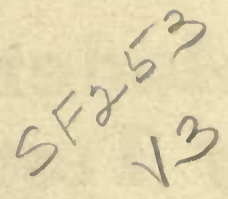

\section{GENERAL}

COPYRIGHT, 1906, I907, BY

ORANGE JUDD COMPANY

All Rights Reserved

[ENTERED AT STATIONERS' HALL, LONDON, ENGLAND] 


\section{PREFACE}

To attain the highest degree of success in the production of milk and in the manufacture of its products, it has become essential to acquire some knowledge of the methods of testing milk and milk products. The application of these methods to dalrying has resulted in lifting the dairy industry to a higher plane of intelligence, and in effecting changes of great economic importance, among which may be briefly mentioned: ( I) Greater justice rendered milk producers in paying for milk according to its quality. (2) Prevention of large losses, once very common, in the manufacture of butter and cheese. (3) Improvement of methods of manufacture through better control of details. (4) Increase of yield of products made from a given amount of milk. (5) Improvement in the uniformity and quality of manufactured dairy products.

This little book has been prepared for the use of dairy students, cheese-makers, butter-makers, producers of milk, operators in condenseries, managers of shipping-stations, milk-inspectors, and others interested. Physicians who are specialists in infant-feeding will find the book useful in testing human milk as well as cows' milk that is modified or to be modified.

No previous chemical training is required for operating successfully the methods described. Any intelligent person who can labor with painstaking patience and appreciate the value of attention to little details should be able to master these methods with a rea- 
sonable amount of work. The assistance of a trained teacher will, of course, make the task easier. No one, whatever his educational preparation, can hope to use these or any similar methods successfully who can not or will not follow instructions accurately and exercise patience in mastering every minute detail.

In the preparation of this work, the writer has tried to keep in mind the following points: (I) Accuracy, simplicity and clearness of statement. (2) Making prominent, as far as practicable, the reasons for each step in each process. (3) Emphasis of common difficulties and instructions for overcoming them. (4) Impressing students with the necessity of precision and care in performing every detail given. (5) Selection of the methods approved by experience. ('6) Avoidance of such technical methods as require unusual skill or equipment. (7) Omission of unnecessary details. (8) Embodiment of the results of the most recent investigations. (9) The special needs of those for whose use the work is designed.

The scope of this work is far from exhaustive, but the methods selected are given with necessary completeness. Chemical methods, requiring elaborate equipment and extended special training, are purposely omitted. Any one desiring a full description of such methods can obtain it by addressing a request to the U. S. Department of Agriculture, Bureau of Chemistry, Washington, D. C., asking for a copy of "Methods of Analysis adopted by the Association of Official Agricultural Chemists."

The methods that have been compiled here are in large measure the direct result of the work of our 
agricultural experiment stations, and afford some indication of the direction and value of the work done by these institutions.

In the preparation of Chapter XIII, valuable assistance has been kindly rendered by Mr. George A. Smith, Dairy Expert of this station.

L. L. Van Slyke.

Nere York Agricultural

Experiment Station, 1906. 


\section{PREFACE TO REVISED EDITION}

Two editions of this book have been issued within the first year after its publication. Before printing another edition it seems advisable to make some additions that have been suggested by friendly criticism. A section on the "Sampling and Testing of Gathered Cream" is added to Chapter V. The author has also rewritten Chapter XIV. Gray's rapid test for water in butter, which was included as an appendix in the second edition, is transferred to the body of the book under Chapter VI. For the marked favor with which this little book has been received, appreciation can not be expressed in any way more substantial than by making an effort to keep the subject matter up to date.

$$
\text { L. L. Van Slyke. }
$$

Geneva, N. Y., September, 1907. 


\section{CONTENTS}

I

Chemistry of Cow's Milk and Milk Products . . . 1

II

Methods of Sampling Milk

III

The Babcock Test-Description of Apparatus and Materials . . . . . . . . . 32

IV

Method of Operating the Babcock Test . . . 53

V

Method of Testing Cream by the Babcock Test .: $\quad 69$

VI

Methods of Testing Skim-milk, Whey, Butter, Cheese, etc. . . . . . . . . . . 81

VII

Methods of Testing Acidity of Milk and Milk Products . . . . . . . . . . . . . 96

VIII

Methods of Testing the Bacterial Condition of Milk 113 IX

Methods of Testing Milk by Rennet-Extract and Pepsin . . . . . . . . . . . 121 $\mathrm{X}$

Methods of Testing Specific Gravity and Solids of Milk by the Lactometer . . . . . . . 


\section{XI}

Methods of Testing Milk and Milk Products for Adulterations

\section{XII}

The Babcock Test applied to Farm Conditions . . 151

\section{XIII}

Methods of Commercial Testing and Scoring of Butter and Cheese . . . . . . . . 158 XIV

Methods of Commercial Testing and Scoring of Milk and Cream . . . . . . . . . 182 $\mathrm{XV}$

Arithmetic of Milk and Milk Products . . . . 193

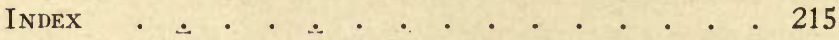




\section{ILLUSTRATIONS}

PAGE

The Original Babcock Tester . . . . Frontispiece Composite-Sample Jars . . . . . . . . . 25

Rack for Composite Samples . . . . . . . 26

Sampling-Dipper . . . . . . . . . . 27

Scovell Milk-Sampler . . . . . . . . 27

Equity Milk-Sampler . . . . . . . . 27

Milk-Testing Bottle . . . . . . . . . 34

Milk-Measuring Pipette . . . . . . . . 35

Greiner's Automatic Pipette . . . . . . 36

Wagner's Pipette . . . . . . . . . . 36

Acid-Measure . . . . . . . . . . . 36

Acid-Burette and Stand . . . . . . . 37

Automatic Burette . . . . . . . . . 37

Steam-Turbine Tester . . . . . . . . . 38

Hand-Tester . . . . . . . . . . 38

Small Hand-Tester . . . . . . . . . 39

Electric Centrifuge . . . . . . . . 40

Hydrometer for Testing Strength of Sulphuric Acid 43

Milk-Bottle Tester . . . . . . . . . . 46

Testing Accuracy of Milk-Bottle . . . . . . 46

Burette and Support . . . . . . . . . . 48

Waste-Jar for Emptying Test-Bottles . . . . 50

Test-Bottle Rinser . . . . . . . . . . 50

Test-Bottle Draining Rack . . . . . . . . 51

Farrington's Bottle-Cleaner-Bottle-Holder Empty . 51 
Farrington's Bottle-Cleaner-Bottle-Holder Immersed 52

Farrington's Bottle-Cleaner-Bottle-Holder Draining 52

Correct Way of Holding Pipette and Bottle . . 55

Wrong Way of Holding Pipette and Bottle . . . 56

Measuring Fat-Column . . . . . . . . 63

Automatic Russian Pipette . . . . . . . . 67

Russian Test-Bottle . . . . . . . . . 67

Bulb-Necked Cream-Bottle . . . . . . 70

Straight-Necked Cream-Bottle . . . . . . 71

Cream-Testing Scales . . . . . . . . 72

Cream-Sampling Sieve . . . . . . . . 74

Bottles for Testing Skim-Milk . . . . . . 82

Bottle for Testing Butter . . . . . . . 86

Wagner's Improved Form of Gray's Water-Test • 91

Mann's Acid Test . . . . . . . . . 101

Farrington's Alkaline-Tablet Test. . . . . 104

Spillman's Acid-Cylinder . . . . . . . 105

Purdue Alkali-Test . . . . . . . . . 107

Hand-Centrifuge for Sedimentation Work . • . 118

Tube for Sedimentation Work . . . . . . 118

Bausch \& Lomb Electric Centrifuge . . . . . . 118

International Instrument Co.'s Electric Centrifuge . 119

Glass for Collecting Sediment in Milk . . . . 120

Monrad Rennet-Test . . . . . . . . . 121

Marschall Rennet-Test . . . . . . . . . 123

Quevenne Lactometer . . . . . . . . . 130

Cylinder for Lactometer . . . . . . . . 133

Comparison of Different Specific Gravity Scales . . 134

Richmond's Slije-Rule . . . . . . . . 138

Butter-Trier . . . . . . . . . . . 159 


\section{Modern Methods of Testing Milk} and Milk Products

\section{CHAPTER I}

\section{Chemistry of Cows' Milk and Milk Products}

THE normal milk of cows contains the following compounds and classes of compounds :
(I) Water.
(4) Milk-sugar.
(2) Fat.
(5) Salts or ash.
(3) Nitrogen compounds or proteids.
(6) Gases.

\section{WATER}

The water present in milk, however much its presence may be disguised, is the compound of hydrogen and oxygen with which we are everywhere familiar. The water in milk serves the purpose of holding in solution the soluble constituents of the milk, and it also acts as a diluent, better fitting the mixture for animal nutrition.

Variation.-The amount of water normally contained in milk varies, depending upon such conditions as individuality, breed, stage of lactation, age, character of food, amount of water drunk, state of health, etc. In the case of single milkings of individual cows, the water may vary from 82 to 90 per cent. or more. In the case of milk from herds of cows, the water varies less, usually ranging from 86 to 88 per cent. 
The influence of breed.-The following figures, from the records of the N. Y. Agricultural Experiment Station at Geneva, illustrate the influence of breed upon the water content of milk:

NAME OF BREED

Holstein Friesian .

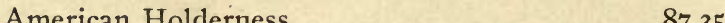

Ayrshire . . . . . . . . . . . . 87.25

Short Horn . . . . . . . . . . 85.70

Devon . . . . . . . . . . . 8550

Guernsey . . . . . . . . . 85.10

Jersey
Per cent. of water in milk 88.20

84.60

The influence of lactation.-The variation of water in milk, as affected by advance of the lactation period, is illustrated by the following figures, which cover a period of ten months from the time of calving:

MONTH OF LACTATION

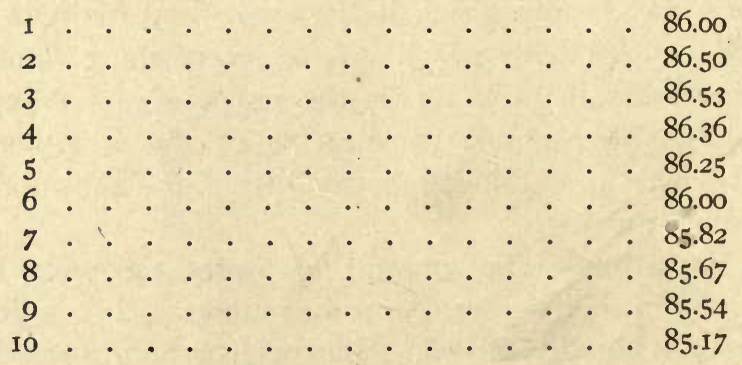

There is noticeable a general tendency for the amount of water in milk to increase for the first three months of lactation, after which there is a continuous decrease to the end of the lactation period. 
Total solids.-Under the general term of total solids or milk-solids, we indicate the constituents of the milk other than water (and gases). The per cent. of water in milk subtracted from Ioo gives the percentage of milk-solids, which include fat, proteids, milk-sugar and salts or ash. The amount of solids in milk varies with the same conditions that affect the percentage of water in milk, but, of course, in just the reverse manner. Most states prescribe a legal standard for milk-solids, usually 12 per cent., and milk containing less than the legal amount is regarded as adulterated.

\section{MILK-FAT}

The composition of milk-fat.-Milk-fat, also called butter-fat, is not a single chemical compound, but is a somewhat variable mixture of several different compounds called glycerides. Each glyceride is formed by the chemical union of glycerin as a base with some acid or acids of a particular kind. These glycerin-acid compounds, or glycerides, of milk-fat contain about ten different acids, some being present in small proportions. The four following acids enter most largely into the composition of milk-fat, in the form of their combinations with glycerin: Palmitic acid, oleic acid, myristic acid and butyric acid. The compounds, or glycerides, formed by the combination of glycerin and the acids, have special names derived from the acids; thus, we have palmitin (glycerin combined with palmitic acid), butyrin (glycerin combined with butyric acid), olein, etc. Milk-fat contains, on an average, about 40 per cent. of palmitin, 34 per cent. of olein, Io per cent. of myristin, 6 per cent. of butyrin, and 
from less than I to nearly 3 per cent. of each of th glycerides of other acids. Milk-fat contains abot I2.5 per cant. of glycerin in combination with th acids. The proportions of these constituents of mill fat vary somewhat, and this variation influences th character of the milk-fat. Thus, palmitin and myri tin tend to make milk-fat harder, while olein and buty rin have the opposite tendency.

The acids contained in milk-fat or butter-fat ma be divided into two groups: (I) The acids in or group (palmitic, oleic, myristic, stearic, lauric) at insoluble in water and non-volatile, while (2) th other acids (butyric, caproic, etc.,) are more or les completely soluble in water and are volatile. Thes differences afford a practical basis for distinguishin pure butter from artificial butter. Of the fat-acic contained in butter-fat, about 87.5 per cent. consis of the insoluble fat-acids, while in other forms animal fat (beef-fat, lard, etc.,) the amount of thes insoluble fat-acids is considerably greater. The amour of volatile fat-acids in milk-fat or butter-fat is muc greater than in other forms of animal fat.

Fat-globules in milk.-Milk-fat is present in mill not in solution, but suspended in the form of ver small, transparent globules. Globules varying in siz between one twenty-five hundredth and one fifteer thousandth of an inch in diameter are the ones mos commonly present. The average size of fat-globule in milk is somewhat more than one ten-thousandth 0 an inch in diameter. The smaller globules are mor numerous than the larger ones. In one drop of aver age milk there are more than one hundred million fat 
globules. Skim-milk contains fewer and smaller globules than whole milk, while the reverse is true of cream. The large globules do not differ in composition from the small ones. The size and number of fat-globules in milk are influenced by such conditions as advance of lactation, breed of cow, food, age, health, different milkings, different parts of the same milking, etc.

It was formerly believed generally, and is still by some, that the fat-globules of milk are surrounded by a membranous covering, or else by a semi-liquid, albuminous layer. We may, however, accept it as established beyond reasonable doubt that the fat-globules of milk have no special covering of any kind, but are simply minute particles of fat floating free in milk in the form of an emulsion. Fat-globules quite generally retain their individuality even in butter and cheese.

Amount of fat in milk.-Normal milk varies greatly in its fat content, containing from below 2 to over ro per cent., if we consider single milkings of individual cows. The milk from herds of cows varies in fat more commonly between the limits of 3 and 5 per cent. The average amount of milk-fat in milk produced in this country, taking the true average for the entire year, lies somewhere near 4 per cent., perhaps a little under. Many of the conditions that affect the percentage of fat in milk are fairly well known, while others are little understood. We will briefly consider some of the well-recognized conditions that influence the fat content of milk.

(I) Infuence of individuality of cow on fat content of milk.-It is uncommon to find in a herd of 
cows two individuals whose milk contains the same per cent. of fat, whether we consider single milkings or the average of many milkings.

(2) Influence of breed of cow on fat content of milk.-It is well known that the per cent. of fat in milk varies in a somewhat characteristic way with the kind of breed of cow. While there is marked variation in individuals of the same breed, there is found to be a fairly uniform difference, more or less marked, if we consider the averages of several individuals. It is largely owing to this influence that we find the milk of one country differing from that of another, or the milk of one section of a country differing from that of another section. For example, the average amount of fat in milk in Germany and Holland is fully one-half per cent. lower than in this country, because the prevailing breeds of cows there are those producing milk comparatively low in fat. The following figures, taken from the records of the New York (Geneva) Agricultural Experiment Station, represent averages of many individuals for several periods of lactation:

Per cent. of fat in milk

NAME OF BREED

Average Lowest Highest

Holstein Friesian.

2.88

3.85

Ayrshire . . . . . . 360

$3.20 \quad 4.24$

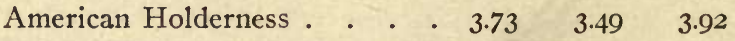

Short Horn . . . . . . . $4.44 \quad 4.28 \quad 4.56$

Devon .. . . . . . $4.60 \quad 4.30 \quad 5.23$

Guernsey . . . . . . . $5.30 \quad 4.51 \quad 6.13$

Jersey . . . . . . . $\quad .5 .60 \quad 4.96 \quad 6.09$

(3) Influence of age of cow on fat content of milk.-So far as published data throw light upon this 
point, there appears to be a tendency for milk to become less rich in fat with each succeeding period of lactation, especially after the second, though individual exceptions are not infrequent. More data are needed to settle the question definitely.

(4) Influence of advance of lactation on the fat content of milk.-In general, it is found that the per cent. of fat in milk increases as the stage of lactation advances after the third month, as illustrated by the following data from the records of the New York (Geneva) Station, covering Io months from the time of calving:

NUMBER OF

MONTH OF LACTATION

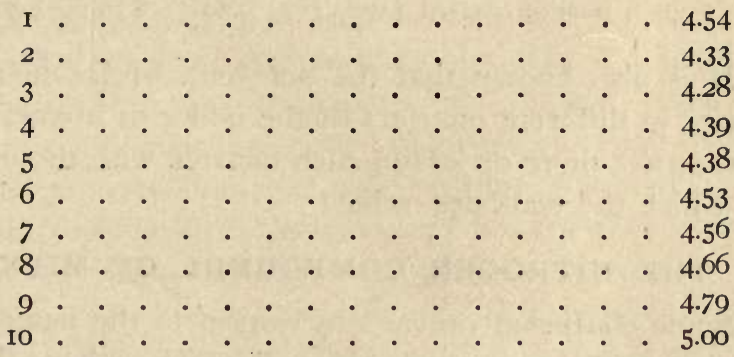

(5) Variation of time between milkings in relation to the fat content of milk.- As a rule, the longer the time between two successive milkings, the smaller is the per cent. of fat in the milk; and the shorter the time between milkings, the greater the per cent. of fat. When the time between milkings is uniformly equal, the variation of fat in milk is small, provided the general environment of the animal is the same. However, as there are not commonly such entirely uniform 
conditions of surroundings during the day and night, there appears to be a common tendency for the presence of a little more fat in the morning's milk, even when milkings are apart the same length of time.

(6) Variation of fat content in different portions of milk drawn from the udder.-The following figures, taken from the writer's records, illustrate the general rule that the first milk drawn contains least fat, the milk last drawn (strippings) being the richest in fat:

\begin{tabular}{|c|c|c|c|c|}
\hline \multirow[b]{2}{*}{ First portion drawn . } & & \multicolumn{3}{|c|}{ Per cent. of fat in milk } \\
\hline & & 0.90 & 1.60 & 1.60 \\
\hline Second portion drawn & & 2.60 & 3.20 & 3.25 \\
\hline Third portion drawn & & 5.35 & 4.10 & 5.00 \\
\hline Fourth portion drawn & (strip'gs) & 9.80 & 8.10 & 8.30 \\
\hline
\end{tabular}

It is also known that the per cent. of fat in milk varies in different quarters of the udder of a cow, and also varies more or less in each quarter with the order in which the teats are milked.

\section{THE NITROGEN COMPOUNDS OF MILK}

Some confusion prevails in respect to the names of the nitrogen compounds of milk. They have been spoken of as albuminoids, proteids, etc. Frequently the word casein is erroneously used to include all the nitrogen compounds of milk.

How many nitrogen or proteid compounds are prescnt in normal milk? What are they? Different workers have reported from one to seven or more. The chemical evidence at hand justifies us in the belief that fresh, normal milk contains not more than three or, perhaps, four nitrogen-containing or proteid bodies, 
viz., casein, albumin, globulin and galactase. Globulin and galactase are present in so small quantities that we can properly regard casein and albumin, quantitatively, as being essentially the nitrogen compounds of milk.

Milk-Casein is the most important nitrogen compound in milk, because, (Ist) it is the one present in largest quantity; (2d) its presence makes it possible to convert milk into cheese; and (3d) it has a high value as food. Milk-casein is most familiar to us in the form of the solid, white substance called curd, which forms in milk when it sours (though, strictly speaking, this well-known, white substance is not milkcasein, but casein lactate).

(I) Composition of milk-casein.-Casein is a very complex chemical compound, containing the elements carbon, oxygen, hydrogen, nitrogen, sulphur, and phosphorus. In milk the proteid molecule of casein is combined with calcium, or some calcium compound, and hence the proper chemical name of milk-casein is calcium casein. It exists in milk, not in solution, but in the form of extremely minute, solid, gelatinous particles in suspension. The slime found in the bowl of centrifugal separators consists, to a considerable extent, of milk-casein.

(2) Action of acids upon milk-cascin.-When milk sours in the ordinary way, the lactic acid formed acts upon the calcium casein, two definite changes taking place. First, the lactic acid combines with the calcium of the calcium casein, forming calcium-free casein, or simply casein set free from its combination with calcium. When more lactic acid forms, the sec- 
ond change takes place, the free casein taking up the acid without definite combination and forming a substance which is familiar as the curd of sour milk. Similar changes occur when milk is treated with other acids, such as hydrochloric, acetic, sulphuric, etc. Free casein is insoluble in water and also in very dilute acids at ordinary temperatures. The action of acids on calcium casein and on free casein is hastened by increase of temperature. Casein dissolves easily in an excess of acid, forming soluble casein salts.

(3) Action of alkalis on milk-casein.-Dilute solutions of alkalis (caustic soda, ammonia, etc.) act upon casein and its salts with acids, forming compounds that dissolve easily in water. These alkali compounds of casein are not affected by rennet. Some of these compounds are found in commerce as food and medicinal preparations under such names as Plasmon, Nutrose, Santogene, Eucasein, Galactogene, etc.

(4) Action of heat on milk-casein.- Heat alone under ordinary conditions, even at the boiling point of water, does not coagulate the casein in milk. Casein may be coagulated by heating under pressure at a temperature of about $270^{\circ} \mathrm{F}$. The browning of milk heated under pressure is more or less due to changes in the casein. The formation of a peculiar skin on the surface of milk heated above $140^{\circ} \mathrm{F}$. is largely due to the calcium casein of the milk and not to albumin as was formerly supposed. The skin itself contains practically all of the constituents of the milk and may be regarded as a kind of evaporated milk.

(5) Action of rennet on milk-casein.-One of the most characteristic properties of the calcium casein 
of milk is its coagulation by the enzym or chemical ferment contained in rennet, which is an extract of the mucous membrane of a calf's stomach. This property makes possible the manufacture of cheese from milk. The curd formed by the action of rennet is called paracasein or, more properly, calcium paracasein. There appears to be little or no chemical difference between calcium casein and calcium paracasein. The coagulation of calcium casein produced by rennet is quite different from that produced by acids. Calcium paracasein behaves towards acids and alkalis much like calcium casein.

(6) Other changes caused in milk-casein.-Under the action of chemical reagents, of enzyms and of various organisms, calcium casein and paracasein may be changed into a large number of other substances. Among the compounds and classes of compounds thus formed are paranuclein, albumoses, peptones, amides (crystallizable bodies) and ammonia. These products are never found in normal milk as it leaves the cow, but may be present in milk that has stood some time.

Milk-Albumin.-Milk-albumin differs from milkcasein in composition and behavior. Thus, milk-albumin (I) is not acted upon by rennet; (2) is not coagulated by acids at ordinary temperatures; (3) is coagulated by heat alone, though not completely, above $160^{\circ} \mathrm{F}$; ; and (4) is in solution in milk.

Milk-Globulin.-This compound is present only in small quantities in normal milk and is of no special importance, so far as known.

Galactase.-This substance is an unorganized ferment, or a mixture of such ferments, present in normal milk. It somewhat resembles pepsin in its action, be- 
ing able to coagulate milk-casein and then digest it or make it soluble. It is present in very small amounts in milk and its action is very slow. It has never been isolated from milk in pure form. It is probably a nitrogen-containing substance. Our knowledge of galactase is very far from complete.

Amounts of casein and albumin in milk.-In single milkings of individual cows, the casein and albumin, taken together, vary from 2.5 to 6 per cent. and average about 3.2 per cent. Milk-casein varies in amount from 2 to 4 per cent. and averages about 2.5 per cent. Albumin varies from 0.5 to 0.9 per cent. and averages about 0.7 per cent. The amount of casein in relation to albumin varies greatly. On an average, milk contains about 3.6 parts of casein for one of albumin, or, stated another way, casein constitutes about 80 per cent. of the nitrogen compounds of milk.

The amount of casein and albumin in milk is influenced by many conditions, such as influence the general composition of the milk, among which are individuality, breed, advance of lactation, etc. As the lactation period advances, there is a general tendency on the part of casein and albumin in milk to increase.

Relation of fat and nitrogen compounds in milk.In normal milk containing over 3 per cent. of fat, the amount of casein and albumin is rarely greater than the amount of fat, especially in the milk of herds of cows. When the per cent. of fat is less than that of the nitrogen compounds, the milk may generally be regarded as skimmed, especially in the case of milk from herds. 


\section{MILK-SUGAR}

Milk-sugar, also called lactose, is present in cows' milk in solution. In general composition, it resembles ordinary sugar, but it is less sweet and less soluble in water. The amount of sugar in milk varies from below 4 to over 6 per cent. and averages about 5 per cent. Its importance in dairy work, especially in connection with the manufacture of butter and cheese, comes from the ease with which it is converted into lactic acid by certain forms of bacteria. In the ordinary souring of milk, the amount of milk-sugar decreases somewhat more than one-fourth and there is formed as a maximum about 0.9 per cent. of lactic acid. More acid may be formed after some time. Hence, sour milk, when two or three days old, contains only 3.5 to 4 per cent. of milk-sugar. The sugar of milk passes largely into the whey in cheese-making and forms over 70 per cent. of the solids in whey. The milk-sugar of commerce is usually prepared by evaporating whey and purifying the impure product first obtained.

\section{THE SALTS OF MILK}

The salts of milk, commonly included under the term "ash," are present in only small amounts, 0.7 per cent. on the average; but they have important relations to milk and its products. Our knowledge of these compounds is very incomplete. The salts of milk are commonly spoken of as the ash or mineral constituents. This conception is somewhat misleading, because the materials appearing in the ash of milk are, to some considerable extent, combined in organic compounds, instead of existing in the milk as separate 
inorganic bodies. The ash represents in amount, therefore, more than the so-called mineral constituents of milk and less than the salts of milk. While the ash in milk amounts to about 0.7 per cent., the amount of salts probably approximates 0.9 per cent. A portion of the salts of milk is in solution, including such compounds as calcium citrate, sodium chloride, potassium acid phosphate, etc., while a portion (tricalcium phosphate) appears to be in suspension in the form of very finely divided particles.

\section{THE GASES OF MILK}

Milk contains more or less oxygen and nitrogen, these gases being carried into it mechanically from the air in the process of milking. It contains also, when freshly drawn, carbon dioxide, already present in the udder milk, there being probably between 3 and 4 per cent. by volume, a portion of which escapes. at once while being drawn from the udder under usual conditions.

\section{GENERAL SUMMARY}

Milk contains water, fat, casein, albumin, sugar, salts, carbon dioxide and some other constituents in small quantities. The fat and casein and some of the salts are in suspension and not in solution, while albumin, sugar and the larger portion of the salts are held in solution by the water.

As a matter of convenience, the compounds of milk are divided into certain arbitrary groups. By one system of division, the compounds of milk are arranged in two classes:-( I) Water, and (2) milksolids (or total solids), this second class including 
fat, casein, albumin, sugar, salts (ash), etc. Another division is made on the basis of the milk-fat into (I) fat and (2) milk-serum, which includes all the milk constituents except the fat. Separator skim-milk is nearly pure milk-serum. Then we have the milksolids subdivided into (I) fat and (2) solids-not-fat (casein, albumin, sugar, salts (ash), etc.)

The following arrangement shows the general relation of the compounds contained in milk, the figures indicating the percentages present in average milk:

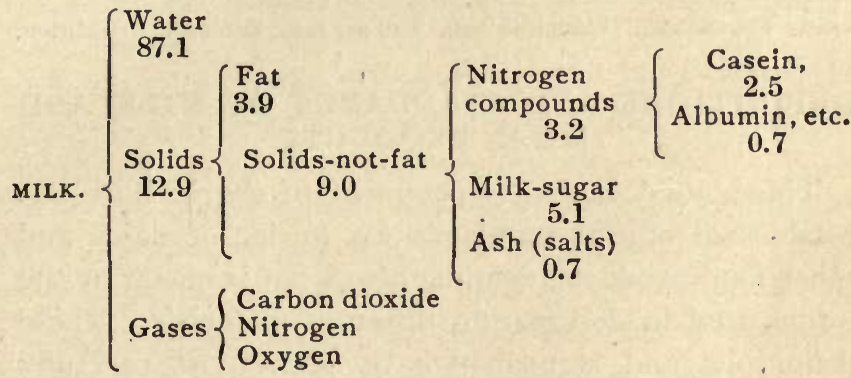

AVERAGE ANALYSIS OF COWS' MILK

\begin{tabular}{|c|c|c|c|c|c|c|c|}
\hline & WATER & $\begin{array}{l}\text { TOTAL } \\
\text { SOLIDS }\end{array}$ & FAT & CASEIN & $\begin{array}{l}\text { ALBU- } \\
\text { MIN }\end{array}$ & SUGAR & ASH \\
\hline & Perct. & Perct. & Perct. & Perct. & Perct. & Perct. & Perct. \\
\hline $\begin{array}{c}\text { Average of } 5,552 \\
\text { American an- } \\
\text { alyses c o m- } \\
\text { piled by the } \\
\text { author.......... }\end{array}$ & 87.1 & 12.9 & 3.9 & 2.5 & 0.7 & 5.1 & 0.7 \\
\hline $\begin{array}{l}\text { Average cheese- } \\
\text { factory mi1k } \\
\text { for the season } \\
\text { (May to Nov.) } \\
\text { in N. Y. State... }\end{array}$ & 87.4 & 12.6 & 3.75 & 2.45 & 0.7 & 5.0 & 0.7 \\
\hline
\end{tabular}


REPRESENTATIVE ANALYSES OF PRODUCTS AND BY-PRODUCTS OF MILK

\begin{tabular}{|c|c|c|c|c|c|c|c|}
\hline & WATER & $\begin{array}{l}\text { TOTAL } \\
\text { SOLIDS }\end{array}$ & FAT & CASEIN & $\begin{array}{l}\text { ALBU- } \\
\text { M1N }\end{array}$ & SUGAR & ASH \\
\hline & Perct. & Perct. & Perct. & Percl. & Perct. & Perct. & Perct. \\
\hline Butter............. & 13.0 & 87.0 & 83.5 & 1.0 & $\cdots$ & $\cdots$ & $2.5^{1}$ \\
\hline Cheddar Cheese & 36.8 & 632 & 33.75 & 23752 & & & 573 \\
\hline $\begin{array}{l}\text { Skim-milk } \\
\text { (separator) }\end{array}$ & $90: 3$ & 9.7 & 0.10 & 2.75 & 0.80 & 5.25 & 0.80 \\
\hline whey............ & 93.4 & 6.6 & 0.35 & 0.10 & 0.75 & 4.80 & 0.60 \\
\hline Buttermilk ....... & 90.6 & 9.4 & 0.10 & 2.80 & 0.80 & $4.40^{4}$ & 0.70 \\
\hline
\end{tabular}

${ }^{1}$ Salt. 2 Paracasein. ${ }^{3}$ Salt and Ash. $\$ 60$ per cent. lactic acid in addition.

\section{DEFINITIONS AND STANDARDS OF MILK AND MILK PRODUCTS}

The United States Department of Agriculture has established official standards for purity of dairy and other food products, defining also what is meant by the terms used in designating different materials. These definitions and standards have been most carefully worked out by members of the Association of Official Agricultural Chemists, several years having been devoted to the collection of data. The official definitions and standards relating to milk and milk products are as follows:

\section{MILK}

Definitions.-I. Milk (whole milk) is the lacteal secretion obtained by the complete milking of one or more healthy cows, properly fed and kept, excluding that obtained within fifteen days before and five days after calving.

2. Blended milk is milk modified in its composition 
so as to have a definite and stated percentage of one or more of its constituents.

3. Skim-milk is milk from which a part or all of the cream has been removed.

4. Buttermilk is the product that remains when butter is removed from milk or cream in the process of churning.

5. Pasteurized milk is milk that has been heated below boiling but sufficiently to kill most of the active organisms present and immediately cooled to fifty degrees $\left(50^{\circ}\right)$ Fahr. or lower to retard the development of their spores.

6. Sterilized milk is milk that has been heated at the temperature of boiling water or higher for a length of time sufficient to kill all organisms present.

7. Condensed milk is milk from which a considerable portion of water has been evaporated.

8. Sweetened condensed milk is milk from which a considerable portion of water has been evaporated and to which sugar (sucrose) has been added.

9. Condensed skim-milk is skim-milk from which a considerable portion of water has been evaporated.

Standards.-I. Standard milk contains not less than twelve (I2) per cent. of total solids, not less than eight and one-half (8.5) per cent. of solids-not-fat, and not less than three and one-quarter (3.25) per cent. of milk-fat.

2. Standard skim-milk contains not less than nine and one-quarter (9.25) per cent. of milk-solids.

3. Standard condensed milk contains not less than twenty-eight (28) per cent. of milk-solids, of which not less than one-fourth is milk-fat. 
4. Standard swectened condensed milk contains not less than twenty-eight (28) per cent. of milk-solids of which not less than one-fourth is milk-fat.

\section{MILK-FAT OR BUTTER-FAT}

Definition.-Milk-fat or butter-fat is the fat of milk.

Standard.-Standard milk-fat or butter-fat has a Reichert-Meissl number not less than twenty-four (24) and a specific gravity not less than $0.905\left(\frac{40^{\circ} \mathrm{C}}{40^{\circ} \mathrm{C}}\right)$

\section{CREAM}

Definitions.-I. Cream is that portion of milk, rich . in butter-fat, which rises to the surface of milk on standing, or is separated from it by centrifugal force.

2. Evaporated cream is cream from which a considerable portion of water has been evaporated.

Standard.-Standard cream contains not less than eighteen (18) per cent. of milk-fat.

\section{BUTTER}

Definitions.- I. Butter is the product made by gathering in any manner the fat of fresh or ripened milk or cream into a mass, which also contains a small portion of the other milk constituents, with or without salt.

2. Renovated or process butter is the product made by melting butter and reworking, without the addition or use of chemicals or any substances except milk, cream or salt.

Standards.-I. Standard butter contains noí less than eighty-two and five-tenths (82.5) per cent. of 
butter-fat. By acts of Congress approved August 2, I886, and May 9, 1902, butter may also contain additional coloring matter.

2. Standard renovated or process butter contains not more than sixteen (16) per cent. of water and at least eighty-two and five-tenths (82.5) per cent. of butter-fat.

\section{CHEESE}

Definitions.-I. Cheese is the solid and ripened product made by coagulating the casein of milk by means of rennet or acids, with or without the addition of ripening ferments and seasoning. By act of Congress, approved June 6 , 1896 , cheese may also contain additional coloring matter.

2. Whole-milk or full-cream cheese is cheese made from milk from which no portion of the fat has been removed.

3. Skim-milk cheese is cheese made from milk from which any portion of the fat has been removed.

4. Cream-chcese is cheese made from milk and cream, or milk containing not less than six (6) per cent. of fat.

Standard.-Standard whole-milk or full-cream cheese contains, in the water-free substance, not less than fifty (50) per cent. butter-fat.

\section{MISCELLANEOUS MILK PRODUCTS}

Definitions.-1. Whey is the product remaining after the removal of fat and casein from milk in the process of cheese-making.

2. Kumiss is the product made by the alcoholic fermentation of mares' or cows' milk, with or without the addition of sugar (sucrose). 


\section{CHAPTER II}

\section{Methods of Sampling Milk}

Too much emphasis can not be placed upon the importance of taking for analysis a sample of milk that truly represents the whole body of milk from which the sample is taken. This statement applies equally to any product or by-product of milk that is to be tested. Before a sample for testing is taken, the body of milk from which the sample is to be drawn should be uniform throughout in composition. Several conditions may disturb the desired uniformity of composition of a mass of milk, among which are the following:
(I) Separation of fat.
(2) Partial churning of fat.
(3) Freezing of milk.
(4) Souring of milk.

\section{SAMPLING MILK WHEN FAT HAS SEPARATED}

The rapidity with which fat-globules rise to the surface of milk in the form of cream is well known. Therefore, milk standing at rest soon loses its uniformity of composition, the upper layers containing more fat than the lower ones. On this account it is always necessary, just before taking a sample of milk for testing, to make sure that the body of milk to be tested has an even composition throughout.

Milk in which fat separation is slight.-In milk 
in which there is no visible separation of cream, evenness of mixing may be best effected by pouring the milk from one vessel to another several times immediately before each sample is drawn for testing. Stirring milk, as with a dipper, is less effective than pouring.

Milk in which fat separation is marked.-In milk in which the cream has separated in a visible layer, the pouring needs to be done a greater number of times than in cases where the separation of cream is not noticeable; and, in order to prevent possible churning of particles of cream, the agitation should be as gentle as may be consistent with thorough mixing.

Milk containing dried cream.-In cases where the cream is somewhat dried or hardened, the milk should be warmed to $105^{\circ}$ or $110^{\circ} \mathrm{F}$. for 5 or 10 minutes to allow the cream to melt. The milk is then vigorously agitated and immediately sampled.

\section{SAMPLING MILK WHEN FAT IS PARTIALLY CHURNED}

Milk-fat may separate from milk in the form of small butter-granules, as (I) when the mixing or shaking of the sample to be tested is done too violently; (2) when milk in cans is excessively agitated in transportation; and (3) when bottles, partly full of milk, are sent by mail or express. In such partially churned milk it is difficult to get a representative sample, and the results of testing are, at best, only approximate, unless special measures are resorted to in sampling.

Distributing fat by warming.-In the case of par- 
tially churned milk, the fat may be redistributed in the milk by warming it to $105^{\circ}$ or $110^{\circ} \mathrm{F}$. long enough to melt the butter-granules, after which the sample is vigorously shaken, until the fat is evenly distributed through the milk, and then the sample is drawn at once for analysis.

Dissolving fat in ether.-Another method of treating partially churned milk, previous to sampling, is to shake the milk with 5 per cent. of its volume of ether until the fat-granules are redissolved and then, after further vigorous shaking, to take the sample at once. In this case it is necessary to make a correction by adding to the results 5 , per cent. or one-twentieth of the result obtained. For example, a milk, treated with 5 per cent. of ether, and giving, on testing, 3 per cent. of fat, should have added .I5 ( 5 per cent. of 3 ), making the corrected result 3.15 per cent. When ether is used, extra care must be observed in mixing the acid and milk, (see p. 58) as the heat developed may cause the ether to boil up out of the neck of the test-bottle.

Measures for preventing the churning of fat in milk.-It is better to prevent the churning of fat in milk than to be put to the extra trouble required to get a good sample from milk that has in it fat-granules. Cans of milk, when necessarily exposed to much motion in transportation, should be made as nearly full as possible. In the case of bottles of milk sent by mail or express for analysis, the churning of fat may be prevented in the following manner: Fill the bottle full of milk to overflowing. Then push in tightly a stopper of cork or rubber in which has been made 
from top to bottom a hole one-eighth inch in diameter or less. Finally, push a close-fitting plug of wood or a glass rod into the hole in the stopper.

\section{SAMPLING FROZEN MILK}

Frozen milk is of very uneven composition in different portions of its mass. The crystals of ice contained in it consist largely of water, while the liquid portion contains most of the milk-solids. In such cases it is necessary to melt the frozen portion by warming, and then to mix well by gentle pouring from one vessel to another, after which the sample is at once taken for testing.

\section{SAMPLING MILK COAGULATED BY SOURING}

A sample of thickened, sour milk can not, without special treatment, be taken so as to give reliable results in fat determination. In ordinary curdled milk the percentage of fat remains unchanged in amount, but it is not evenly distributed through the milk. In order to overcome this difficulty, the curdled casein lactate must be dissolved before sampling. This is done by adding to the milk a strong solution of caustic soda or potash (lye), or strong ammonia water, to the extent of 5 or Io per cent. of the volume of the milk used for sampling. The alkali is shaken with the milk until the mixture becomes completely liquid, after which the sample is at once drawn for testing. It is necessary to make a correction by adding to the results 5 or Io per cent. of the amount of fat found, according to the amount of alkali solution used. In place of using a solution of alkali, one can add, in 
small portions at a time, finely powdered caustic soda or potash, allowing the milk to stand some time after each addition of powdered alkali and shaking vigorously, the additions of alkali and the agitation being continued only until the milk becomes completely liquid. In using the alkali in solid form, no correction of results needs to be made. The alkali solution or tablets described on page 96 may be used. A darkening of the milk by alkali may occur without affecting the results of the test. In testing, caution must be observed when adding sulphuric acid (see p. 56) to milk in which an alkali has been used, since an unusual degree of heat is produced and the contents of the testbottle may spurt out. The acid must be added slowly and mixed with the milk much more deliberately than usual.

\section{COMPOSITE SAMPLING OF MILK}

Composite samples of milk.-A mixture of daily samples of milk, taken from day to day for several days in succession, is known as a composite sample. In commercial work at creameries, cheese-factories, milk-shipping stations, etc., where the number of patrons is large, a daily test of the milk for its fat content is impracticable. To obviate the great amount of work involved in making daily tests, a jar is provided for the milk of each patron and in this jar is placed a sample of each day's milk, when it is delivered, these daily samples being mixed and allowed to accumulate for a period of one or two weeks. A determination of fat in such a composite sample gives the average percentage of fat in the milk for the period covered 
by the mixture of daily samples. This method has been proved to be as accurate as that of testing each sample daily by itself; but there are several precautions to be observed carefully in applying this methor in commercial practice.

The conditions that are necessary for success in using the method of composite sampling may be considered under the following heads: (I) Systematic

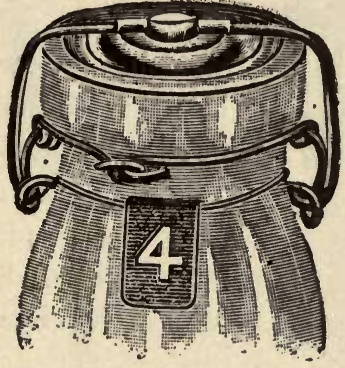

FIG. I

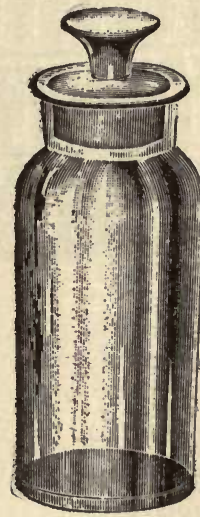

FIG. 2

preparation, (2) methods of taking daily samples, (3) use of preservatives, (4) care of composite samples, (5) age of composite samples, and (6) preparation of composite samples for sampling and testing.

Systematic preparation for taking composite samples.-A round glass jar or bottle, holding a pint or quart, should be provided for each patron. The forms given in Figs. I and 2 are suitable, or ordinary Mason 
fruit-jars may be used. Whatever form of compositesample jar or bottle be used, the stopper or cover should fit perfectly tight, so as to prevent any possible evaporation of water from the sample of milk,

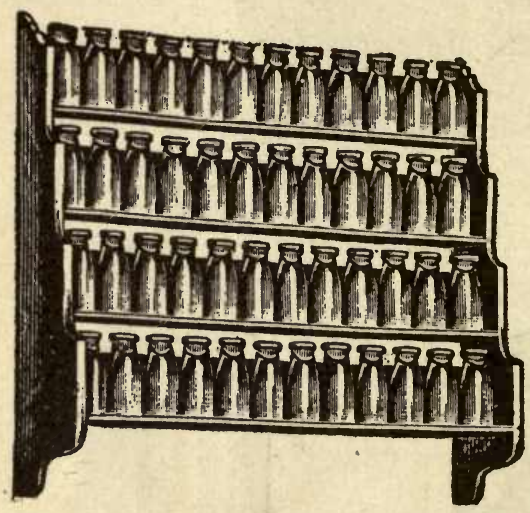

FIG. 3-RACK FOR COMPOSITE SAMPLES and care should be taken to keep the covers or stoppers tight. Each sample-bottle or jar should be labeled with a name or number easily identifying the patron furnishing the milk. The jars should be arranged in definite order on a rack (Fig. 3), placed conveniently near the point where the milk is delivered. As explained later, some preservative is used in each jar.

Taking daily samples for composite samples.Each day when milk is delivered, the sample should be taken immediately after the milk has been poured into the weighing can before weighing, and should then be placed at once in the composite jar or bottle prepared for it. Two methods of sampling are in common use, (I) by means of a small dipper, and (2) by means of a sampling-tube.

(I) Taking sample with dipper.-A half-ounce dipper (Fig. 4) is used for taking the sample from the weigh-can, as soon as the milk is poured in. The 
sample is at once placed in its proper jar or bottle. Providing the milk is thoroughly mixed in the weighcan and the quantity of milk delivered by a patron

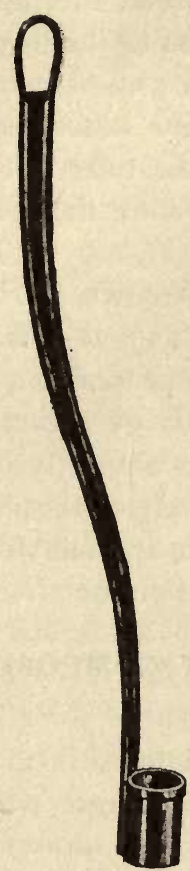

FIG. 4 ;

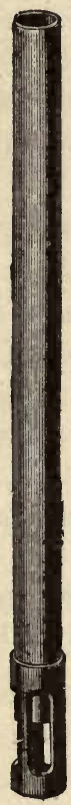

FIG. 5

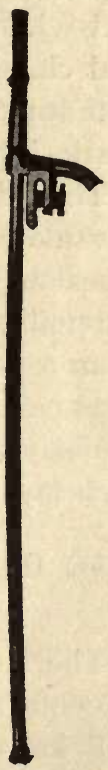

FIG. 6

EQUITY SAMPLER

from day to day does not vary much, this method of sampling gives correct results.

(2) Taking sample with sampling-tube.-There are different types of sampling-tubes (Figs. 5 and 6), of which the Scovell sampler is one of the best. In this 
instrument the main tube is open at both ends, the lower end closely fitting into a cap furnished with three elliptical openings. When the sampler, open at the bottom, is let down into a can of milk, the liquid pours into the openings and fills the tube to the height of the milk in the can. When the cap comes in contact with the bottom of the can, the tube slides down and closes the openings, after which the tube can be withdrawn and its contents emptied into the composite jar.

The tube method of sampling possesses two marked advantages over the dipper method: (I) It always takes an aliquot portion, or uniform proportion, of the milk, representing a small column of the milk from top to bottom; and (2) it provides a strictly representative sample of the milk, even when sampling is delayed, because it takes a uniform amount from each layer of milk, going from top to bottom.

\section{THE USE OF PRESERVATIVES IN COMPOSITE SAMPLES}

The successful use of composite samples is made possible only by the presence of some substance which will keep the milk from curdling. Three preservatives have been found especially useful for this purpose: (I) Corrosive sublimate, (2) formalin, and (3) bichromate of potash.

Corrosive sublimate, known chemically as mercuric chloride, has the advantage of being a more powerful antiseptic than the other substances, much smaller quantities being effective in keeping milk longer, but it has the disadvantage cf being a violent poison. 
When this is used as a milk preservative, it is a wise precaution to add a little coloring matter to the milk in order to warn every one of its abnormal character. Corrosive sublimate, mixed with coloring matter, is put up in convenient tablet form and has found extensive use in preserving composite samples. All things considered, it is probably the most satisfactory of the preservatives commonly employed.

Formalin is a liquid containing about 40 per cent. of the chemical compound known as formaldehyde. It is an effective antiseptic and has the advantage of being in liquid form. One cubic centimeter of formalin should keep a pint or quart sample of milk two weeks or more. Formalin possesses the disadvantage of so hardening the milk-casein that it is not as readily dissolved by sulphuric acid (see p. $5^{8}$ ) as is the casein of untreated milk. An excessive use of corrosive sublimate may produce a similar hardening of casein.

Bichromate of potash, also called potassium bichromate, is extensively used in preserving samples of milk for testing. It is best to use it in powdered form. It has the following advantages: ( $\mathrm{I}$ ) It is comparatively inexpensive. (2) It colors milk yellow and thus shows its presence. (3) It is not a very violent poison, though not entirely harmless. (4) It is efficient in keeping milk for one or two weeks. However, it has some disadvantages as a preservative of composite samples of milk: (I) If too much bichromate is used, the solution of the casein in sulphuric acid is somewhat difficult and the final results of testing may not be clear. (2) In hot weather, it is often difficult to keep samples without using an excessive amount of 
bichromate. (3) Lactic acid in milk considerably reduces the efficiency of bichromate in preserving milk. (4) Samples of milk preserved with bichromate are apt, when exposed to light, to form a tough skin on the surface, which interferes with proper sampling.

The amount of potassium bichromate to be used in composite samples is about 8 or Io grains for half a pint to a pint of milk. The bichromate is put up for sale in tablets of convenient size, ready for use in preserving milk samples. Bichromate can be satisfactorily used even in hot weather, if the samples are kept in a dark, cool place most of the time.

\section{CARE OF COMPOSITE SAMPLES}

In caring for composite samples of milk or cream, some special precautions must be observed. (I) Composite sample jars must be kept covered tight to prevent evaporation of water, which would result in giving a test for fat higher than the correct amount. (2) They should be kept in a cool place, so that the smallest possible amount of preservative will need to be used. (3) They should be kept in the dark most of the time, since direct sunlight may cause the formation of a tough cream, rendering difficult the taking of a good sample for testing. (4) When the daily sample of milk is added to the composite sample, the contents of the jar should be mixed by giving the jar a gentle, rotary motion. Unless this is done regularly each day, the cream that rises becomes tough, especially where it is in contact with the sides of the jar, and this condition makes it difficult to get a proper sample for testing. This daily mixing 
also insures the complete solution and distribution of the preservative through the milk, which is an essential condition of success in keeping samples. If a composite sample shows any dried or churned cream, the sample should be warmed to $105^{\circ}$ or $110^{\circ} \mathrm{F}$. for some minutes and then agitated vigorously before drawing the sample for testing.

\section{AGE OF COMPOSITE SAMPLES WHEN TESTED}

It is advisable to make the fat-test in composite samples, when they have been accumulating for a week or ten days. In any case the limit should be placed at two weeks. The custom practiced by some of testing composite samples only once a month should be severely condemned. When samples are kept longer than two weeks, it is more difficult to get a perfectly reliable test for fat.

\section{PREPARATION OF COMPOSITE SAMPLES FOR SAMPLING AND TESTING}

When a composite sample is to be tested, it is treated like any other sample previous to taking the sample for testing, as has already been described in the first part of this chapter on pp. 20-24. 


\section{CHAPTER III}

\section{The Babcock Test-Description of Apparatus and Material}

The Babcock test is a method for ascertaining the anount of fat in milk and milk products. It was devised by S. M. Babcock, Ph.D., chief chemist of the Wisconsin Agricultural Experiment Station, and was first made public in 1890 . There are in use, especially in Europe, other tests, which are more or less imitations or modifications of the Babcock test, such as the Gerber test or acid-butyrometer and DeLaval's butyrometer.

The Babcock test solved the problem of a rapid, accurate, inexpensive and simple method of testing milk and milk products for fat, and it has found extensive application in many lines of dairying, as may be shown by mention of the following important results coming from its use: (I) The payment for milk according to its fat content has been made practicable. (2) Makers of butter and cheese have been able to detect and prevent abnormal losses of fat in the process of manufacture. (3) It has enabled milk producers to detect unprofitable cows, thus furnishing an intelligent guide in improving their herds. (4) It has done more than any other means to stop the watering and skimming of milk in connection with creameries and cheese-factories. (5) It has been of great service in scientific dairy investigations and has, in general, been a source of educational inspiration. 


\section{PRINCIPLES AT BASIS OF BABCOCK TEST}

This method is based on the action of two agents: (I) the action of strong sulphuric acid upon the constituents of milk-serum, and (2) the action of centrifugal force.

Action of sulphuric acid in Babcock test.-The sulphuric acid used in the Babcock test performs, at least, three functions, which we will consider briefly.

(I) Action on serum-solids of milk.-Strong sulphuric acid acts chemically and physically upon the milk-serum solids (casein, sugar, albumin and salts) in such a way as to destroy that strong mechanical, adhesive influence exerted by the milk-serum solids, which tends to prevent the fat-globules separating from the form of an emulsion. When this influence is overcome, the fat-globules are more free to collect in a mass.

(2) Heat furnished by action of sulphuric acia.The action of sulphuric acid upon the water of milkserum and also upon the organic solids of the serum generates so much heat that the fat-globules easily lose their individuality and run together, a condition favoring rapid separation of fat from serum.

(3) Specific gravity of serum increased by sulphuric acid.-The sulphuric acid, being nearly twice as heavy as milk, increases the difference in specific gravity between the milk-fat and the liquid surrounding it. The milk-fat, being much lighter, more readily rises to the surface of the heavy liquid.

Action of centrifugal force in Babcock test.-The action of the sulphuric acid having released the milkfat largely from the form of an emulsion in the milk- 


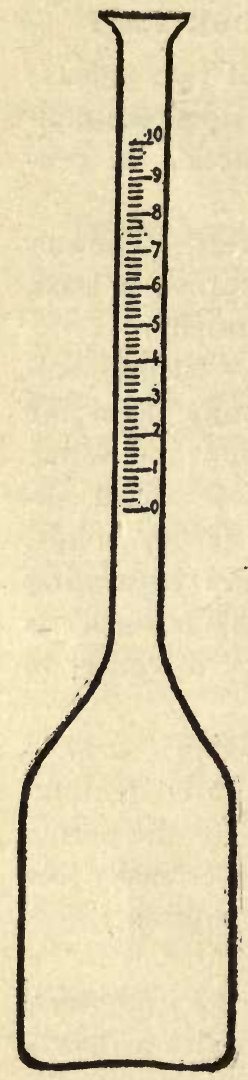

FIG. 7

MILK-TESTING

BOTTLE

serum, the completion of the separation of fat is effected by centrifugal force. When the bottles containing the mixture of milk and acid are whirled, the centrifugal force acts more strongly upon the heavier portion, that is, the mixture of acid and milk-serum. Hence this heavy mixture is forced to the outside, which is the bottom of the bottle, while the much lighter fat is forced to the top. A small amount of fat (.I to .2 per cent.) remains unseparated under usual conditions.

The following apparatus and material are used in making the test: (I) Test-bottles, (2) pipette for measuring milk, (3) acid-measure, (4) tester or centrifugal machine, and (5) sulphuric acid.

\section{TEST-BOTTLES}

The usual form of bottle used in testing milk is shown in Fig. 7. The neck of the bottle is marked with a scale so graduated that each small division represents .2 per cent. and five of these divisions, making one large division, represent I per cent., when we use I7.5cc.* or 18 grams of milk. The marks extend from o to Io

${ }^{*} \mathrm{cc}$. is the abbreviation for cubic centimeters (see p. 205). 
per cent. Why do these divisions represent exact percentages by weight of fat in milk, when no weighing is done in testing milk? We use, in testing, $17.5 \mathrm{cc}$. of milk, which is known to weigh almost exactly 18 grams. The graduated portion of the neck of the test-bottle is made to hold exactly $2 \mathrm{cc}$. between the $O$ and Io marks. Since I cc. of pure milk-fat is known to weigh .9 gram, 2 cc. of milk-fat, the amount required to fill the neck between the 0 and Io marks, weighs $I .8(.9 \times 2)$ grams, which amount is just Io per cent. of the 18 grams of milk sample used in testing.

The divisions on the neck of the test-bottle should be accurate and uniform; the lines should run straight across the neck and not obliquely. When the marks and numbers become indistinct from use, they can be rendered clear by rubbing the scale over with the lead of a pencil or with a cloth having on it a little printer's ink or black paint. When in use, each bottle should be numbered or labeled in a distinctive way.

\section{MILK-MEASURING PIPETTE}

The form of pipette in common use is shown in Fig. 8. Other forms are shown in Figs. 9 and ro. The pipette should hold I7.6 cc. when filled to the mark. Since FIG. 8 PIPETTE about .I cc. of milk will adhere to the in- 
side, such a pipette will furnish a sample amounting to I7.5 cc. of milk, which weighs about 18 grams, I cc. of milk weighing about 1.03 grams on an average. The accuracy of the test, so far as regards the amount of sample taken, depends upon the exactness of the pipette in holding $17.6 \mathrm{cc}$. The mark on the stem should, for convenience, be two inches or more from the upper end of the pipette.

\section{MEASURE FOR ACID}

A cylinder of glass, like that shown in Fig. II, with a lip to pour from and

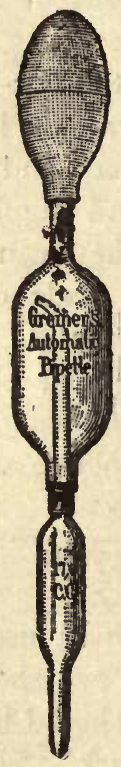

FIG. 9 a single mark at $17.5 \mathrm{cc}$., is the form commonly used. Other forms are shown in Figs. I2 and I3. These latter forms, made so as to hold enough acid for 20

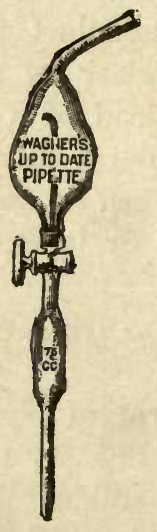

FIG. IO

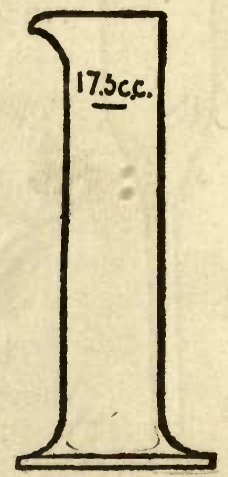

FIG. II AUTOMATIC PIPETTE WAGNER'S PIPETTE ACID-MEASURE 
or more tests, are probably the most convenient where many samples are to be tested at the same time.

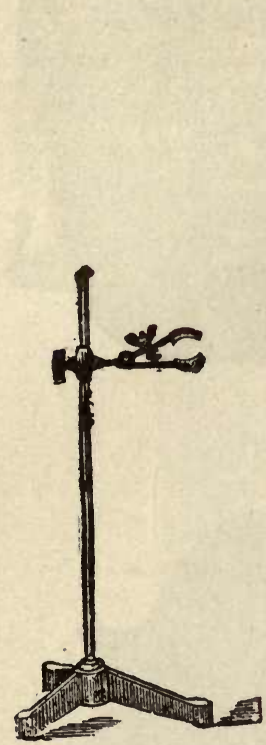

FIG. I2

ACID-BURETTE AND STAND

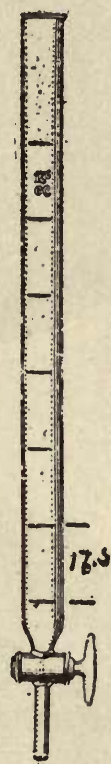

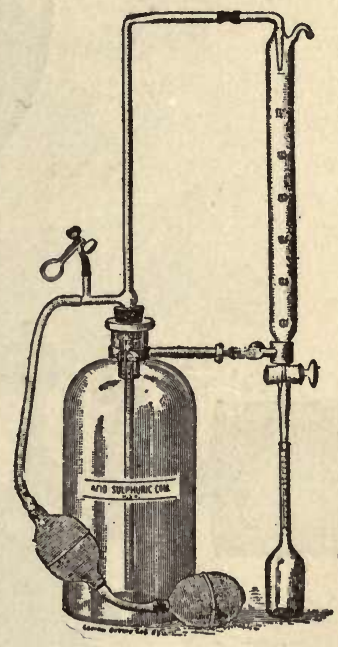

FIG. I3

AUTOMATIC BURETTE

\section{THE CENTRIFUGAL MACHINE, OR TESTER}

The centrifugal machine used in the Babcock test is commonly called the Babcock tester. Various forms have been devised, varying in size from those adapted for a single duplicate test up to the needs of large factories. The designs of recent years are much superior to the early forms. Some of the different types are 

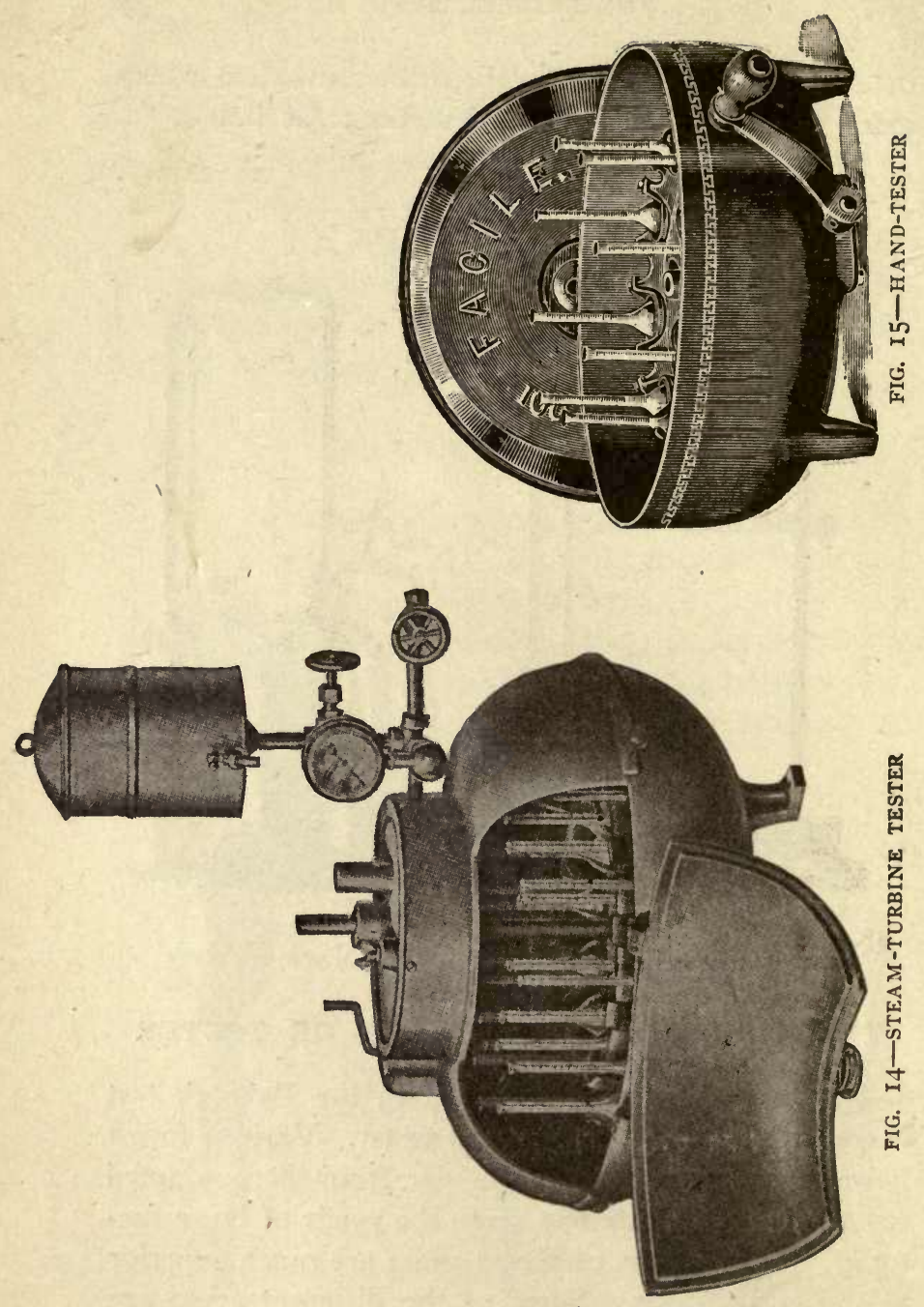
represented in Figs. I4, 15, 16 and 17 . In general they all consist of a revolving disc placed in a horizontal position, and provided with swinging pockets,

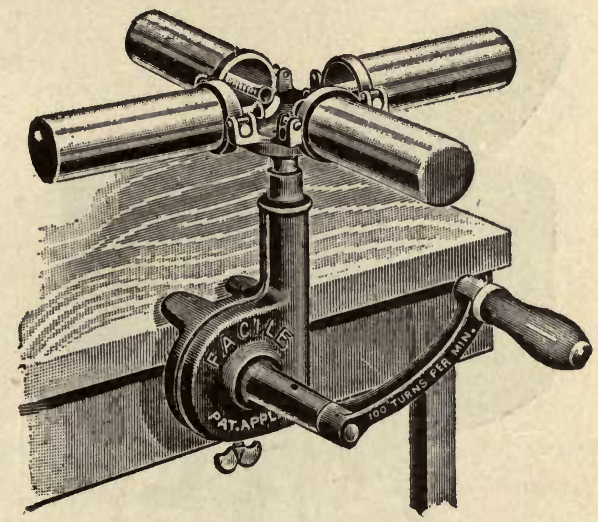

FIG. I6-SMALL HAND-TESTER

in which the test-bottles are placed. When at rest, the pockets hang down, permitting the bottles to stand upright. When the disc is in motion the pockets swing out, carrying the bottles to a horizontal position, the necks of the bottles being directed in toward the center. The testers should be made to carry an even number of bottles. The steam-turbine tester is the best form of centrifugal for factory work. It has the advantage of maintaining a uniform rate of speed and, in addition, the contents of the bottles are kept hot, and hot water is supplied. In some forms, in which the exhaust steam is not carried away and in 
which no dampers are provided in the cover, the steam testers may heat the fat too high. For use on farms, hand-testers are available. It is always necessary that

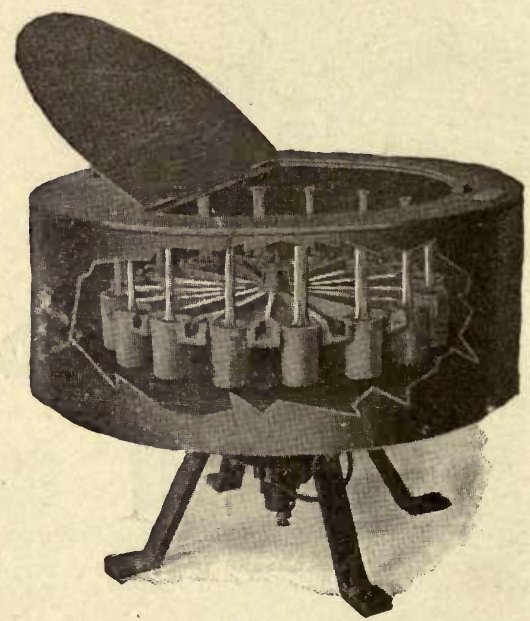

FIG. I7-ELECTRIC CENTRIFUGAL MACHINE OF LATEST DESIGN FOR USE IN BABCOCK TEST

Capable of unusually high speed-safe, accurate and convenient. Made by International Instrument Co. Cambridge, Mass.

the tester should be securely fastened to a firm foundation and so set that the revolving disc is level. The centrifugal should run smoothly, without jar or tremble, when going at full speed.

Estimating speed of centrifugal tester.-In order to cause separation of the most fat possible, the centrifugal disc must move at a sufficient speed. The required number of revolutions depends upon the diameter of the disc, to the edge of which the test-bottles are 
attached. The smaller the wheel, the greater must be the number of revolutions a minute.

Farrington and Woll have prepared the following table, showing the necessary number of revolutions for different sizes of testers :

DIAMETER OF

WHEEL IN INCHES

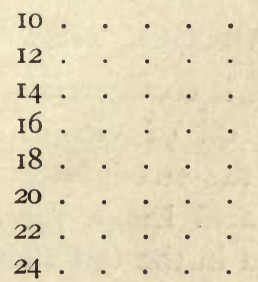

No. of revolutions of disc per minute

In the case of steam-turbine testers, they are, or should be, made to run at the desired speed under a definite head of steam. These testers should always be provided with a pressure-gage, and a speed-indicator is also desirable.

In the case of hand-testers, the speed can be ascertained in the following manner: Give the handle one full turn and count the number of times a given point on the disc goes round. Suppose, for example, that the diameter of the disc is 16 inches and that it revolves 14 times for one turn of the handle. Such a disc ought to revolve 848 times per minute according to the preceding table. The handle must be turned around as many times a minute as $\mathrm{I}_{4}$ is contained in 848 in order to attain the desired speed, which is found to be about 60 times, or once a second. Then, with watch in hand, regulate the turning of the handle until it 
is made to turn 60 times a minute. The proper speed once attained should be kept up during the testing of a sample. The efficiency of whirling can be further tested by treating different samples of the same milk at different rates of speed, the highest per cent. of fat beyond which there is no increase, showing the right speed.

\section{KIND OF ACID USED IN BABCOCK TEST}

The acid used in the Babcock test is commercial sulphuric acid, commonly known as oil of vitriol. It should not be quite as strong as the strongest commercial acid. While the strong acid has a specific gravity of about 1.84 , the acid used in the test should be between $\mathrm{I} .82$ and $\mathrm{I} .83$ at $60^{\circ} \mathrm{F}$.

Effect of weak acid.-If the acid is weaker than that indicated by specific gravity 1.82 , there is danger that some of the coagulated casein may not be completely redissolved and this, mixing with the fat, makes the fat-column in the test-bottle more or less pale and cloudy, when it should be clear and usually golden yellow in color. In addition, there is apt to be a collection of cloudy matter at the foot of the fatcolumn, obscuring the line of division and making sharp reading difficult. The use of more than $17.5 \mathrm{cc}$. of acid not too weak may give good results.

Effect of too strong acid.-When the acid is too much above specific gravity 1.83 , the fat-column is dark in color. There is a layer of black material below it, and the amount of fat is difficult to read with accuracy. When the acid is too strong, it is possible to secure accurate results by using less than $17.5 \mathrm{cc}$. 
of acid, the exact quantity being determined by trying different amounts of acid, until the fat-column obtained is clear and yellow. Strong acid, if allowed to stand open to the air, will in time absorb enough moisture to reduce it to proper strength. By far the best plan is to purchase the acid of guaranteed specific gravity $\mathrm{I} .82$ to $\mathrm{r} .83$, since all dairy-supply houses now furnish such acid, and then take pains to keep the acid in tightly stoppered bottles when not in use.

Testing strength of acid.-The strength of sulphuric acid may be conveniently tested by a specially designed hydrometer (Fig I8). This instrument or acidometer is simply allowed to float in the sulphuric acid, which must be at $60^{\circ} \mathrm{F}$., and the specific gravity is read from the scale where it coincides with the upper surface of the liquid, which should be between the scale-marks 1.82 and 1.83 . No acidometer should be used whose accuracy is not reliably guaranteed.

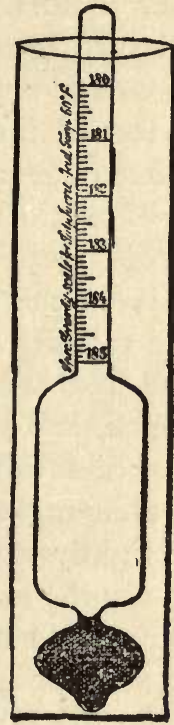

FIG. 18

HYDROMETER FOR

TESTING STRENGTH OF SULPHURIC ACID

Reducing the strength of strong acid.-With the aid of an acidometer, it is possible to purchase strong sulphuric acid and dilute it to proper strength. This is not advised for the average worker. When this is done, extreme caution must be used in diluting the acid. Never pour water into strong sulphuric acid, but always add the acid to the water. The amount of 
dilution depends upon the strength of the acid used. One should start with a small dilution and increase gradually until the specific gravity of the acid becomes I.82 to I.83. After diluting the acid with water, the mixture becomes hot, and it is necessary to allow it to cool to $60^{\circ} \mathrm{F}$. before testing with the acidometer.

Useful indications regarding strength of acid.After one has acquired some skill in making the Babcock test, one can readily tell whether the acid is too strong or too weak from its action when mixed with milk in the test-bottle. One bases his judgment on the rapidity with which the milk-casein is coagulated and redissolved, and also upon the quickness with which, and the degree to which, the mixture of acid and milk turns dark.

Keeping acid from air.-The acid should be kept in tightly stoppered bottles, because, if exposed to air, it absorbs moisture and becomes too weak. The stopper should be glass, since a common cork stopper is soon destroyed by the acid, and even rubber is not long satisfactory.

Care in handling sulphuric acid.-Strong sulphuric acid is extremely corrosive and is dangerous to handle except with care. In contact with articles like clothing or leather, it quickly ruins them, while on the skin it causes serious burns in a short time. If sulphuric acid gets upon one's skin, it should be immediately and thoroughly washed with an abundance of water, and this may be followed by washing with dilute ammonia or sodium carbonate. In case acid gets on the clothing, treat it first with abundance of water and then with ammonia. Red discoloration on cloth- 
ing caused by acid may be remedied by treatment with ammonia, if not too long delayed. Acid on tables, floors, etc., may be neutralized by treatment with washing soda or other alkali.

\section{METHODS OF TESTING ACCURACY OF APPARATUS}

The correctness of the graduation of the glassware used in the Babcock test is a fundamental condition of accuracy in the results obtained. In some states all graduated glassware used in the Babcock test must be tested by the state and found correct before its use is permitted in commercial operations. Reliable dealers guarantee the accuracy of their glassware, and it is found to be much more reliable than formerly. However, it is a safe precaution always to test new apparatus before using it. Testing graduated glassware, is known technically as calibration.

Testing or calibrating milk-bottles.-Test-bottles which show a variation, above or below, of more than one division, or .2 per cent., in the Io per cent. scale, should not be used. The different methods of testing will now be considered.

(I) Testing with special bottle-tester.-The quickest method of testing the accuracy of the scale of a test-bottle is to use a special device, which is essentially a simple brass plunger (Fig. 19). This instrument is divided into two equal portions, each part being made of such a size as to displace exactly one cubic centimeter of liquid. This bottle-tester is used as follows: The test-bottle is filled to the zero mark with milk, or one may use water or, better, wood alcohol, imparting 
color to the water or alcohol by adding some black aniline or carmine ink. Fill the bottle nearly to the zero mark and then finish with a pipette or dropper,

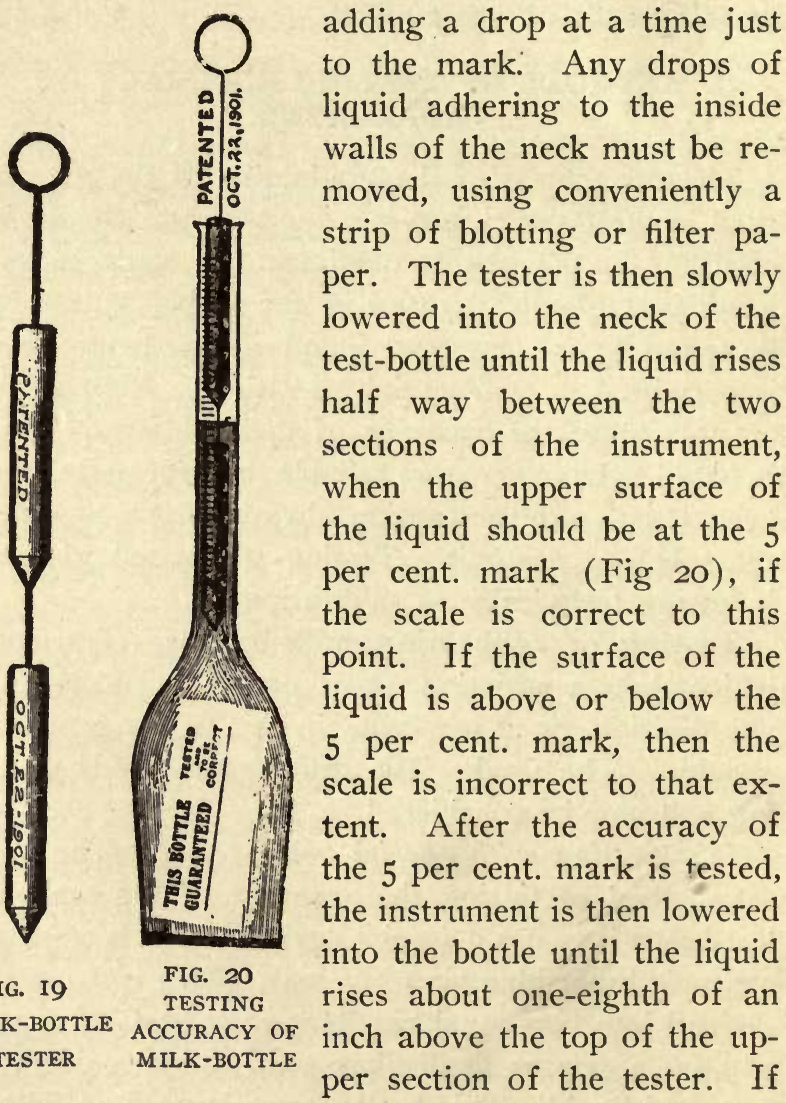
the upper surface of the liquid is level with the ro per cent. mark, the graduation is correct at that point. The graduation of the scale is regarded as correct, if 
the tester shows the 5 and ro per cent. marks to be correct.

In explanation of the use of this form of bottle-tester, it is to be remembered that the neck of the milkbottle is so graduated as to hold $2 \mathrm{cc}$. between the $\mathrm{o}$ and Io marks; hence, the volume between the o and 5 marks should be I cc., and that between the 5 and Io marks should be also I cc. The brass plunger is so made that each section displaces, or forces up into the neck, I cc. of liquid, the whole instrument displacing $2 \mathrm{cc}$. This tester therefore gives two tests of the scale, one at the 5 per cent. mark and the other at the ro mark.

Some of these instruments are made to test the 4 and 8 per cent. points, so that with two testers, one can, if desired, test the accuracy of the scale at the $4,5,8$ and ro points. There are also testers of the same form made for cream-bottles.

In using this bottle-tester, the following precautions are to be observed:

(I) Have the upper surface of the liquid exactly on a level with the zero mark in the neck of the testbottle before putting the tester in.

(2) Clean the inside walls of the neck of the bottle from adhering liquid before testing.

(3) No air-bubbles should be allowed to adhere to the tester when it is below the liquid.

(4) The tester should be dry each time before using.

(2) Testing with mercury.-From an accurately graduated burette (Fig. 2I), measure 2 cc. of clean mercury into the bottle to be tested. Then push down into the neck of the bottle as far as the top line of 
graduation a close-fitting cork or plug, cut off square at the lower end. Turn the bottle upside down, causing the mercury to run into the neck. The mercury just fills the space in the neck between the o and ro

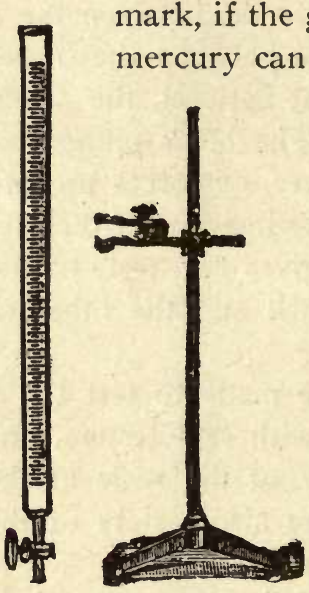

FIG. 2 I

BURETTE AND SUPPORT ing one bottle after another by transferring all the mercury from one bottle to another, which may be conveniently done by slipping a piece of elastic rubber tubing over the ends of the necks of the two bottles. In using the same mercury for testing one bottle after another, no mercury must be lost in transferring, and none must be left in the bottle last tested. The inside walls of the test-bottle must be dry and clean in order to prevent any mercury adhering.

(3) Testing with water.-The bottle to be tested is filled with water, slightly colored with carmine ink, or otherwise, up to the zero mark. The coloring of the water makes easier the reading of the height of the liquid. Any water adhering to the inside of the neck is removed by a strip of blotting or filter paper. Then one runs into the test-bottle $2 \mathrm{cc}$. of colored water from a burette or pipette, graduated to twentieths of a cubic centimeter. The upper surface of the liquid should be on a level with the Io per cent. mark if the scale is correct. Any part of the scale can be similarly 
tested, remembering that each per cent. on the scale should contain just $.2 \mathrm{cc}$. of liquid.

Testing accuracy of pipette.-When many pipettes are to be tested, one runs into one pipette from an accurately graduated burette (Fig. 2I), I7.6 cc. of mercury, closing the lower end of the pipette. The mercury should fill the pipette just to the $17.6 \mathrm{cc}$. mark, if the mark is correct. The same mercury can be transferred to other pipettes in succession. Care must be taken to have the pipettes clean and dry inside and that all the mercury is transferred without loss.

When only one or a few pipettes need testing, water can be used, running from a burette into each pipette I7.6 cc. of water, which should just fill the pipette to the mark, if accurate.

Testing accuracy of acid measure.-Ordinarily the acid measure does not need testing, since a little variation does not affect the results. When desired, it can be tested by running in water or milk from a $17.6 \mathrm{cc}$. pipette, known to be accurate.

\section{KEEPING GLASSWARE CLEAN}

It is very important that the test-bottles and the pipettes used in the Babcock test should be kept as clean as possible from fat adhering to the inside surface. Unless a special effort is made, the bottles quickly become covered inside with a film of fat, which may be sufficient to increase appreciably the results obtained when the bottles are used in testing. The bottles should be kept entirely free from any fat- 
film and the wall should be clear and bright. This can be accomplished without serious trouble.

As soon as a test is completed and the amount of

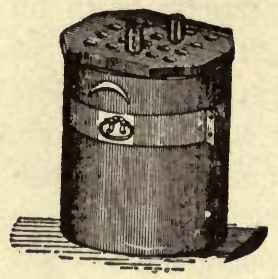

FIG. 22-WASTE-JAR FOR EMPTYING TEST-BOTTLES fat read, the test-bottle, while still warm, should be emptied. This may easily be done by having a large earthenware jar or crock, covered with a board (Fig. 22), in which are several holes large enough to admit easily the necks of test-bottles. The bottle is inverted, the neck run down through one of these holes, and at the same time the bottle is shaken up and down in order to remove the white calcium sulphate deposited on the bottom of the bottle during the test. Then, when one is ready to clean up all the bottles that have been used, each one is rinsed with 8 or Io

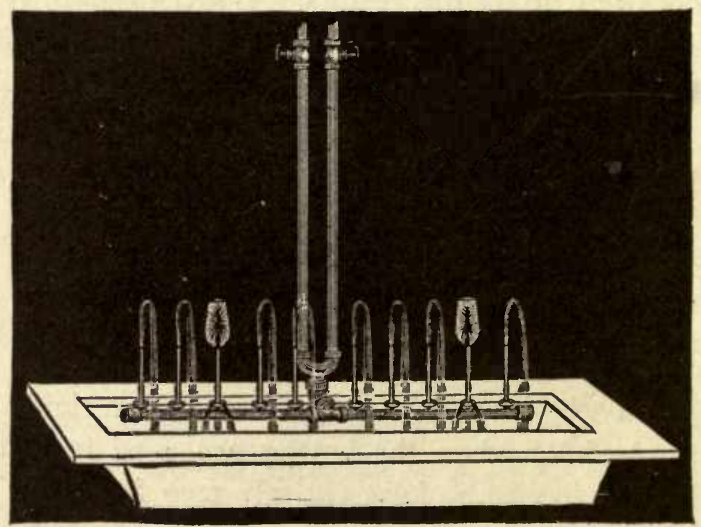

FIG. 23-TEST-BOTTLE IRINSER 


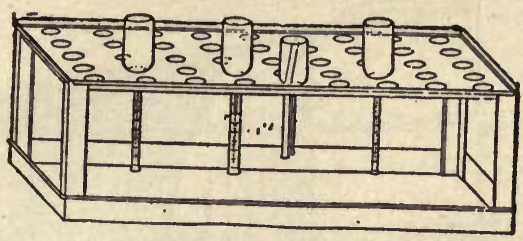

FIG. 24-TEST-BOTTLE DRAINING RACK

cc. of a solution, consisting of one ounce of potassium bichromate dissolved in one pint of sulphuric acid.

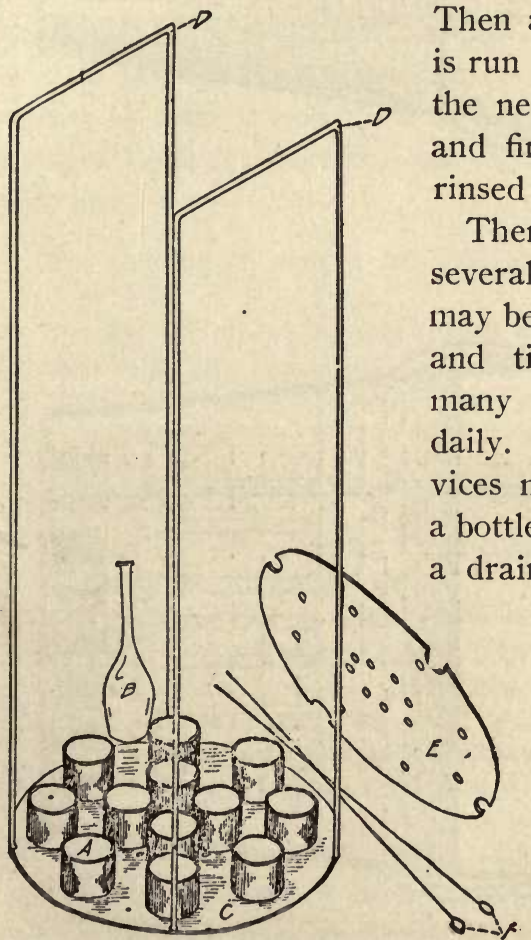

FIG. 25a-BOTTLE-HOLDER, EMP'TY Then a test-bottle brush sun once up and down the neck of each bottle, and finally each is well rinsed with hot water.

There are available several devices which may be found convenient and time-saving where many bottles are used daily. Among these devices may be mentioned a bottle-rinser (Fig. 23), a drain-rack (Fig. 24), and a bottlewasher (Figs. $25 a, b$, and $c$ ), described by Farrington (Bulletin I29, Wis. Agr. Exp. Station, pp. 2224). 


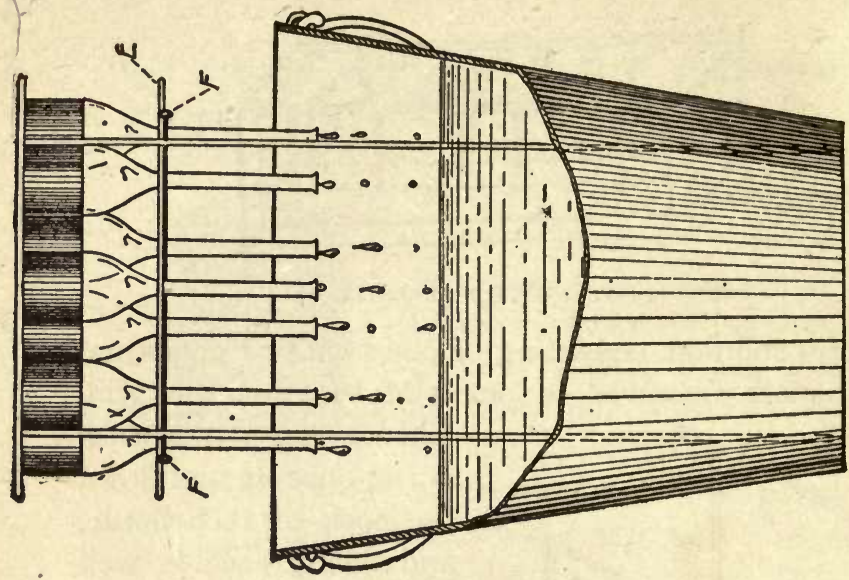

요

幽完

음

3

$\propto$ 음

동

넝 응

出

쇠

次

동 똑

क

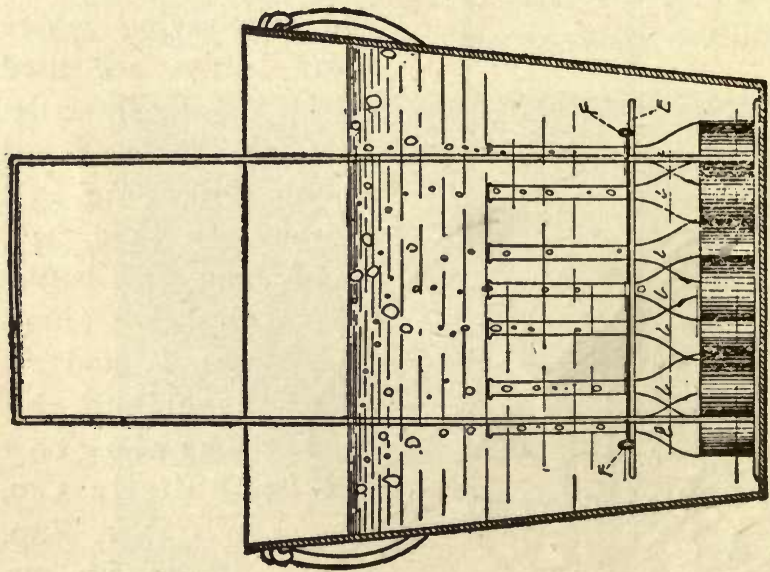

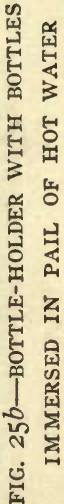




\section{CHAPTER IV}

\section{Method of Operating the Babcock Test}

In describing the method of operating the Babcock test, when determining the amount of fat in milk, special attention will be called at each step to such difficulties as may occur, and emphasis will be placed upon such precautions as experience has shown to be necessary in order to obtain accurate results.

In brief outline, the different steps may be stated as follows:

I Mix thoroughly sample of milk, which is at $60^{\circ}$ to $70^{\circ} \mathrm{F}$.

2. Quickly fill pipette to mark with milk.

3. Run milk into test-bottle.

4. Fill acid-measure to mark with acid and pour into test-bottle.

5. (I) Mix milk and acid thoroughly by rotary motion; (2) let stand 2 to 5 minutes; and (3) mix again.

6. Put test-bottles in tester (centrifuge) and whirl 4 or 5 minutes at proper speed.

7. (I) Add fairly hot water up to neck of bottles; (2) whirl one minute; (3) add hot water to 8 or 9 per cent. mark; and (4) whirl one minute.

8. Read results at temperature of about $130^{\circ} \mathrm{F}$.

\section{PREPARING SAMPLES OF MILK FOR TESTING}

The milk, which should be at a temperature of $60^{\circ}$ to $70^{\circ} \mathrm{F}$., is thoroughly mixed by pouring from one vessel to another two or three times, at least, imme- 
diately before taking the sample for testing. The special methods of preparing milk for sampling under various conditions are fully considered in Chap. II, p. 20. The fat must be evenly distributed through the milk just before sampling.

Every sample of milk should always be tested in duplicate, that is, two tests should be made at the same time. This insures greater accuracy. If the results of the duplicate test do not agree, there is an error somewhere and the work must be repeated. Also, in case one test is lost and another sample can not be obtained, the remaining test can be used, and the whole work will not be lost.

\section{TAKING SAMPLES OF MILK WITH PIPETTE}

The measuring pipette (Fig. 8, p. 35), is filled at once after the thorough mixing of the milk. This is done by placing the lower end of the pipette well down in the milk and sucking up the milk until it reaches a point in the pipette somewhat above the mark around its upper stem. Then the forefinger, which must be $d r y$, is quickly placed over the upper end of the pipette before the milk runs down below the mark. By lightening the pressure of the finger on the end of the pipette, the milk is allowed to flow out slowly until its upper surface just reaches the mark on the stem. Some practice is necessary before one can easily and rapidly manipulate the pipette with accuracy.

The pipette must be kept very clean. When samples of several different milks are to be drawn in succession, the pipette may be satisfactorily rinsed by 
drawing it full of the milk next to be sampled, this portion being thrown away.

\section{TRANSFERRING SAMPLE OF MILK FROM PIPETTE TO TEST-BOTTLE}

- Having filled the pipette just to the $17.6 \mathrm{cc}$. mark, one holds the pipette obliquely to the bottle, placing the point of its lower end within the neck and against the side of the neck of the test-bottle. The right way of holding the pipette is shown in Fig. 26. By loosening the finger at the upper end of the pipette, one allows the milk to flow slowly down the inside of the neck. The small portion of milk adhering to the inside of the pipette is nearly all carried into the bottle by blowing through the pipette several times before removing it from the neck of the bottle. Not a drop of the milk should be FIG. 26-CORRECT WAY OF allowed to spill outside the HOLDING PIPETTE AND bottle in transferring from

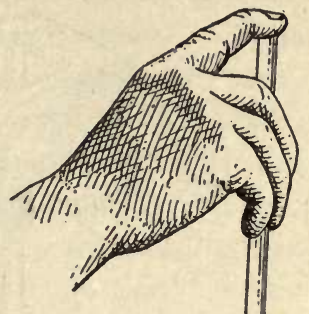
(n) 


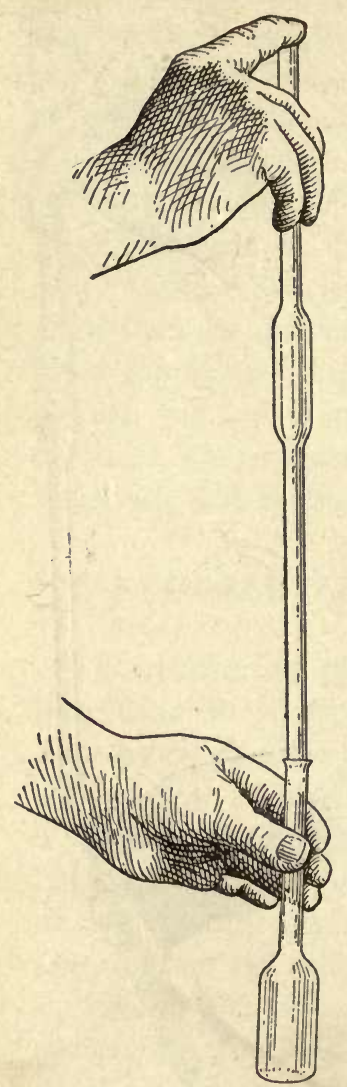

FIG. 26a-WRONG WAY OF HOLDING PIPETTE AND BOTTLE

what remains is made in the construction of the pipette. Special experiments having shown that .I cc. of milk will remain adhering to the inside, the pipette is made to hold I7.6 cc. to the mark, but is expected to deliver into the bottle only $17.5 \mathrm{cc}$., the exact amount required for the test.

In delivering the milk, the pipette must never be held perpendicularly in a line with the neck of the test-bottle, running the milk straight down as shown in Fig. 26a, since the narrow neck may easily choke up with milk and run over the top.

\section{MEASURING AND ADDING ACID}

When the samples of milk are in the test-bottles, the acidmeasure (Fig. II, p. 36), is filled to the $17.5 \mathrm{cc}$. mark and the acid (see p. 42) is poured into the test-bottle. The acid should be at a temperature of $60^{\circ}$ to $70^{\circ} \mathrm{F}$. Much care must be exercised in pouring the acid into the test-bottle containing the milk. The test-bottle is held in an inclined position, so that the 
acid will follow the inside wall down to the bottom, and the pouring should be slow and steady. Thus handled, the acid, being much heavier than the milk, forms a layer by itself at the bottom of the bottle, while the milk forms a separate layer by itself on top of the acid. While pouring in the acid, it is well to turn the test-bottle around slowly so the acid may in turn come in contact with different portions of the inside walls of the neck and wash down any adhering milk. Unless this is done, some milk may remain on the wall of the neck, in which case it will not be properly acted on by the acid, and the fat-column will contain particles of undissolved casein.

If one attempts to pour the acid straight down the neck of the bottle, two difficulties are liable to occur: (I) The neck may easily choke up and the acid overflow on the operator's hands. (2) The acid may drop into and partially mix with the milk, in which case black particles may appear on the upper surface of the acid layer and later, mixing in the fat-column, may interfere with accurate reading of the results.

Temperature of milk and acid.-It is directed to have the milk and acid at a temperature of $60^{\circ}$ to $70^{\circ} \mathrm{F}$. before they are placed in the test-bottle. There are good reasons for this precaution. If the milk or acid is decidedly cold, as may easily happen in cold weather, the action of the acid may not be vigorous enough to redissolve completely the coagulated casein, thus producing white specks or a cloudy appearance in and below the fat-column at the end of the test. On the other hand, if the milk or acid is at too high a temperature, as may easily happen in hot weather, 
the action of the acid is much the same as if it were too strong, producing dark-colored specks or a darkened appearance in and below the fat-column. Experience shows that when the milk and acid are at a temperature between $60^{\circ}$ and $70^{\circ} \mathrm{F}$., there is no danger of too slight or too strong action of acid. More acid can be used at lower temperatures and less at higher temperatures with satisfactory results, but this involves experimenting; the best way will be to use the regular amount of acid and regulate the temperature of the milk and acid.

\section{MIXING MILK AND ACID IN TEST-BOTTLE}

When the measured amount of acid has been placed in the test-bottle, the acid and milk should be thoroughly mixed. This is best done by giving the botthe a rotary motion, with gentle shaking, until the whole mass becomes liquid and free from solid particles of casein. Much motion up and down should be avoided, since milk might be thrown up into the neck of the bottle beyond reach of the acid, in which case coagulated casein would contaminate the fat-column and impair the results.

When the acid and milk first mix, the casein is coagulated in a somewhat solid mass, which gradually redissolves as the mixing becomes complete. The mixing, once begun, should continue until the casein appears to be redissolved. If the operation of mixing milk and acid is incomplete or is interrupted, black particles may appear in the fat-column at the end of the test.

It is a wise precaution to allow the bottle to stand 
2 to 5 minutes after the mixing appears complete and then to agitate a second time with rotary motion just before placing in the tester.

The action of the sulphuric acid upon the water and organic solids of the milk produces a marked degree of heat, as soon as the acid and milk begin to mix. The color of the solution becomes yellow at first and then passes through varying darker shades of yellow to violet, brown and finally dark-brown, if the acid is of the right strength. (See p. 42.) The coloration is due to the action of the acid upon the milk-sugar and milkcasein. Too strong acid produces a dense black color. In samples of milk containing too much bichromate of potash, the color becomes greenish black.

Samples of milk that have been preserved for some time with bichromate or formalin, especially when the preservative is used in larger than usual amounts, require more time and agitation to redissolve the coagulated casein than do ordinary samples, since these preservatives harden the coagulated casein. (See p. 29).

\section{WHIRLING THE TEST-BOTTLES}

The test-bottles containing the mixture of milk and acid, after being agitated a second time as stated above, are placed in the centrifugal tester (p. 37), and whirled. This is better done soon after the milk and acid are mixed, but it may be delayed without harm for 24 hours, in which case, however, the bottles should be placed in water at $160^{\circ}$ to $180^{\circ} \mathrm{F}$. for 15 or 20 minutes before whirling.

An even number of bottles should be whirled at the same time and they should be placed about the disc 
in pairs opposite to. each other, so that the equilibrium of the tester will not be disturbed. When all the samples to be tested are placed in the tester, the cover is placed on the jacket and the machine turned for 4 or 5 minutes at proper speed, 600 to $\mathrm{I}, 200$ revolutions per minute, according to the diameter of the centrifugal disc. (p. 40.)

The whirling brings the fat to the top of the mixture in the test-bottle. The whirling of the bottles should never be done without having the cover on the jacket, for two reasons: (I) The cover prevents the cooling of the fat in the test-bottles during whirling, and (2) the operator is protected from injury in case a bottle should break and scatter its contents whilebeing whirled.

In the case of hand-testers, it may be necessary to put hot water in the jacket in cold weather in order to keep the bottles warm enough.

\section{ADDING HOT WATER TO THE TEST-BOTTLES}

When the bottles have been whirled 4 or 5 minutes, moderately hot water is added to each bottle until the contents come to the lower end of the neck. The water may be added with a pipette or by means of any convenient arrangement. The cover of the machine is replaced and the bottles are whirled at full speed for one minute. Hot water is again added to the bottles until the fat, which is lighter than the rest of the liquid, rises in the neck to the 8 or 9 per cent. mark. One must be careful never to run the water above the Io per cent. mark. The whirling is then re. peated for one minute at full speed. 
Three points deserve attention in this connection: (I) The temperature of the water added, (2) the kind of water used and (3) the number of times water is added.

(I) The temperature of the water added should be above $120^{\circ} \mathrm{F}$. The aim in general should be to have the temperature of the fat at the close of whirling at $130^{\circ}$ or $140^{\circ} \mathrm{F}$, and the temperature of the water added should have reference to this fact. However, any effect of too hot or too cold water can be remedied after the final whirling by adjusting the temperature as needed.

(2) Clean, pure, distilled water is the best form to use and, next, soft rain water. Hard water may seriously affect the results. Objections to hard water may in most cases be overcome by thorough boiling or by previous treatment with a few drops of sulphuric acid.

(3) Some operators add the hot water only once, filling the bottle to near the top of the neck immediately after the first whirling. The advantage of adding the water in two portions is that the fat is washed free from adhering impurities, since the fat-column is often mixed with various particles which render the reading uncertain and frequently too high.

\section{READING RESULTS IN PERCENTAGE OF FAT}

After the last whirling is completed, the test-bottles are removed from the tester, one at a time, in order to read the results of the test. To ascertain the amount of fat, hold the test-bottle upright, having the graduated scale of the neck of the bottle on a level 
with the eye. Notice the divisions marking the highest and lowest limits of the fat-column. The difference between them gives directly the per cent. of fat in the milk tested. The readings can be made accurately to one-half of a division, that is, to one-tenth of one per cent. Some test-bottles are provided with a regulator which moves the bottom of the fat-column to a level with the nearest numbered mark.

In connection with the measuring of the fat-column, the following points deserve attention: (I) Using dividers to assist in reading, (2) the temperature of the fat-column, (3) the upper and lower limits of the fat-column, (4) the correct appearance of the fatcolumn, (5) defects in appearance of the fat-column.

(I) If one uses test-bottles not provided with a regulator for adjusting the level of the fat-column, the reading of the percentage of fat on the scale may be made with less liability of error by measuring the length of the fat-column with a pair of dividers, one point of which is placed at the bottom and the other at the upper limit of the fat-column. The dividers are then removed and one point is placed on the zero mark of the scale on the bottle used, when the other point will be at the exact per cent. of fat in the milk tested.

(2) The temperature of the fat, when it is read or measured, should be above $120^{\circ} \mathrm{F}$. and not above $140^{\circ} \mathrm{F}$., preferably about $130^{\circ} \mathrm{F}$. This will insure sharply defined upper and lower limits of the fat-column. In case the contents of the bottles are below $120^{\circ} \mathrm{F}$., the bottles should be placed for 15 or $20 \mathrm{~min}$ utes in water that has a temperature of $130^{\circ}$ to $140^{\circ} \mathrm{F}$., 
before the reading is made. This usually needs to be done in cold weather, when hand-testers are used, especially if no hot water has been placed in the jacket during the whirling. If the fat is above $150^{\circ} \mathrm{F}$., it should be allowed to cool to $140^{\circ} \mathrm{F}$. or below before reading the results. Too high temperatures give too high results, because the fat-column expands.

(3) The line of division between the fat-column and the liquid beneath is nearly a straight line when the testing is properly done, and one need have no doubt about the reading of the scale at this point. But the upper surface of the fat-column is concave instead of straight, which may cause some uncertainty as to the exact point at which the reading should be made on the scale. The correct reading is taken at the line where the upper surface of the fatcolumn meets the sides of the neck, the very highest point at which the fat-column is seen. The reading should not be made from the dark line or meniscus lower down, which is caused by the refraction of the curved surface. The points at which the readings should be made are shown in Fig. 27, indicated as A and B. Results read this way agree with those

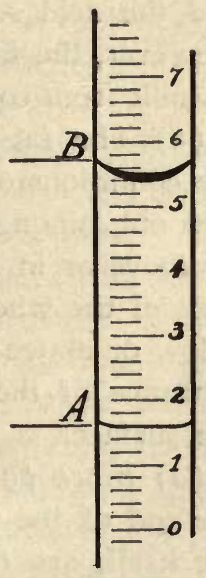

FIG. 27 MEASURING FAT-COLUMN obtained by gravimetric analysis. The objection may be raised that we get too high results by reading from the extreme top points of the fatcolumn, just as if the upper surface were straight at 
these points instead of concave. While there is such an apparent error, the excessive reading thus caused is only enough to make up for the loss of fat which can not be separated from the rest of the liquid by centrifugal force and brought into the fat-column. The amount of fat thus left in the mixture of milk-serum and acid is ordinarily about .2 per cent. and this is about the amount of excess obtained by the approved method of reading the upper limit of the fat-column.

(4) The fat appearing in the neck of the test-bottle at the end of a successful test is of a clear, yellow color, and the line of division between its lower limit and the acid solution beneath it is sharply distinct. However, the fat is apt to be light-colored in the case of milk from cows far along in lactation.

(5) The fat-column may show certain defects, if the conditions of the test have not been properly carried out, among which are $(a)$ black particles below or above or in the fat-column, or a darkened appearance of the whole column of fat; $(b)$ white particles below or above or in the fat-column, or a cloudy appearance of the whole column; and $(c)$ bubbles on the surface.

(a) Black particles in the neck of the test-bottle at the end of the test, or a darkened appearance of the fat itself, are due to one or more of the following causes: (I) Too strong acid (above 1.83 specific gravity), (2) too much acid (more than I8 cc.), (3) too high temperature of the milk or acid (over $75^{\circ} \mathrm{F}$.), (4) allowing milk and acid to stand in test-bottle too long before mixing, (5) allowing the acid to drop 
through the milk when poured into the test-bottle, (6) interrupting the mixing of the milk and acid after beginning and before completion.

(b) White particles of undissolved casein below or above or in the fat-column, or a cloudy appearance of the fat, are due to one or more of the following causes: (1) Too weak acid (below I.82 specific gravity), (2) insufficient amount of acid (less than $\mathrm{I} 7 \mathrm{cc}$ ), (3) too low temperature of milk or acid (below $60^{\circ} \mathrm{F}$.), (4) incomplete mixing of milk and acid, (5) insufficient speed of tester.

Sometimes when the fat is not clear, good results may be obtained by allowing the bottles to cool enough for the fat to harden some, and then warming in water at $140^{\circ} \mathrm{F}$. before reading.

(c) Bubbles of gas, appearing as foam on the top of the fat-column, are generally due to the use in the test-bottle of hard water containing carbonates. This condition may be prevented by adding to the water, previous to use, a few drops of sulphuric acid. When the foam appears and interferes with the reading, a few drops of alcohol are put on the top of the fat-column and the reading is at once made. The alcohol causes the bubbles to disappear and produces a sharp line of division between the fat and alcohol. If the alcohol is allowed to be in contact with the fat for some time before the reading is made, the alcohol and fat mix and increase the height of the fat-column, thus producing misleading results. 


\section{OUTLINE STATEMENT OF SOME SPECIAL PRECAUTIONS}

I. Always make tests in duplicate.

2. Make sure that the sample is a representative one.

3. Have the temperature of the milk and acid at $60^{\circ}$ to $70^{\circ} \mathrm{F}$. before putting in test-bottle.

4. Use only acid of right strength.

5. Mix milk and acid thoroughly as soon as acid is added.

6. Mix a second time after a short interval.

7. Make sure that the tester runs at right speed and does not jar.

8. Use only clean, soft water in filling bottles.

9. Read bottles before they cool and at about $\mathrm{I}_{30} \mathrm{O}^{\circ} \mathrm{F}$.

IO. To insure accuracy, read each test twice.

SOME MODIFICATIONS OF THE BABCOCK TEST

One frequently sees references in dairy literature to other forms of tests for milk. As a matter of information, we will notice a few of the modifications of the Babcock test together with other forms that are in use, giving good results.

The Russian Test.-This is a modification of the Babcock test, differing mainly in respect to some of the mechanical details. A special automatic pipette is used (Fig. 28), a special form of test-bottle (Fig. 28a), the neck being separate from the rest of the bottle, and also a special form of acid-measure. The pipette and acid-measure are one-half the usual size. The milk and acid are run into the bottle very easily, and the bottles are filled with hot water automatically while the machine is in motion, the tester also being of a special form. 
The Gerber Butyrometer.-Special forms of tester, test-bottle, etc., are used. The test uses I I cc. of milk, Io cc. of sulphuric acid (I.825 specific gravity),

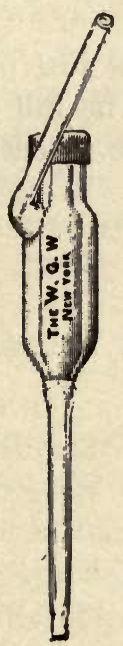

FIG. 28

AUtOMATIC "RUSSIAN" PIPETTE

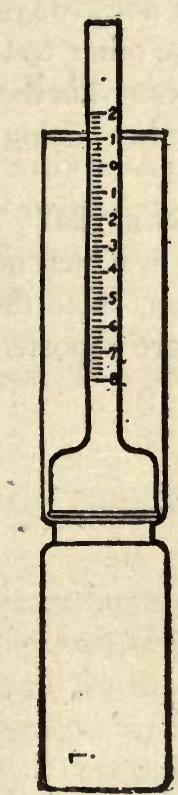

FIG. $28 a$

"RUSSIAN" TEST-BOTTLE

and I cc. of amyl alcohol. The operations are carried out about the same as in the Babcock test.

The "Sinacid" (no acid) Test.-The distinctive feature of this test is that, in place of sulphuric acid, it uses a patented mixture, consisting of sodium phosphate and citrate, which, unlike sulphuric acid, is entirely free from any dangerous properties; it uses also a colored 
alcoholic solution. After mixing the "sinacid" liquid with the milk, the mixture is heated to $200^{\circ} \mathrm{F}$. for 5 minutes before being whirled in the tester. The results do not always appear to agree closely with those given by other tests, according to the reports of some operators. There is, moreover, some natural prejudice against using a process, any part of which is patented.

Gerber's "Sal" Test.-Gerber has just published a method in which no acid is used. The full details are not given, since the method is to be patented. Good results are reported. 


\section{CHAPTER V}

\section{Method of Testing Cream by the Babcock Test}

The Babcock test can be used in ascertaining the amount of fat in cream, but certain precautions and modifications are necessary to insure correct results. A special form of test-bottle is generally used. Special pains must be taken in sampling cream. For strictly accurate work, the cream sample must be weighed for testing.

\section{USE OF MILK TEST-BOTTLES IN TESTING CREAM}

Test-bottles used in testing milk can be used in testing cream only under special conditions. Cream containing over Io per cent. of fat will fill the neck of the test-bottle too full for measurement, when we take I 8 grams (about $I 7.5 \mathrm{cc}$.) to test. This difficulty may be overcome in two ways: (I) By using a sample of cream less than I 8 grams, and (2) by dividing an I8-gram sample in roughly equal parts between two or more bottles, according to its richness in fat. In the former case the per cent. of fat read is increased by a correction to be considered later. In the second case, the tests are made as in case of milk and the percentages found in the different bottles are added, the sum being the per cent. of fat in the cream tested. The volume of cream in each test-bottle is always made up 
to about $17.5 \mathrm{cc}$. by adding water to the cream and mixing before adding acid.

\section{SPECIAL CREAM-TESTING} BOTTLES

To test in one bottle an I8-gram sample of cream containing over Io per cent. of fat, the neck must be made to hold more than the neck of a milk-bottle, that is, more than $2 \mathrm{cc}$. This additional space must be obtained (I) by using a neck of larger diameter, keeping the length the same as in the milk-bottle or (2) by making the neck longer, keeping the diametér the same. There is this objection to making the necks of test-bottles too large in diameter, that the divisions on the scale come nearer together and the reading of the results is less accurate. If the neck is made long enough to allow as fine graduation as in the milk-testing bottles, then the bottles are too long to use in an ordinary tester.

Bulb-necked cream-bottle.-Both of the difficulties mentioned above are overcome by having a bulb made in the neck of the bottle (Fig. 29). In this cream-testing bottle the graduation is as fine as in the milk-testing bottles, the smallest division representing .2 per cent., and the scale ex-

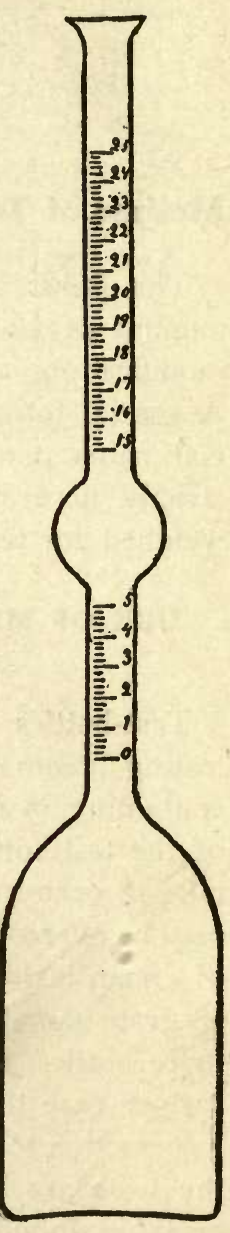

FIG. 29 BULB-NECKED CREAM-BOTTLE 
tends from o to 25 per cent. Hence, in these bottles we can use 18 grams of cream, provided the cream does not contain over 25 per cent. of fat, while, with cream testing over 25 and up to 50 per cent., a 9gram sample can be used for the test. In using this

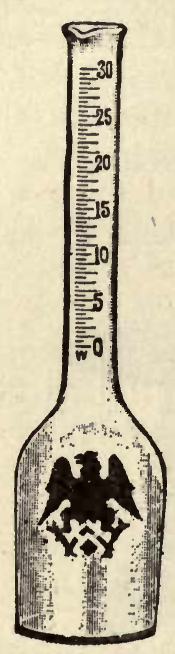

FIG. 30 STRAIGHT-NECKED

CREAM-BOTTLE form of bottle, care must be observed when water is added near the close of the test. Neither the lower nor the upper surface of the fat-column must be allowed to come in the bulb, since, obviously, it is impossible then to read the results. This style of bottle is also made with a scale measuring 50 per cent., the smallest divisions being .25 per cent.

Straight-necked cream-bottles.

The other varieties of cream-testing bottles are straight-necked, varying in respect to (I) diameter, (2) length of neck, and (3) fineness of graduation. These vary in length from the ordinary size to 9 and 10 inches, the longer sizes requiring special testers. In capacity, the necks vary from 6 to $20 \mathrm{cc}$., which is equivalent to 30 to Ioo per cent., when an I8-gram sample of cream is used. In fineness of graduation, the smallest divisions vary in different bottles from .2 to I per cent. One type of straight-necked bottle is shown in Fig. 3o. For strictly accurate work, bottles graduated to .2 per cent. should be used; and the use of bottles whose finest division is more than .5 per cent. should be condemned, except for rough work. 


\section{CREAM-TESTING SCALES}

For weighing samples of cream, a set of accurate scales is required. Different forms are illustrated in Figs. $3 \mathrm{I}$ and 32 . Scales with agate bearings are much preferable to other . forms, since the agate bear-

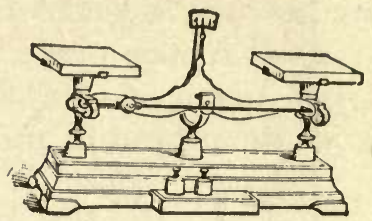

FIG. 3 I

CREAM-TESTING SCALES ings do not rust. Torsion balances and those with steel bearings are liable to rust when kept in damp

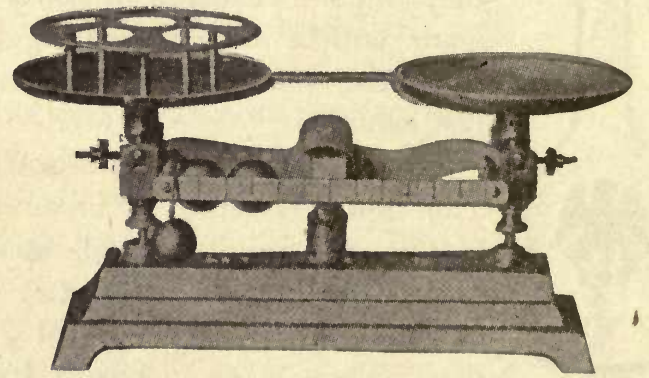

FIG. 32-CREAM-TESTING SCALES

places, and this in time makes them unreliable for accurate work. The scales should be kept in perfect condition and tested for accuracy from time to time.

\section{METHOD OF SAMPLING CREAM}

Cream, from which the test sample is to be taken, whether for part of a composite sample or for direct testing, must be made as uniform as possible throughout its mass. The best method of sampling any but 
small amounts of cream is by means of a samplingtube (Fig. 5, p. 27), which must be cleaned for each sample before using. Frozen cream must be thawed and mixed before sampling. Large lots of dried cream or partially churned cream can not be sampled with complete accuracy. Cream adhering to the outside of the sampler should not be allowed to go into the test sample.

\section{METHOD OF KEEPING CREAM SAMPLES}

In keeping composite samples of cream, the same precautions are to be observed as in the case of milk (p. 3o). With thick cream special effort may be needed to cause the preservative, especially potassium bichromate, to dissolve and be distributed through the sample. This may be done by warming the jars and mixing the cream carefully by a gentle rotary motion.

\section{PREPARATION OF SAMPLES FOR TEST}

Before taking from the cream sample the amount to be used in the test, the cream must have its. fat evenly distributed. To accomplish this, the cream is heated to $105^{\circ}$ or $110^{\circ} \mathrm{F}$. until it is quite fluid. As recommended by Hills (Bulletin IOO, Vermont Exp. Sta., p. 5), the cream is passed through a small sieve (Fig. 33), such as is commonly used in kitchens. Any remaining lumps found in the sieve are rubbed through the meshes by the finger, after which the cream is thoroughly mixed by pouring from one cup to another. The sample is then quickly taken for testing. 


\section{WHY USE OF PIPETTE IS INACCURATE FOR CREAM}

The use of a pipette in measuring cream samples is inaccurate for the following reasons: (I) More fat adheres to the inside of a pipette than in case of milk, the error increasing with the thickness of cream. (2) The weight of cream decreases as the per cent. of fat in cream increases, since milk-fat is lighter

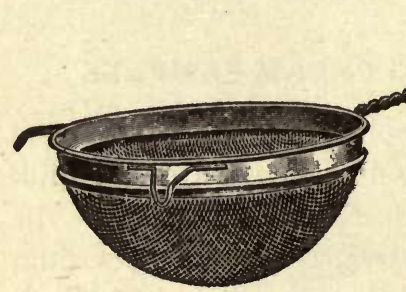

FIG. 33

CREAM-SAMPLING SIEVE

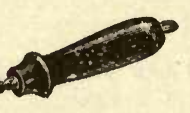

than the other constituents of cream. The scale of the test-bottle is based on the use of 18 grams of material, but the amount of cream that occupies the volume filled by I8 grams of milk ( $77.5 \mathrm{cc}$.) is found to be more or less below 18 grams according to the increased percentage of fat in the cream, running even below I7 grams in very rich cream. (3) Separator cream is more or less filled with bubbles of air, and ripened cream contains gases produced by fermentation. These decrease the weight of a given volume of cream.

For the preceding reasons, the result of trying to measure by pipette a sample of cream to be used for testing its fat content is that less cream will be used than should be, and therefore the results will be too low. Any system of volumetric measurement proposed is open to some uncertainty and inaccuracy. The use of a pipette in testing cream is justifiable only for work that is not expected to be strictly accurate. 
If one uses a pipette in measuring cream for testing, somewhat more accurate results are generally obtained by measuring $18 \mathrm{cc}$. of cream and also rinsing the pipette into the test-bottle with a small amount of water. Pipettes are obtainable which have an $18 \mathrm{cc}$. mark as well as a $17.6 \mathrm{cc}$.

\section{WEIGHING SAMPLE OF CREAM}

The operation of weighing cream is simple. One places the empty test-bottle on one pan of the scales and balances it by a slide-weight or some form of counterpoise. One then places an 18-gram weight on the other pan, after which the pipette is filled with cream somewhat above the $17.6 \mathrm{cc}$. mark, and this is run into the bottle, the last portion being run in more slowly, until the two scale-pans just counterbalance each other. A little practice enables one to weigh the exact amount rapidly. In case the amount of cream taken in the pipette is not enough, agitate the sample, draw a little more into the pipette and run this slowly into the bottle until it counter-balances the weight. In case too much cream is run into the bottle, the surplus can easily be withdrawn by the pipette. No cream must be allowed to get on the outside of the bottle or on the scale-pan while the weighing is done.

Using less than 18 grams.-In case of very rich cream it is preferable to use 9 grams for a sample, in which case the reading of the fat-column is multiplied by 2 ; or the I8-gram sample may be divided between two cream-bottles, in which case water should be added to each bottle so as to bring the liquid to about I $8 \mathrm{cc}$. in volume. The results of the test in the two 
bottles are added. It is more convenient after a little practice to weigh exactly 9 or 18 grams than to run in an approximate amount of cream and weigh that accurately.

In case one uses any amount less than 18 grams for a sample, it is necessary to correct as follows the per cent. of fat read: Divide 18 by the number of grams of cream used and multiply the result by the per cent. of fat read in the test. For example, one uses 13.5 grams of cream and the result reads 15.6 per cent. of fat. Divide 18 by I 3.5 , which gives I.33, and multiply this by 15.6 , which equals 20.8 per cent., the true percentage of fat in the sample.

\section{SPECIAL POINTS ABOUT TESTING CREAM}

When one uses 18 grams of cream in one test-bottle, the operation is completed as in testing milk. When one uses less than 18 grams in one test-bottle, enough water is added to make the volume about 18 cc. Thus, when an I8-gram sample is divided between two bottles, or a 9-gram sample in one bottle is used, we add $9 \mathrm{cc}$. of water to the cream, mix them thoroughly and then proceed as usual. The water and cream should always be well mixed before adding acid.

When it is difficult to get a clear column of fat, it may be remedied by the use of a little less acid, the exact amount to be found by trial. In general, the richer the cream, the less acid is required, $15 \mathrm{cc}$. often being enough. The full amount of acid is used whenever the cream is diluted with water before adding acid, as in the case of taking a 9-gram sample, or dividing an 18-gram sample between two cream-bottles. 
Sometimes it is well to let the bottles stand a little while after being mixed with the acid, until the mixture turns dark, before whirling.

When the liquid just below the fat-column is milky and the fat looks cloudy and light, exact reading is difficult. In such cases the bottles may be placed in water at $130^{\circ}$ to $140^{\circ} \mathrm{F}$. for 15 or 20 minutes before whirling, or, if this fails, the fat may be solidified by placing the bottles in cold water after the last whirling and then heated to $130^{\circ}$ or $140^{\circ} \mathrm{F}$. before reading.

\section{READING THE PER CENT. OF FAT IN CREAM- TESTING BOTTLES}

In reading the results of a cream test, more care is needed than in testing milk, especially if widenecked bottles are used in which the finest divisions represent . 5 per cent. or more. For accurate work, one should use narrow-necked cream-bottles in which the results can be read to .2 per cent.

In no case, should there be used in the same creamery at the same time different varieties of cream-bottles, having necks of widely-varying diameter. It has been shown by Webster (Bulletin No. 58, Bureau of Animal Industry, Dairy Division, U. S. Dept. of Agr.), that the results obtained with cream-bottles having necks of varying diameters are wide apart, when read in the ordinary manner. This is due to the fact that the depth of the meniscus increases with the diameter of the neck of the bottle. The wider the neck the greater the error, this being in the direction of too high results. 


\section{SAMPLING AND TESTING GATHERED CREAM}

In many dairying communities, hand separators are used by dairymen, and cream instead of milk is sent to the creamery. The cream of several patrons is gathered at intervals by some one employed for the purpose. The ideal plan would be to keep each patron's cream separate until delivered and sampled at the creamery, but usually the different lots of cream, being comparatively small in amount, are not kept separate, being put together indiscriminately into large cans on the gathering wagons, as a matter of convenience. Under such circumstances, it becomes necessary to obtain at each farm a sample of the patron's cream before it is mixed with other lots. Outlining the general procedure, the person collecting cream carries a sample bottle for each patron, puts into this a sample of cream, takes this to the creamery and either tests at once or makes up a composite sample for each patron from the samples gathered during a period of one or two weeks. These composite samples are carefully prepared and kept in the manner described on pp. 24-3I and p. 73. The test for fat is made according to the directions given on pp. 69-77.

Taking up the details, the method of sampling gathered cream on farms is carried out in the following manner: The person who collects the cream is equipped with (I) large cans into which different lots of cream are poured after weighing and sampling, (2) spring balance, (3) two pails for weighing cream and mixing before sampling, (4) sampling-tube, and (5) a case containing sample-bottles. At each dairy the 
collector takes the weighing and sampling equipment from the wagon, including one sample-bottle marked so as to identify the individual patron whose cream is put into it. The cream is poured from one pail to another twice or more until it is completely mixed, and then it is quickly weighed, after which a sample is at once taken and placed in the sample-bottle. The samples should be taken by means of a sampling-tube ( $p$. 27), which, after using, should be rinsed each time with the cream next to be sampled. This is done simply by lowering the tube in the usual manner to the bottom of the pail that holds the cream and then drawing the tube out and allowing all the cream to run back into the pail. After this rinsing, the sample is drawn and, after allowing the cream adhering to the outside of the tube to drain off for a few seconds, the contents of the tube are transferred to the sample-bottle. In case a patron has more than one pailful of cream, a sample is taken from each weighing, the same weighing-pail being used each time; in this case the different samples are put into one sample-bottle.

After each patron's cream is weighed and sampled, it is poured into the collector's large can. The sample-bottles are carried to the creamery and the contents of each transferred to the corresponding composite-sample jar. The collecting bottles must be thoroughly cleaned and dried before using again. If any difficulty is experienced in the management of the composite samples, it is advisable to test each sample of cream after it reaches the creamery and not prepare composite samples.

Cream that is frozen or sour can not be handled sat- 
isfactorily for sampling or testing and should not be taken. For judging and scoring the quality of cream according to the method given in Chapter XIV, one may make use of the collected sample before it is put into the composite sample. 


\section{CHAPTER VI}

\section{Method of Testing Skim-Milk, Whey, Butter, Cheese, Etc.}

Dairy products, such as cheese, condensed milk, and milk powders can be tested for fat by the Babcock test, and also by-products such as skim-milk, buttermilk and whey. In general, the operation is carried out as in testing milk, but some special modifications are necessary.

METHOD OF TESTING SKIM-MILK, WHEY, ETC.

In testing materials containing only .2 or .3 per cent. of fat, two difficulties are experienced: (I) In the ordinary test-bottle, the reading of so small amounts of fat can not be easily done with accuracy. (2) Some fat is necessarily left in the mixture of acid and milkserum, which may constitute an important factor when the total fat content is small.

Special forms of test-bottles used in testing whey, etc.-To enable one to make readings of small amounts of fat with increased accuracy, special forms of doublenecked test-bottles have been devised, which are so graduated as to enable readings to be made as low as .oI per cent. (Figs. 34 and 35.) In using these bottles, the milk and acid are delivered into the larger neck, the fat being driven up into the small neck by the hot water added toward the end of the test. 
Enough water is added to bring the fat-column into the middle of the small neck. In mixing milk and acid and in running in hot water, care must be taken to prevent any liquid but fat going into the small neck or fine measuring-tube. The stoppers in the bottles

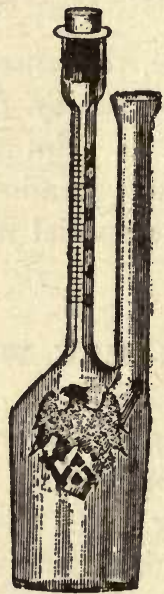

FIG. 34

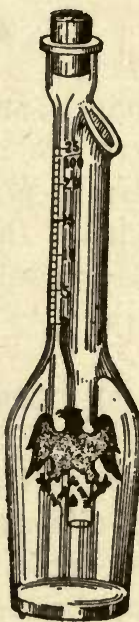

FIG. 35

BOTTLES FOR TESTING SKIM-MILK

are used to adjust the fat-column for reading. These double-necked bottles should be placed in the tester in such a way that the filling-tube is toward the center, thus avoiding the danger of having any fat caught between this tube and the side of the bottle when resuming the upright position after whirling.

Separating fat from mixture in bottle.-Attention has previously (p. 64) been called to the difficulty experienced in separating all the fat from the mixture 
of acid and milk-serum. Under ordinary conditions of working, materials low in fat, like skim-milk, may fail to give up to the fat-column .05 or even .I per cent. of fat. Some double the reading of fat when it is below .I per cent. in order to make allowance for the unseparated fat. The fat may be separated from the rest of the liquid more completely by proceeding as follows: Use $20 \mathrm{cc}$. of sulphuric acid, whirl the bottles at full speed one or two minutes longer than usual and read the fat when at a temperature of $130^{\circ}$ to $140^{\circ}$ F. Steam-turbine testers, which keep the bottles hot, give best results. Any test of these by-products showing less than .05 per cent. of fat is open to the suspicion of being defective.

Skim-milk and buttermilk are treated alike. In working with whey, it is noticeable that after adding acid the mixture turns dark very slowly, due to the presence of less sugar and to the absence of casein. Less than the usual amount of acid is sufficient for whey, 8 or io cc. frequently being sufficient.

\section{METHOD OF TESTING CHEESE}

In applying the Babcock test to cheese, it is necessary to prepare the sample in a special way and to weigh the amount used. A 9-gram sample is a convenient amount to use, in which case the reading of fat is multiplied by 2 ; or an I8-gram sample may be divided between two cream-bottles, the final readings being added. Cream-testing bottles graduated to .2 per cent. divisions should be used. 
Sampling cheese for fat-test.-Since different portions of the same cheese vary in composition, special means must be used to get a representative sample. The sample for testing is prepared as follows: When a cheese can be cut, a narrow, wedge-shaped segment is taken, reaching from the outer edge to the center. This is cut into strips and passed through a meat-grinding machine two or three times. This mass is carefully mixed, and from this a 9-gram sample is weighed into a cream-testing bottle, or a 4.5 -gram sample into an ordinary milk-testing bottle.

When cheese can not be cut, samples are obtained by a cheese-trier. If possible, three plugs should be drawn, one at the center, one about an inch from the outer edge, and one at a point half way between the other two. If only one plug can be drawn, this should be taken at a point about half way between the margin and center. The plugs should be taken perpendicular to the end surface of the cheese and should reach either entirely through the cheese or just half way. The plugs should be made fine by grinding or cutting and carefully mixed before weighing samples. In preparing samples, they should not be exposed to the air longer than necessary, since loss of moisture should be prevented as much as possible before weighing.

Testing sample of cheese.-The sample is weighed into the bottle. Then one adds about $15 \mathrm{cc}$. of hot water in the test-bottle and agitates until the water disintegrates the cheese; this may be hastened by adding a few cubic centimeters of acid, and keeping the bottle in slightly warm water. When no more lumps 
are seen in the liquid, $17.5 \mathrm{cc}$. of sulphuric acid is added. The test is then completed in the usual way. To obtain the per cent. of fat in the cheese, if less than 18 grams is used, multiply the reading of fat by 18 and divide by the number of grams of cheese used in the test.

\section{METHOD OF TESTING BUTTER}

The Babcock test has not been adapted to determine accurately the amount of fat in butter. A mass of butter is so variable in its composition, owing to the uneven distribution of water, that it is difficult to obtain a representative sample when only a small amount is used. Since butter contains over 80 per cent. of fat, a sample of less than 9 grams must be used in a test-bottle made to measure less than 40 per cent. of fat. . Approximate results can be obtained by observing certain precautions.

Preparing sample of butter.-With a butter-trier draw several samples, aggregating 4 to 8 ounces. Place these samples in a fruit-jar or composite-sample bottle, melt completely by placing in fairly hot water with the jar closed; then remove from hot water and shake vigorously for one or two minutes, after which moderate agitation is continued until the butter solidifies. The cooling may be hastened by holding the jar under a stream of cold water, continuing to shake the bottle vigorously until the butter hardens.

Testing sample of butter.-On a cream-scale place a bottle of the form shown. After balancing the bottle, one takes on the point of a knife from different 
parts of the sample of buiter, prepared as above described, small pieces of butter and places them in the funnel-shaped tube of the bottle until the sample weighs 9 grams. The bottle is then placed in hot

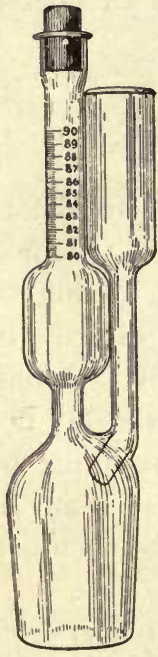

FIG. 35

BOTTLE FOR USE

IN TESTING

BUTTER water until the butter melts and runs into the test-bottle. The fat adhering to the inside wall of the funnel is washed down into the bottle with $8.8 \mathrm{cc}$. of hot water and the same amount of sulphuric acid ( $8.8 \mathrm{cc}$.) is added. After the contents are thoroughiy mixed, the bottle is placed in a tester and whirled for about 5 minutes. To read the result, fill the funnelshaped tube with hot water, which raises the fat-column in the graduated neck. By gently pressing down or gently drawing up the rubber cork at the top of the graduated neck, the fat-column may be moved in the graduated neck so as to bring the lower end of the fat-column level with zero mark, which is indicated by a ring below the bulb. The percentage of fat is read directly. Before reading the test, let the bottle stand for ten minutes in water at $120^{\circ}--130^{\circ} \mathrm{F}$.

\section{GRAY'S RAPID TEST FOR WATER IN BUTTER}

The method described below for the determination of water in butter has been recently devised by $\mathrm{Mr}$. C. E. Gray, Assistant Dairyman in the Dairy Divisirn, Bureau of Animal Industry, U. S. Department of Agriculture. (Circular No. I00, Dec. 31, 1906.) The 
operation requires 15 to 20 minutes. The principle of the test depends on the separation of water from butter by distillation in the presence of a slightly volatile mixture of high boiling point which does not mix with water. The apparatus will be furnished by dairy-supply houses.

Apparatus.-The following apparatus is required for the test:

(I) Balance and weights.-A creari-testing balance (see p. 72), sensitive to 0.025 gram; and two weights, one 5-gram and one Io-gram.

(2) Graduate.-Measuring $6 \mathrm{cc}$.

(3) Burner.-A gas burner or an alcohol lamp.

(4) Paper.-Parchment, perfectly dry, 5 by 5 inches in size.

(5) Special testing apparatus.-This includes three essential pieces, (a) a flask (A Fig. 36a) holding about 70 cc., (b) a receiving bulb with graduated tube (C Fig. 36a), and (c) a condensing jacket (E Fig. $36 \mathrm{a})$. The receiving bulb is connected with flask $\mathrm{A}$ by means of a rubber stopper (B). G is a ground glass stopper fitting tightly into the tube above the graduated scale. Each stopper and tube should be marked so that each stopper shall always be used with its corresponding tube. The graduation of the tube is done after the glass stopper is fitted, so that the zero mark is the end of the stopper. Each mark of the graduated scale represents 0.2 per cent. of water when a ro-gram sample of butter is used. The glass condensing jacket (E Fig. 36a) is connected to the graduated tube by a rubber stopper (D Fig. 36a). 


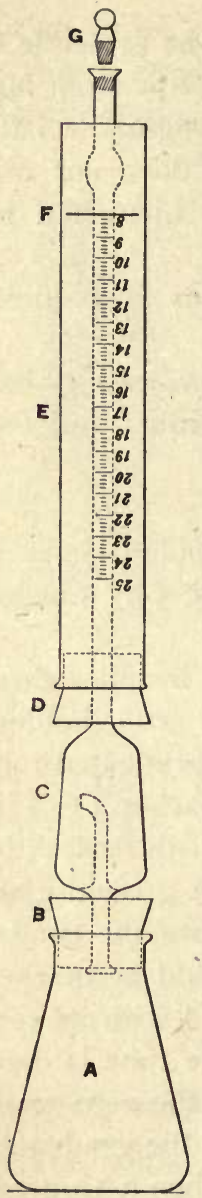

FIG. $36 \mathrm{a}$

GR $\triangle$ Y'S APPARATUS TEADY FOZ USE IN TESTING WATER IN BUTTER
(6) Rubber stoppers.-The rubber stopper $B$ is so acted upon in testing by the heat and reagent, that a new one is required after about Ioo tests.

Reagents.-Reagents are required as follows:

( I) Amyl reagent.-This consists of a mixture of 5 parts of amyl acetate and I part of amyl valerianate, and these must be entirely free from watersoluble impurities.

(2) Alcohol.--This is used for burning when gas is not available.

Operation of the test.-The details of the method of determining water in butter are performed as follows:

( I) Preparation of sample-See p. 85 .

(2) Weighing sample.-Place on each pan one sheet of parchment paper and balance accurately. Weigh exactly Io grams of sample (see p. 75), p'acing in center of paper.

(3) Transferring sample to flask.The paper, containing the Io-gram sample, is folded in such a shape that the paper and butter may be slipped into flask A without losing any of the sample.

(4) Adding amyl reagent.-Fill the 
graduate, which must be dry, with amyl reagent to the $6 \mathrm{cc}$. mark and pour into flask A.

(5) Connecting the apparatus.-Connect the apparatus as shown in Fig. 36a, fill the condensing jacket $\mathrm{E}$ with cool water to within one inch of the top ( $\mathrm{F}$ Fig. 36a) and remove the glass stopper.

(6) Distilling the water from the butter.-Heat the bottom of flask A over the flame of the burner. The butter soon melts, mixes with the amyl reagent, and later the water passes as steam into the receiving bulb (C), in which it is condensed and held. The condensation in the graduated part'of the tube must be carefully watched and the steam not allowed to go higher that the 15 per cent. mark, in order to avoid risk of losing water. If it goes higher than this, remove the flame for a short time. If the mixture in flask A shows a tendency to foam over, remove the flame. In case of continued foaming, cool the flask and contents, add about 2 cc. more of amyl reagent and continue heating.

(7) How to know when the distillation is complete. -When the mixture in the flask becomes brown and all crackling noise in boiling ceases, the water has all been driven from the flask. This usually requires from 5 to 8 minutes.

(8) Disconnecting apparatus.-After completing the distillation, flask $\mathrm{A}$ is disconnected from stopper $\mathrm{B}$ and the glass stopper $\mathrm{G}$ is firmly placed in tube C. The tube is then inverted, transferring the water from the receiving tube into the graduated tube, care being taken not to allow any water to be lost through the 
small bent tube inside the butb. The water is then poured from the condensing jacket, after which the jacket may be removed.

(9) Separating amyl reagent from water.-Some amyl reagent is distilled with the water, but does no harm as they can be easily separated. This is done as follows: Hold the receiving bulb in the palm of the hand and the stoppered end away from the body; then raise to a horizontal position and swing at arm's length sharply downward to the side. This is repeated several times until the line of separation between the water and amyl reagent is sharply distinct, no amyl reagent being seen with the water, or vice versa. The tube should then be held a short time with the stoppered end downward and the amyl reagent in the bulb agitated in order to rinse down any water adhering to the sides of the bulb.

(Io) Reading the test.-After cooling the tube and contents, the percentage of water may be read directly from the scale, when a Io-gram sample is used. The water is in the bottom of the tube. The reading is made to the lower part of the meniscus.

Cleaning the apparatus.-The flask and tube should always be perfectly dry before being used. An occasional cleaning with washing soda in hot water or other cleansing mixture will keep the apparatus sufficiently clean. After making the test, tube $\mathrm{C}$ is emptied by holding the stoppered end downward, removing the stopper and allowing contents to flow out quickly. The tube is further cleaned and dried by swinging in the manner described above under (9). 
Improved form of Gray's apparatus.-The Wagner Glass Works, of New York, has devised an improved form of apparatus for Gray's test (Fig. 36b. It is simple, durable and conveniently operated. The water content of the butter is collected in the graduated bore as rapidly as distilled from the butter, and the result may be read directly from the graduated bore without swinging or otherwise changing the position of the apparatus. There are no stoppers to remove, to replace, or to lose. Steps (8) and (9) (pp. 89-90) are obviated by this improved apparatus.

\section{METHODS OF TESTING CONDENSED MILK}

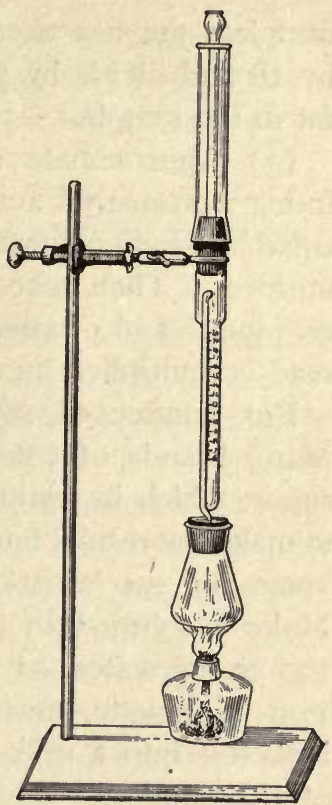

FIG. $36 \mathrm{~b}$

WAGNER'S IMPROVED FORM OF GRAY'S WATER-TEST

For condensed milk containing no added sugar.-

( I) Weigh 9 grams into a milk-testing bottle, add about ro cc. of water, then the usual amount of acid. Complete test as for milk. Multiply fat-reading by 2 .

(2) Weigh 40 grams of the well-mixed sample into a roo cc. glass cylinder, such as is used in the alkalinetablet test (Fig. 38, p. I04). Add water to the $100 \mathrm{cc}$. mark and shake until well mixed. Then, with a 17.6 cc. pipette, take for testing a sample of this solution, representing 7 grams of the undiluted sample, and 
complete the test as usual. Multiply the fat-reading by 18 and divide by 7 to find the correct per cent. of fat in the sample.

(3) Approximate results may be obtained by diluting a measured amount of condensed milk with an equal volume of water, agitating the mixture until uniform. Then take sample for testing with a 17.6 cc. pipette and proceed as usual. The per cent. of fat read is multiplied by 2 .

For condensed milk containing added sugar.Many brands of condensed milk contain added cane sugar, which in testing is so blackened by the acid as to make the results unreliable. This trouble can be overcome by special treatment devised by Farrington. Make a solution of 40 grams of condensed milk in Ioo cc. of water, as directed above in (2). With a I7.6 cc. pipette, measure the same amount as for a milk test into a milk-testing bottle. Add about $3 \mathrm{cc}$. of the sulphuric acid used in the test and mix the acid and milk by shaking vigorously. The acid is added to coagulate the curd and enclose the fat, allowing the sugar to separate in the surrounding liquid. The curd is compacted into a lump by whirling the testbottles in a steam-turbine tester at high speed and at a temperature of $200^{\circ} \mathrm{F}$. After this whirling, the bottles are taken from the tester and the liquid portion, containing much of the sugar, is carefully poured from the neck without breaking the lump of curd. Then an addition of Io cc. of water is made to the test-bottles, the curd is shaken up to wash out more sugar, and again $3 \mathrm{cc}$. of sulphuric acid added. The bottles are again whirled and the liquid portion de- 
canted. Then the test is completed by adding ro cc. of water, $17.5 \mathrm{cc}$. of sulphuric acid, and proceeding as usual. Correct the fat-reading by multiplying by 18 and dividing by 7 .

\section{METHOD OF TESTING FOR FAT IN INFANT FOODS}

Some infant foods contain so much sugar that, like sweetened condensed milk, it is impossible to use the Babcock test unmodified. Cochran recommends a method for the determination of fat in such cases, which he has found very useful (Journal of the American Chemical Society, Vol. 27, p. 908). A doubletubed test-bottle is used, the larger tube reaching only a short distance into the bowl of the bottle.

To determine fat in sweetened condensed milk, make a solution of the condensed milk in the manner given above under (2). Of this solution put $17.5 \mathrm{cc}$. in the test-bottle, add $9 \mathrm{cc}$. of 80 per cent. acetic acid and $9 \mathrm{cc}$. of strong sulphuric acid. Mix the acids and milk and set the bottle in hot water until the mixture in the bottle turns a coffee-brown color. Then remove the bottle, cool, add $15 \mathrm{cc}$. of ether and mix thoroughly with the liquid. The flask is again placed in hot water and the ether allowed to evaporate. A layer of fat will appear floating on the surface of the liquid. By pouring hot water into the side tube, the liquid fat is raised into the graduated tube, where its amount can be read. The reading is corrected by multiplying by 18 and dividing by 7 .

In the case of powdered infant foods, like malted milk, weigh 6 grams of the powder into the bottle, 
add I7.5 cc. of water, dissolve the powder as completely as possible, and proceed as above. Multiply the reading by 3 .

\section{METHOD OF TESTING DRIED MILK OR MILK POWDER}

Successful means of drying milk have recently been devised, and products are appearing on the market in the form of dried skim-milk and dried milk. These materials are in the form of fine flaky or powdery substances. Owing to the great advantages of handling milk in such forms, these products are destined to find extensive use, and the desirability of testing them is obvious.

The Babcock test, when applied to these materials, gives results much below the truth. The writer has obtained quite satisfactory results by a combination of the Gottlieb and Babcock methods of determining fat. The process used is as follows: Dissolve ro grams of milk powder in Ioo cc. of water. Take Io cc. of this solution in a $100 \mathrm{cc}$. glass cylinder (Fig. 38, p. 104). Add I cc. of strong ammonia and shake until thoroughly mixed with the solution. Then add the following reagents, one after the other, shaking vigorously after each addition before adding the next material: Io cc. of 92 per cent. alcohol, $25 \mathrm{cc}$. of washed ether, and $25 \mathrm{cc}$. of gasoline or, better, petroleum ether (boiling point below $80^{\circ} \mathrm{C}$.). The cylinder is closed with a tightly-fitting, moistened cork stopper. The contents of the cylinder, after thorough shaking, are poured into a $200 \mathrm{cc}$. beaker, the cylinder being rinsed with a little gasoline, and this being added to the 
beaker. The beaker is then placed on a steam-batl or in boiling water and kept there until the ether, alcohol and gasoline are completely evaporated. The remaining liquid is then poured into a milk-testing bottle, the beaker is rinsed with a little ether, which is also added to the test-bottle. The test-bottle is then placed in boiling water a few minutes to evaporate the ether. After cooling the contents of the test-botthe to about $70^{\circ} \mathrm{F}$., one adds $17.5 \mathrm{cc}$. of sulphuric acid and completes the operation as in the case of milk by the Babcock test. The reading is multiplied by $\mathrm{I} 8$. In some cases, as in dried skim-milk, it will be desirable to make the original solution more concentrated by having 20 or more grams in $100 \mathrm{cc}$. of solution. The following precautions must be observed in using this method:

(I) The milk-powder solution must be made uniform before sampling.

(2) The shaking of the mixture must be vigorous and thorough after the addition of each of the reagents used.

(3) The evaporation of the reagents added must be complete; otherwise, the final results are apt to be too high.

(4) The evaporation must not be carried so far as to cause any appearance of solid particles in the liquid. When this happens, the fat-column contains dark material, which makes the results uncertain.

This method is applicable to skim-milk, whey and buttermilk, which do not usually give high enough results by the Babcock method. 


\section{CHAPTER VII}

\section{Methods of Testing the Acidity of Milk and Milk Products}

It is often necessary to know how much acid is present in milk, cream, whey, etc. The amount of acid in milk may be a suggestive indication of the age of milk and of its care. In butter-making, the uniformity of the product depends largely upon the ripening of cream, which can be well controlled only by knowing its acidity. In cheese-making, it is at times important to know whether milk contains too much acid and it is also quite essential to have some knowledge of the amount of acid present in the milk and whey at different stages of the operation.

\section{THE CAUSES OF ACIDITY IN MILK AND ITS PRODUCTS}

We may distinguish two kinds of acidity in milk and its products: (I) Apparent acidity, and (2) acidity due to lactic acid. The apparent acidity is due to the presence in normal milk of casein and acid phosphates, which have the power, like free acids, of neutralizing alkalis. This apparent acidity in fresh milk is about .07 or .08 per cent. on the average. It varies with different conditions, increasing, for instance, with advance of lactation.

Acidity due to lactic acid is formed in milk after it is drawn, and is caused by the action of certain forms 
of bacteria upon milk-sugar. In general, when milk contains over .Io per cent. of acid, it may safely be assumed that it contains some lactic acid. The amount of lactic acid present in milk may be approximately found by subtracting. Io from the total amount of acid apparently present. However, in speaking of the acidity of milk, we usually mean the total acidity, and not that due to lactic acid alone. One can not commonly detect a sour taste in milk that has a total acidity under $\cdot 3$ per cent.

\section{GENERAL PRINCIPLES OF TESTING ACIDITY}

The method of determining the amount of acid in milk and its products is based upon the well-known chemical action taking place between acids and alkalis. Whenever we bring together in solution an acid and an alkali, they combine with each other and form a third compound, the acid and alkali disappearing as such. The acid and alkali are said to neutralize each other and the process is called neutralization. For example, if we add together some hydrochloric (muriatic) acid and sodium hydroxide (caustic soda) in right proportions, we shall have neither hydrochloric acid nor caustic soda, but a new compound, sodium chloride (common salt), which has been formed by the action of the acid and alkali upon each other. The hydrochloric acid used in the experiment tastes sour and biting, while the caustic soda solution has a peculiar odor, feels soapy on the skin, and, if strong enough, destroys the skin. After these two compounds are brought together in proper proportions, there is no 
longer observed any sour taste of acid or soapy feeling or odor of alkali, because the acid and alkali have neutralized each other and have combined to form simply common salt, the presence of which is noticed by its taste. The solution is said to be neither alkaline nor acid, but neutral.

\section{USE OF INDICATORS IN TESTING ACIDITY}

In working with acids and alkalis, it is necessary to have some simple means of knowing when a solution is acid, alkaline or neutral (neither acid nor alka- line). This can be found by using some substance, called an indicator, which is so acted on by alkalis and acids as to undergo changes of color, being changed one color by alkalis and a different color by acids. One substance which finds wide use as an indicator is a chemical compound called phenolphthalcin, a solution of which is turned pink by alkalis and colorless by acids. For use in testing acidity, one dissolves Io grams of the dry powder in $300 \mathrm{cc}$. of 90 per cent. alcohol. It is necessary to use only 5 or 10 drops of this solution as indicator.

\section{GENERAL APPLICATION OF PRINCIPLES OF NEUTRALIZATION}

What use can be made of the foregoing facts in finding the per cent. of acid in a solution? For simplicity, we will use the following illustrative experiment: In a glass or teacup we put $100 \mathrm{cc}$. of a solution containing .25 per cent. of lactic acid and add 5 or to drops of indicator solution. Into this mixture 
we run from a graduated cylinder or burette some standard solution of caustic soda, prepared by dissolving 4 parts by weight of pure caustic soda in $\mathrm{I}, 000$ parts of distilled water. This solution of caustic soda we add, a little at a time, to the solution of lactic acid, stirring or otherwise agitating the mixture thoroughly after each addition. The pink color that appears when the caustic soda solution is added disappears on stirring. After the alkali has been added several times, the color disappears less rapidly each time. The gradual addition of the alkali is continued until finally the pink color does not disappear readily on continued agitation but remains for some moments. The neutralization of the acid by the alkali is complete, and the addition of alkali stops at this point. The appearance of the pink color throughout the body of the liquid means that enough alkali has been added to combine with the lactic acid, and a little more, one drop of the alkali solution being enough to produce the pink color with the indicator after the acid is nettralized. The liquid in the cup contained at the start only a solution of lactic acid. As soon as we added alkali, it combined with the lactic acid, forming the neutral compound, sodium lactate. We then had a mixture of lactic acid and sodium lactate. As we continued to add alkali, the amount of sodium lactate increased, while the amount of lacti acid decreased. Finally, a point is reached when the solution in the cup contains no free lactic acid, but only sodium lactate, and the addition of one more drop of alkali turns the indicator pink, producing a more lasting coloration throughout the solution and showing that the acid 
has been completely neutralized, that is, changed into sodium lactate.

Having completed the neutralization of the acid, we examine the burette or the graduated cylinder containing the alkali to find exactly how much alkali solution has been used in neutralizing the acid. The lactic acid has required, say, $28 \mathrm{cc}$. of soda solution. Each cubic centimeter of alkali neutralized by acid corresponds to .009 gram of acid, and $28 \mathrm{cc}$. would therefore correspond to .25 gram of lactic acid. This amount of lactic acid in $100 \mathrm{cc}$. is .25 per cent. The process of making a chemical determination by means of a standard solution is known as titration.

\section{NEUTRALIZATION METHOD APPLIED TO TEST- ING ACIDITY OF MILK AND MILK PRODUCTS}

In practical dairy work, one is freed from the necessity of preparing standard solutions, except in a simple way, and the calculations needed to figure the results are direct and easy. The caustic soda solution is prepared in such strength that a certain amount of it equals .I per cent. of lactic acid, when a certain amount of milk or other substance is used. All tests for the acidity of milk and its products are based upon the general principles previously described and differ from one another simply in some of the details of carrying out the process. There are now available several forms of so-called acid tests, among which we shall describe the following: "Mann's acid test," "Farrington's alkaline-tablet test," and the "Purdue alkali test." 


\section{DESCRIPTION OF MANN'S ACID TEST}

Apparatus and materials. - The apparatus and materials used in this test are: (I) A $50 \mathrm{cc}$. glass burette, with stopcock, (2) a $50 \mathrm{cc}$. pipette for measuring samples, (3) a glass beaker and stirring-rod, (4) an alcoholic solution of phenolphthalein, and (5) a standardized alkali solution labeled "neutralizer," each cubic centimeter of which contains enough sodium hydroxide (.004 gram) to neutralize .009 gram of lactic acid. The outfit is shown in Fig. 37 .

Operating the test.-(I) Measuring sample.-Into a clean beaker or white porcelain cup, one measures with the pipette exactly 50 cc. of the material (milk, cream, etc.) to be tested. The pipette is then rinsed by filling with water, preferably distilled, and this

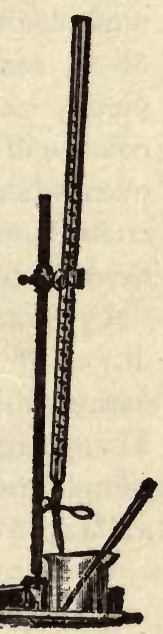

FIG. 37-MANN'S ACID TEST rinsing water is added to the sample.

(2) Adding alkali.-The indicator (5 or Io drops) is then added to the sample. The burette is then filled to the zero mark with the neutralizer, and some of it is run into the sample in the beaker or cup. A pink color appears, but disappears on stirring. The addition of alkali in portions is continued with care, the sample being stirred after each addition. It will be noticed sooner or later, according to the amount of acid present, that, after each addition of alkali, the 
pink color disappears more slowly, showing that the acid is becoming more nearly neutralized. When the color disappears quite slowly, the neutralizer should be added a drop at a time. Finally a point is reached when, after the addition of one drop of alkali, the pink color does not disappear even after stirring io or 55 seconds. This indicates that the acid is completely neutralized. Add no more alkali. The pink color will slowly disappear after standing some time, even when the solution is alkaline. Some experience enables one easily to know when the pink color is sufficiently permanent.

(3) Calculating results.-Having completed the addition of alkali, the burette is examined to see how many cubic centimeters of neutralizer have been used. The percentage of acid for $50 \mathrm{cc}$. or any amount of sample taken is calculated from the following formula :

Per cent. of acid $=\frac{\text { No. cc. of alkali } \times}{\text { No. cc. of sample taken }} \times 100$.

When one uses $50 \mathrm{cc}$. of the sample, this formula becomes

Per cent. of acid $=$ No. cc. of alkali $\times$.or 8 .

From this last formula one can prepare a table which gives the results and saves making calculations at every test: 
C.C. OF ALKALI SOLUTION

(NEUTRALIZER) USED

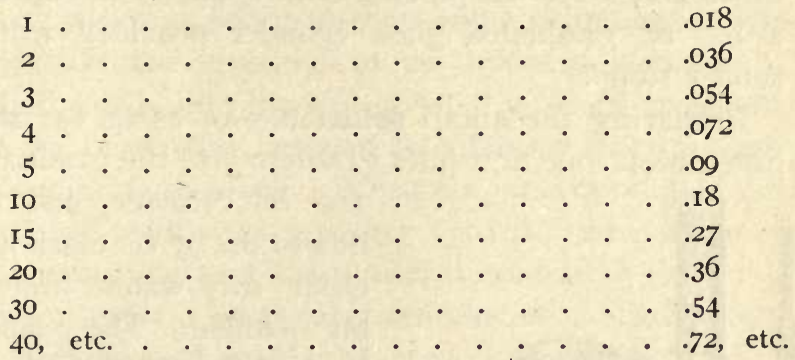

By using the first formula above, similar tables can Le prepared when the amount of sample taken is any amount other than $50 \mathrm{cc}$.

Using Babcock Pipette with Mann's Test.-If a I7.6 cc. pipette is used in measuring the liquid to be tested, the percentage of acid may be found by dividing by 2, the number of cubic centimeters of Mann's alkali used, the result being expressed as tenths per cent. Thus, if the liquid tested neutralizes $\mathrm{I} 3 \mathrm{cc}$. of alkali, the acidity is $\mathrm{I} 3$ divided by 2 , which, expressed as tenths, is .65 per cent. By diluting Mann's "neutralizer" with an equal volume of water, the number of cubic centimeters gives directly the percentage of acidiry, expressed as tenths.

\section{FARRINGTON'S ALKALINE-TABLET TEST}

Apparatus and materials.-In this method the same chemical principles are employed as in Mann's test, but the alkali, in the form of a carbonate, and indicator are mixed together in the form of solid tablcts. Each tablet contains enough alkali to neutralize 
.034 gram of lactic acid. The apparatus (Fig. 38) consists of a $17.6 \mathrm{cc}$. pipette, a white porcelain cup, and a IOo cc. graduated glass cylinder provided with a rubber stopper.

Preparing the alkali solution.-In using the alkaline tablets, one first puts 5 tablets into the graduated

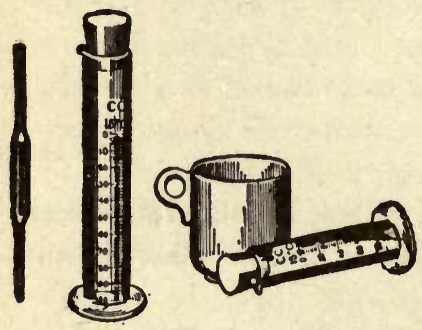

FIG. 38-FARRINGTON'S ALKALINE-TABLET TEST Ioo cc. cylinder, and fills this to the $97 \mathrm{cc}$. mark with clean, soft water, preferably distilled. The cylinder is then tightly corked and laid on its side until the tablets dissolve, which requires several hours. The cylinder must be kept tightly corked so that none of the solution can be lost while the tablets are dissolving. A slight flocculent residue will not dissolve, consisting of some inert matter used in the making of the tablets.

Precautions in using alkali solution.-The solution should always be shaken well before using. It should always be kept tightly stoppered when not in use. The solution, if kept perfectly stoppered, will not greatly change in a week. Solutions older than this may change their strength and should not be used. It is a wise precaution to throw away solutions previously used for some days and to prepare a fresh solution. The solid tablets do not change if kept dry.

Operation of alkaline-tablet test.-The material (milk, cream, etc.) to be tested is thoroughly mixed, 
and $17.6 \mathrm{cc}$. is then measured into a clean porcelain cup with a pipette. The pipette is rinsed by filling with water, which is added to the sample in the cup. The tablet solution prepared in the manner described is poured slowly into the cup in small portions at a time, and the mixture is agitated by rotating the cup after each addition of alkali. When the pink color does not disappear readily on agitating (p. IO2), the number of cubic centimeters of alkali used is read from the graduated cylinder. Each cubic centimeter of alkaline-tablet solution used equals .or per cent. of lactic acid in the sample tested. For example, the use of $25 \mathrm{cc}$. of alkali solution equals .25 per cent. of acid; $40 \mathrm{cc}$. equals .40 per cent., etc.

\section{SPILLMAN'S MODIFICATION OF ALKALINE-TABLET TEST}

The apparatus consists of an ordinary teacup, a regular $17.6 \mathrm{cc}$. pipette, a quart Mason fruit-jar, and "Spillman's acid-test cylinder" (Fig. 39). The alkali solution is prepared by dissolving alkaline tablets in water at the rate of 5 tablets for one cylinder of water filled to the mark 8 , the solution being made and kept in the fruit-jar. Observe the precautions given above in using tablet solutions. In making the test, put I7.6 cc. of the material to be tested in a teacup,

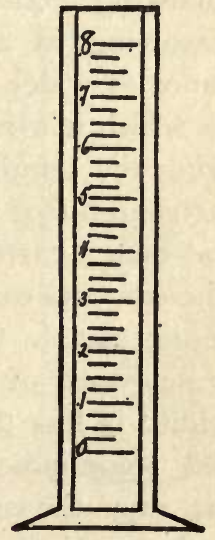

FIG. 39

SPILLMAN'S ACIDTEST CYLINDER pour into the cup the alkali solution in the manner described above, until the pink color remains. Then 
pour the contents of the teacup into the Spillman cylinder and read the scale at the surface of the liquid in the cylinder. The results indicate the acidity in tenths of one per cent. The cylinder reads as high as 8 tenths.

\section{TABLET TEST MODIFIED FOR RAPID ESTIMA- TION OF ACIDITY}

It is often desirable to ascertain quickly whether milk or cream contains more or less than .2 or .3 per cent. of acid. Farrington and Woll have devised the following method: An alkali solution is prepared by dissolving in an 8-ounce bottle 2 tablets for each ounce of water used. A No. Io brass cartridge shell, on which a wire handle is soldered, is used for measuring the sample to be tested and also the alkali. A cartridgeful of milk or cream, is placed in a teacup and then a cartridgeful of the alkali solution is added. The contents of the cup are mixed by a rotary motion. If the sample tested remains white, it contains over .2 per cent. of acidity; if a pink color remains, the acidity is less than .2 per cent. The intensity of the pink color indicates the relative amount of acid present, since the color will be more intense in proportion as there is less acid. Any other measure may be used in place of the brass cartridge-shell, but in every case care must be taken to use equal amounts of milk or cream and of alkali solution. 


\section{THE PURDUE ALKALI TEST}

This test was devised by H. E. Van Norman (Bulletin No. 104, Purdue Univ. Agr. Exp. Sta., 1905.) The following apparatus (Fig, 40) is used: (I) An

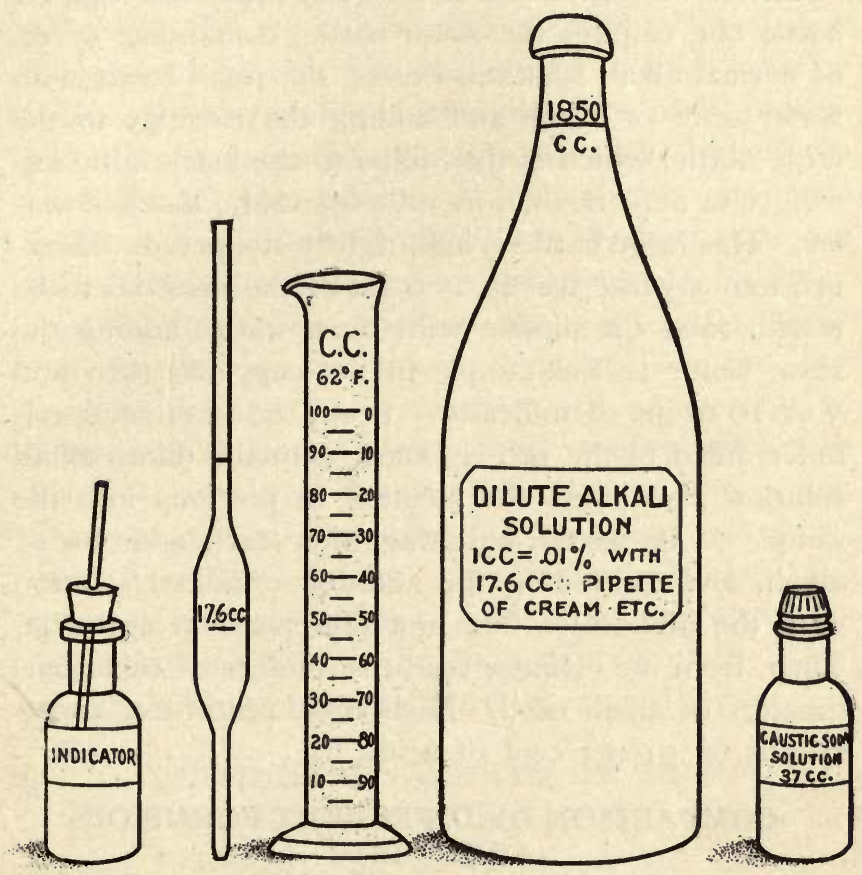

FIG. 40-PURDUE ALKALI TEST

ordinary $17.6 \mathrm{cc}$. pipette, (2) a $100 \mathrm{cc}$. cylinder, such as is used in the alkaline-tablet test, (3) a 2-quart bottle graduated at $1850 \mathrm{cc}$., (4) sealed bottles, each containing $37 \mathrm{cc}$. of normal solution of sodium hydroxide (caustic soda), (5) a bottle of phenolphthalein indi- 
cator and (6) an ordinary white teacup. The alkali solution must be of guaranteed accuracy and should be obtained only from a reliable chemical or dairysupply house.

The test is conducted as follows: Into the $1850 \mathrm{cc}$. bottle one empties the small bottle, containing $37 \mathrm{cc}$. of normal alkali solution, rinsing the small bottle with water once or twice and adding the rinsings to the large bottle, which is then filled to the mark with water: Use only clean, soft or, preferably, distilled water. This large bottle is kept tightly stoppered. Measure into a white teacup I $7.6 \mathrm{cc}$. of the material to be tested, rinse the pipette with clean water, adding the rinse water to the sample in the cup, and then add 5 or 10 drops of indicator. From the graduated cylinder, filled to the Ioo cc. mark with the dilute alkali solution, one pours the solution in portions into the sample to be tested, agitating after each addition of alkali, and continuing the addition of alkali solution until the pink color does not disappear on agitation. Then, from the cylinder read the number of cubic centimeters of alkali used. Each cubic centimeter corresponds to .oI per cent of acid.

\section{COMPARISON OF DIFFERENT FORMS OF ACID TESTS}

Mann's acid test has the advantage of furnishing the alkaline solution ready for use at any time. It has this serious disadvantage, that the alkaline solution is in constant danger of becoming weakened by absorption of carbon dioxide when exposed to the air. A weakened alkali solution gives higher results of 
acidity than the truth. It has also the disadvantage of requiring a calculation to obtain the results in the form of per cent., and any other form of statement ought not to be used.

The alkaline-tablet test has the advantage of giving the results directly in percentages. The tablets do not change if kept dry, and the use of a fresh solution avoids all uncertainity of strength. The cost of transportation is insignificant compared with that of the neutralizer. The tablets are not always absolutely uniform in strength of alkali, but the variations are not sufficient to make serious differences in results.

In the Purdue modification, the small bottles of alkali do not lose strength so long as they are kept properly stoppered, and therefore any number can be ordered at a time. Being more concentrated than Mann's neutralizer, the cost of transportation is less. The solution is more quickly and conveniently prepared than the tablet solution. The strength of the small bottles of alkali is said to be more strictly uniform than in the case of tablets. By high dilution of the alkali solution when used, the chance of error is reduced.

\section{TESTING THE ACIDITY OF WHEY}

Whey may be tested by any of the methods described. Owing to the comparatively low acidity of whey in the operation of cheese-making, it is desirable either to have the alkali dilute ( $\mathrm{c}$ cc. of alkali equal to .or per cent. acid), or else to take twice as much whey for testing as in the case of cream, the final results being corrected by dividing by 2 . The whey should be free from particles of curd, since curd has the 
power of neutralizing alkali to some extent. The percentage of acid in milk can be used as a guide in ripening the milk before adding rennet, in the rate of heating (cooking) the curd, in the regulation of the piling of the curd, in the time of milling, etc.

\section{TESTING THE ACIDITY OF CHEESE}

From a sample of cheese, prepared in the manner described on page $8 \mathrm{r}$, weigh nine grams and to this add water at a temperature of $100^{\circ}$ to $I I O^{\circ} \mathrm{F}$. until the volume equals 90 to Ioo cc. Agitate vigorously and filter. To the filtrate add alkali solution, each cubic centimeter of which equals or per cent. of lactic acid, carrying out the test as with milk, cream, etc. The number of cubic centimeters of alkali used, multiplied by 2 , equals the per cent. of acid in the cheese. Much higher results are obtained if one treats the cheese instead of its water extract with alkali, because the nitrogen compounds of the cheese neutralize alkali.

\section{RELATION OF FAT IN CREAM TO ACIDITY OF CREAM-RIPENING}

Cream rich in fat ripens, that is, becomes acid, more slowly than cream poor in fat. This is so, because the larger the percentage of fat in cream the smaller is the percentage of sugar, and the sugar is the source of lactic acid. The favorable influence of ripening upon the process of churning is believed to be due to the action of the acid upon the calcium casein of the cream, converting it into calcium lactate and so lessening its tenacious hold upon the fat-globules in emulsion. The fat itself of the cream is not changed. The amount 
of acid to be formed in cream-ripening is, therefore, to be governed more by the amount of calcium casein in the cream than by any other constituent. The less fat there is in normal cream, the more casein there will be, and the greater the per cent. of acidity needed. The more fat there is in cream, the less calcium casein there will be, and the less the amount of acid needed. These statements conform to practical experience. Thus, it is found that in cream containing 25 per cent. of fat, it is necessary to produce nearly .7 per cent. of acid in order to get the results sought by ripening, while, in cream containing 35 per cent. of fat, less than .6 per cent. of acid is sufficient.

To ascertain how much acid should be formed in cream before churning, the following rule is suggested by Van Norman (Bulletin 104, Purdue Univ. Agr. Exp. Sta.): From roo substract the per cent. of fat in the cream tested and multiply the result by .9 , or, expressed as a formula, (IOO - per cent. of fat in cream $) \times .9$. For example :

Cream with 20 per cent. fat requires .72 per cent. of acidity.

Cream with 25 per cent. fat requires .67 per cent. of acidity.

Cream with 30 per cent. fat requires .63 per cent. of acidity.

Cream with 35 per cent. fat requires .58 per cent. of acidity.

The use of .9 as a factor for multiplying may not suit all conditions and some other factor, 8 for example, may be used. Each operator may experiment and 
easily find what per cent. of acidity is best adapted to the production of the butter suiting his market, and then a table like the above can be made, using .9 or some other factor.

\section{OUTLINE STATEMENT OF SOME SPECIAL PRECAUTIONS IN TESTING ACIDITY}

I. The material to be tested for acidity must be thoroughly mixed before sampling for a test.

2. The water used in preparing the alkali solution and in rinsing the pipette should be neither acid nor alkaline and should be soft and clean. Use distilled water if possible.

3. The alkaline tablets should be kept dry in wellstoppered bottles.

4. The alkali solution, in whatever form used, must be kept from contact with the air as much as possible to prevent changing strength either through evaporation or absorption of carbon dioxide.

5. When alkaline tablets are used, prepare a fresh solution in order to be sure of its strength, if there is any reason for uncertainty.

6. The tests should be made in a good light so that one can easily see the appearance of the longer-lasting pink color at the end of the reaction.

7. The appearance of the pink color at the end of the test can usually be more sharply seen by diluting the material examined with three or four times its volume of distilled water. 


\section{CHAPTER VIII}

\section{Method of Testing the Bacterial Condition of Milk}

A thorough bacteriological examination of milk requires somewhat extended special training, but there are methods for ascertaining the general bacterial condition of milk which are available in the hands of any careful worker, and which afford most valuable suggestions in regard to the cleanliness of milk. The methods of studying the bacterial condition of milk which we shall notice are (I) determining the acidity, (2) the fermentation method known in its most available form as the "Wisconsin Curd-Test," and (3) testing for dirt in suspension.

\section{THE RELATION OF ACIDITY TO THE BACTE- RIAL CONDITION OF MILK}

The details of the method of determining acidity in milk have been given in Chapter VII. We need say here only a few words in regard to the interpretation of the results as they relate to the cleanly character of milk and its fitness for use. The amount of acid in milk is generally an indication of the care given to the milk after being drawn from the cow; to some extent, it indicates the age of the milk, especially if the terperature at which it has been kept, is known; and, if the age of the milk is known, the acidity indicates, to some extent, the temperature at which the milk has 
been kept. The cleanliness of the milk-pails and other vessels and utensils with which the milk comes in contact is another important factor in influencing acidity.

The average acidity of English market milk, supposed to be 12 to 18 hours old, is .I 8 per cent., and of German milk, .I 3 to .18 per cent. Market milk should not, in any case, contain over .2 per cent of total acidity when it reaches the consumer, and should generally be under .1 5 per cent. This (.2 per cent.) is also the highest limit allowable for milk that is to be used for cheese-making. The test for acidity can thus be made a very useful indication of the bacterial condition of milk so far as it relates to the acidity, and to the abundance of those forms that produce lactic acid.

\section{THE FERMENTATION OR WISCONSIN CURD-TEST}

Milk frequently contains objectionable forms of organisms or ferments that are not made perceptible by ordinary methods of observation. The condition arises particularly in milk used for cheese-making and may result in serious injury to the quality of the cheese. The Wisconsin Experiment Station (Wis. Exp. Sta. I2th and I5th Annual Reports, 1895 and 1898) has applied certain principles to the development of a test that enables one to identify milk containing certain forms of undesirable ferments likely to do serious injury. This method is based, in general, upon the plan of making conditions favorable for the rapid development of the ferments present in milk.

Apparatus.-The apparatus consists of the following parts: (I) Pint glass jars or tin cans with covers; 
(2) a well insulated tank to hold the jars, (3) rennet extract, (4) a thermometer, (5) a case-knife or similar instrument for cutting curd, and (6) a small pipette for measuring rennet-extract.

Operation of test.-The test is conducted as follows: The jars, including covers, just previous to use, are sterilized with live steam, scalding water or dry heat $\left(212^{\circ} \mathrm{F}\right.$.). Each jar or can is filled about two-thirds full with the milk to be tested and the sterilized cover put on at once. The jars are then placed in the tank which is filled with water at $100^{\circ}$ to $102^{\circ}$ F. up to the upper surface of the milk in the jars. The temperature of the water should be kept at $100^{\circ}$ to $102^{\circ} \mathrm{F}$. during the whole operation. To hasten the warming of the milk, the jars are taken out and shaken occasionally. The temperature of the milk is observed with a sterile thermometer, and when the milk has reached $98^{\circ} \mathrm{F}$., one adds 10 drops of rennet-extract to each jar and mixes thoroughly by giving the contants of the jar a rotary motion. When the milk has coagulated, it is allowed to stand until it is firm, usua'ly about 20 minutes. To enable the whey to separate more readily, the curd is then cut fine with a thin knife, which must be carefully rinsed with hot water after finishing each jar and before using it in another, in order to avoid carrying contamination from one milk to another and spoiling the test. The curd is allowed to settle completely. When the whey has been separating half an hour, the samples are examined for flavor by smelling, after which the whey is carefully poured out of the jars and this is re- 
peated at intervals of 30 to 40 minutes for 8 hours or more. Under the favorable conditions of temperature, similar to those employed in cheese-making, the organisms present develop readily and reveal their presence in different characteristic ways. The jars are finally opened, any whey present is drained off, and the following tests are applied: (I) The curd is cut into two pieces. The curd will be solid and free from holes on the cut surfaces, if the milk is not tainted. If it is spongy and full of holes, it contains those undesirable organisms that produce gases in the curd and injure it for cheese-making, showing in the form of "floating curds" and "huffy" cheese. The holes are usually small, their common name being "pin-holes." (2) The curd is examined with reference to any marked disagreeable odors that may be present. Some undesirable organisms reveal their presence by smell without making spongy curd. This may, perhaps, be best perceived by smelling of a freshly cut surface of the curd. Offensive odors are, of course, an undesirable indication. Special apparatus for performing the test is furnished by dairy-supply houses, but pint fruit-jars and other honie-made appliances will answer satisfactorily.

By this method one can learn what particular lot of milk among several is responsible for undesirable fermentations. Moreover, having traced the source of contamination to a single herd of cows, it is easily possible, by applying the test to single cows, to ascertain which individual or individuals may be the source of trouble. 
Precautions.-Two points must be carefully observed in carrying out this test: (I) The temperature must be kept as near $98^{\circ} \mathrm{F}$. as possible, in order that the bacteria may develop as desired. This can be done by keeping the temperature of the water surrounding the jars at $100^{\circ}$ to $102^{\circ} \mathrm{F}$. The temperature must be watched. (2) The thermometer and the knife used should be made not only clean but sterile each time after using in one sample before placing them in another.

\section{GERBER'S FERMENTATION TEST}

This test consists in heating milk in tubes 6 hours at $104^{\circ}$ to $106^{\circ} \mathrm{F}$. and then observing the odor, appearance, taste, etc., for abnormal qualities. The milk is heated a second time for 6 hours at $104^{\circ}$ to $106^{\circ} \mathrm{F}$. Any abnormal coagulation of the milk is noticed, such as holes due to gas. Gerber states that milk coagulating in less than 12 hours is abnormal, due either to the abnormal character of the milk itself when drawn or to improper care after being drawn. Milk that does not curdle within 24 to 48 hours is open to the suspicion of containing preservatives and should be examined for such substances.

\section{METHOD OF TESTING MILK FOR SUSPENDED DIRT}

The amount of dirt in suspension in milk can be estimated without serious difficulty. The best way is to provide a small centrifugal machine that is made to run at higher speed than the Babcock tester. A 


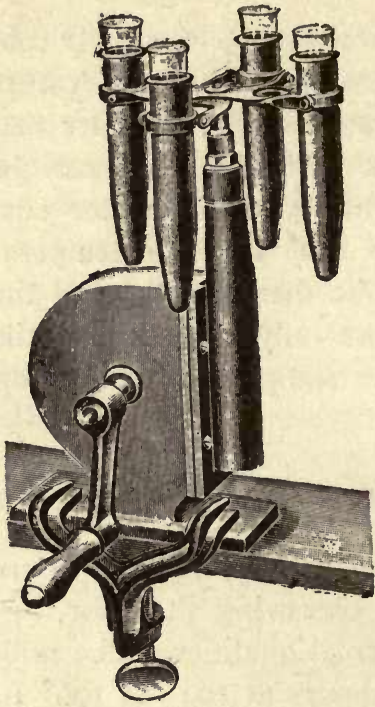

FIG. 4I-HAND-CENTRIFUGE FOR SEDIMENTATION WORK form of hand-centrifuge is shown in Fig. 4I. Special graduated tubes (Fig. 42) are made to use in this. The milk to be tested is stirred thoroughly, the tube is filled to the highest mark, placed in the pocket of the centrifuge and whirled several minutes. The sediment collects at the bottom and can be easily measured by reading the amount on the scale. In Fig. 43 is shown a Bausch and Lomb electric centrifuge. This company also furnishes hand-centrifuges capable of 3,000 to 8,000 revolutions per

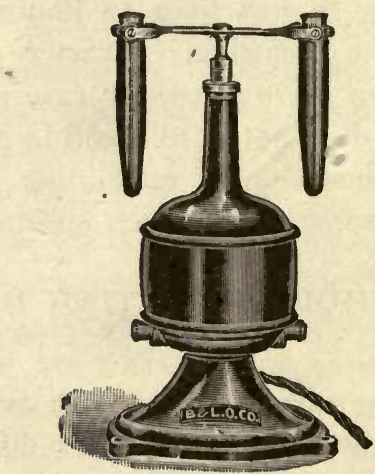

FIG. 43-BAUSCH \& LOMB

ELECTRIC CENTRIFUGE Speed 1,000 revolutions per minute
FIG. 42-TUBE FOR SEDIMENTATION WORK 


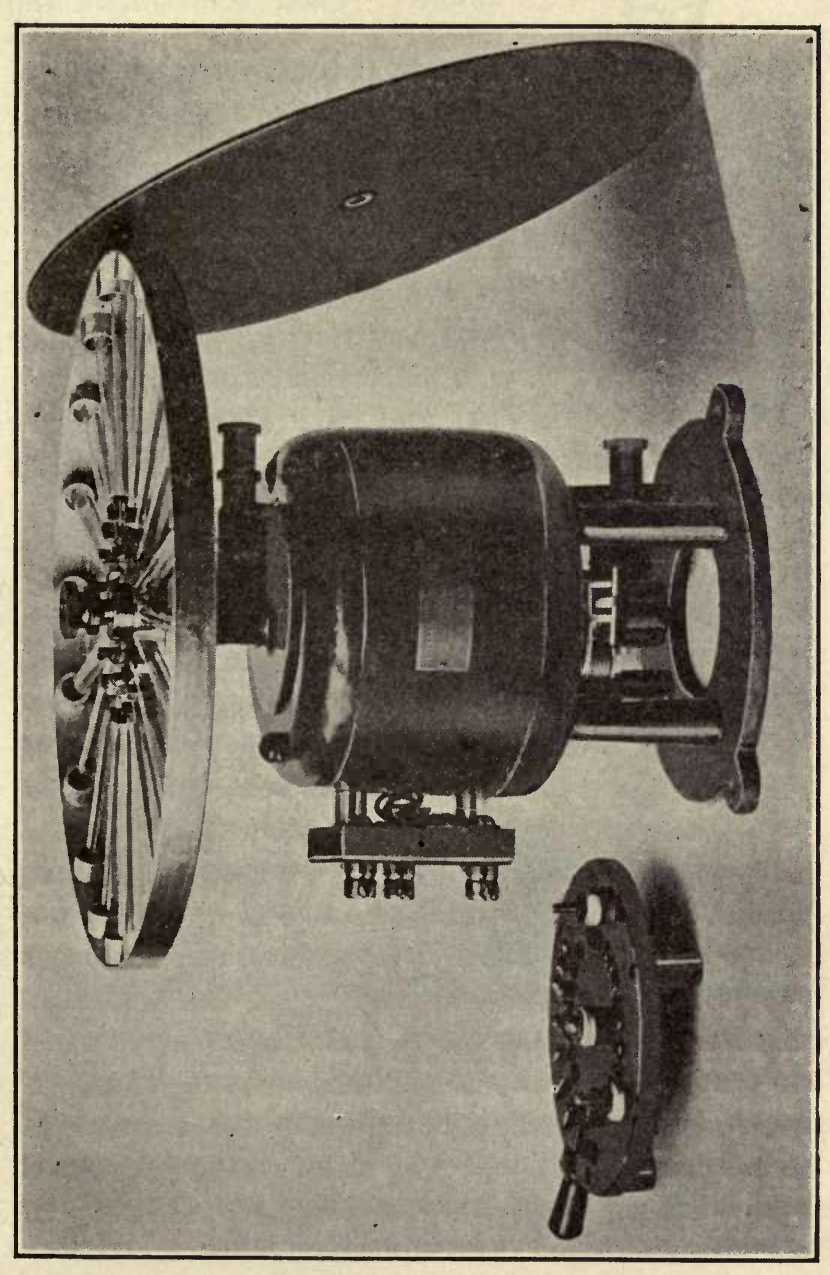

3

Z

융

果

념

년 영

뇌 올

in

द 8

मे ले

8

$\Leftrightarrow \frac{y}{0}$

종

s

品

Un

Z

崖

은

2

똑

䓀

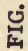




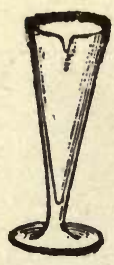

FIG. 45

GLASS FOR COLLECTING SEDIMENT IN MILK

minute. Their centrifuges and tubes can be used also in testing for fat in milk by the Babcock method. In Fig. 44 is shown another form of electrical centrifuge which is very satisfactory for collecting sediments.

A method less accurate, but fairly satisfactory in the absence of any better means, is to place about 4 ounces of milk in a test-glass (Fig. 45) and let it stand for one or two hours. The dirt collects in the bottom and its amount can be roughly estimated by the eye. 


\section{CHAPTER IX}

\section{Methods of Testing Milk by Rennet-Extract and Pepsin}

In cheese-making it is necessary to have some means of finding out when the rennet-extract should be added to milk in order to secure the best results in the process. This is usually known as "testing the ripeness of milk." Two methods are in common use for this purpose: (I) The Monrad test and (2) the Marschall test.

\section{THE MONRAD TEST}

This test is based upon the amount of time required for a definite quantity of milk at a given tem-

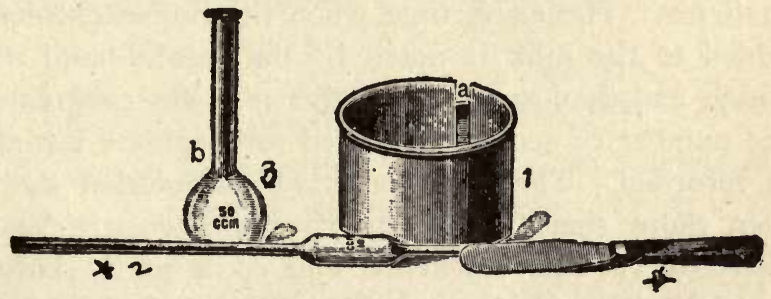

FIG. 46-MONRAD RENNET-TEST

perature to become coagulated by a fixed quantity of rennet.

The pieces of apparatus (Fig. 46) required are the following: ( I) A tin cylinder for measuring milk, holding, when full, I6o cc., (2) a 5 cc. pipette, (3) a. 
50 cc. glass flask, (4) a thermometer, and (5) a halfpint tin basin.

In testing the ripeness of milk by means of rennetextract, one first prepares a dilute solution of the rennet, as follows: One measures with the small pipette $5 \mathrm{cc}$. of rennet-extract into the $50 \mathrm{cc}$. flask. The pipette is then rinsed twice with water by sucking it full of cold, clean water to the mark, the rinsings also being run into the $50 \mathrm{cc}$. flask. The flask is then filled with water to the $50 \mathrm{cc}$. mark, and the contents are well mixed by shaking. The next step is to fill the tin cylinder with the well-mixed milk to be tested and this is emptied into the half-pint basin. The milk must be at the temperature at which one adds the rennet in cheese-making, which is generally about $85^{\circ}$ or $86^{\circ} \mathrm{F}$. To the milk at the desired temperature, one adds $5 \mathrm{cc}$. of the diluted rennet solution, mixes it through the milk quickly, using the thermometer as a stirrer. The exact time when the rennet-extract is added to the milk is noted by the second-hand of a watch and then again when the milk has coagulated; the number of seconds required to coagulate the milk is recorded. The exact point of coagulation can be seen more sharply by scattering a few particles of charcoal (as the blackened end of a partly burned match) on the surface of the milk, and then with the thermometer starting the surface into motion around the dish. The black particles stop the instant the milk coagulates. By using a stop-watch, great accuracy and delicacy can be attained. Care should be taken to keep the temperature of the milk at $85^{\circ}$ or $.86^{\circ} \mathrm{F}$., testing frequently with the thermometer; and, 
in case the temperature drops, it can be raised by placing the basin of milk in warm water. In ordinary cheddar cheese-making, milk is ready for the addition of rennet when it coagulates in 30 to 60 seconds under the foregoing conditions.

\section{THE MARSCHALL TEST}

In this test the same general procedure is followed as in the Monrad test, but the rate of coagulation is observed in a different way. The following pieces of apparatus. (Fig. 47) are used: (a) A testing cup or basin, of about a pint capacity, for holding the milk to be tested. On the inside wall of this cup there are graduated spaces beginning with zero at the top and going by half-divisions to 7 near the bottom of the cup, while in the bottom of the cup is a glass tube with a very small bore.

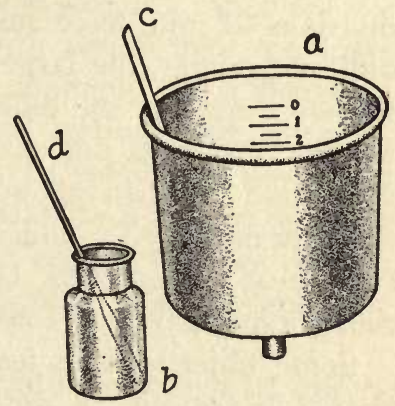

FIG. 47

MARSCHALL RENNET-TEST

(b) An ounce bottle with a mark on it to indicate 20 cc. (c) A spatula for stirring the milk. (d) A I cc. pipette.

The operation of conducting this test is as follows: Measure with the pipette I cc. of the rennet-extract used and empty it into the ounce bottle, previously half filled with clean cold water. Rinse the pipette two or three times by drawing water into it from the bottle and allowing it to run back into the bottle. Mix well by shaking. Then place the milk to be tested 
in the test-cup, setting it in a level position and allowing the milk to run out at the bottom. Taking the bottle of diluted rennet in one hand and the spatula in the other, watch the level of the milk in the cup. The moment the upper surface of the milk drops to the zero mark, pour the diluted rennet into the milk and stir well. Then leave it alone. When the milk coagulates, it stops running through the glass tube. From the graduated scale, read the number of spaces uncovered on the inside of the cup, showing how many divisions of milk have run out. The more slowly the milk coagulates, the larger the amount that runs out; the more quickly the milk coagulates, the smaller the amount that runs out and the fewer spaces there are uncovered. When about $2 \frac{1}{2}$ spaces are uncovered, the milk is ready for addition of rennet. The temperature must be watched, being tested at the start and finish, especially in a cold room.

Some objectionable features of the Marschall test should be noticed. A difference in the size of the bore of the glass tube in the bottom of the cup obviously makes a difference in the results. It is found that the size of the bore of the glass tubing varies in different cups. Therefore, the results given by one cup can not be compared with those of another, unless they are tested on the same milk and found to agree. Special pains must be taken to keep the tube open, since a little dirt quickly stops it. The Marschall test is convenient for ordinary work, but is not capable of as great delicacy as is the Monrad test. Results obtained by different workers can be compared by the Monrad test, but not by the Marschall test. 


\section{METHOD OF TESTING RENNET-EXTRACTS}

Rennet-extract is prepared by soaking calves' stomachs in dilute brine. This treatment dissolves from the mucous membrane the enzym or chemical ferment that has the property of coagulating milk-casein, a property upon which the process of cheese-making is dependent. The ferment contained in rennet-extracts appears to be the same as pepsin in regard to its action upon milk casein. Different brands of rennet-extract vary somewhat in their strength, that is, the rapidity and completeness with which they coagulate milk when used in the same amount. It is therefore important to have a means of testing their strength, in order that their value may be definitely known and that cheese-makers may be able to know in advance of using how much they must use for the best results. The Monrad and Marschall tests are available for this purpose.

In order to test the comparative strength of different rennet-extracts, one treats different portions of the same milk with the different extracts to be tested. In all other respects, the details of the methods previously given are followed. All conditions must be kept alike in the different tests. The strength of the rennet-extracts is shown by the rapidity with which the milk is coagulated; the stronger the rennet, the less the time of coagulation.

\section{METHOD OF TESTING PEPSIN}

Pepsin is beginning to be used in cheese-making as a substitute for rennet-extract. Vivian has worked out the important details. The scale-pepsin, of strength 
known as I-3,000, prepared from stomachs of sheep, is recommended. It may be used at the rate of 5 grams for $\mathrm{I}, 000$ pounds of milk. In testing scalepepsin by the rennet test, one can dissolve the scalepepsin at the rate of 5 grams in 4 ounces of water and use this solution exactly like a rennet-extract with milk. It should be tested in comparison with a sample of rennet-extract whose use in cheese-making has been tested, the test being made on different portions of the same milk.

\section{TESTING THE AGE OF MILK BY RENNET-TEST}

The age of milks and the care with which they have been kept can also be tested in a comparative way by the rennet-test, since with the same rennet-extract or pepsin solution different milks generally coagulate more rapidly in proportion to the amount of acid contained in them, especially if the amount of lactic acid is considerable. 


\section{CHAPTER X}

\section{Methods of Testing Specific Gravity and Solids of Milk by the Lactometer}

The specific gravity of milk may furnish important information, which becomes of special value when taken in connection with the amount of fat present. Thus, with the data furnished by the specific gravity and the per cent. of fat, we can easily calculate the amount of solids in milk and the amount of solidsnot-fat.

\section{THE SPECIFIC GRAVITY OF MILK}

Definition of specific gravity.-By the specific gravity of milk, we mean the weight of a given bulk or volume of milk as compared with the weight of an equal volume of water at the same temperature. To illustrate, suppose we have a vat which, when just full of water, contains exactly $\mathrm{I}, 000$ pounds of water at $60^{\circ} \mathrm{F}$. Now, if we fill such a vat full of milk of average composition at the same temperature, this amount of milk weighs $\mathrm{I}, 032$ pounds. This is so because the milk contains, in addition to the water in it, several solid substances heavier than water. In this illustration we express the relation or ratio of the equal volumes of water and milk by dividing $\mathrm{I}, 032$ by $\mathrm{I}, 000$; the result, I.032, is the specific gravity of the milk. 
Variation in specific gravity of milk.-Since the specific gravity of milk largely depends upon the amount of solids in it heavier than water, the specific gravity should vary, since we know that the amount of solids in milk varies considerably. And so we find the specific gravity of some milks below 1.030 and of some others above 1.035; but most normal milks from herds of cows have specific gravities lying between I.O3O and I.O34.

The solids of milk heavier than water are casein, albumin and milk-sugar. They constitute the solidsnot-fat of milk and have a specific gravity of about I.500.

Effect of milk-fat on specific gravity of milk.Milk-fat is lighter than water, its specific gravity being about 0.900 compared with that of water as I.000. Therefore, an increase of fat in milk, relative to the other solids, lowers the specific gravity of milk. Thus, by adding cream to normal milk, we can make its specific gravity lower than that of normal inilk. On the other hand, by removing fat from milk, we increase the specific gravity, because we remove what is lighter, and leave what is heavier, than water.

Effect of adding water and other substances to milk.-Water being lighter than milk, the specific gravity of milk is lowered by addition of water. Therefore, it is easily possible by removing cream from normal milk to increase the specific gravity and then, by adding water, to decrease the specific gravity again to that of normal milk. The addition of sugar, salt or any similar substance to milk increases the specific gravity. Since water has been the most common adul- 
terant of milk, it was formerly thought that such adulteration could readily be detected by ascertaining the specific gravity; but the results of using the specific gravity may be very misleading, when considered without reference to any other factor.

\section{INFLUENCE OF TEMPERATURE ON SPECIFIC GRAVITY}

Most liquids expand when heated and contract when cooled. A vessel full of milk or water at $40^{\circ} \mathrm{F}$. will overflow when heated considerably higher, that is, will hold less of the fluid, and so the same volume weighs less at higher than at lower temperatures. From this it is readily seen that the specific gravity of a liquid like water or milk grows less when its temperature increases. On the other hand, a vessel full of water at $200^{\circ} \mathrm{F}$. is not full when cooled to $40^{\circ} \mathrm{F}$. The same weight of water occupies less volume and its specific gravity is higher. Decrease of temperature increases the specific gravity of liquids. It is therefore necessary in measuring the specific gravities of different liquids to have the measurements made at the same temperature, if they are to be comparable. The temperature commonly used is $60^{\circ} \mathrm{F}$.

\section{METHOD OF TESTING THE SPECIFIC GRAVITY OF LIQUIDS}

The specific gravity of liquids is readily measured by an instrument known as a hydrometer. The use. of such an instrument is based on the fact that, when a solid body floats in a liquid, it displaces an amount of liquid equal in weight to the weight of the floating 
body. Thus it sinks deeper in a light liquid than in a heavy one, because it takes a larger volume of the light liquid to equal the weight of the floating body.

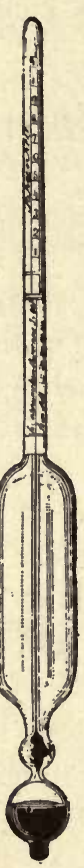
Such an instrument is graduated as the result of extensive experiments, so that the specific gravity of the liquid in which the hydrometer is placed can be read at the point where the scale is even with the upper surface of the liquid. A hydrometer is correct only for the temperature used in standardizing it. When a hydrometer has a scale specially adapted to the limits of the specific gravity of milk, it is called a lactometer. Of the various lactometers made, only two are sufficiently used to deserve attention: (I) The Quevenne, and (2) the New York Board of Health, lactometers.

\section{THE QUEVENNE LACTOMETER}

Description.-This instrument (Fig. 48) is a hydrometer the scale of which is divided into 25 equal parts, going from is to 40. Each division is called a degree, and

FIG. 48 every fifth degree is numbered on the scale. QUEVENNE
LACTOMETER The point marked I5 corresponds to the point marked specific gravity I.OI5 on an ordinary hydrometer, and is the point to which it will sink when placed in liquids whose specific gravity is 1.015. The 40 degree mark on the Quevenne lactometer corresponds to the specific gravity I.O4O mark on a hydrometer. The relation between specific grav- 
ity and the scale of the Quevenne lactometer is shown as follows:

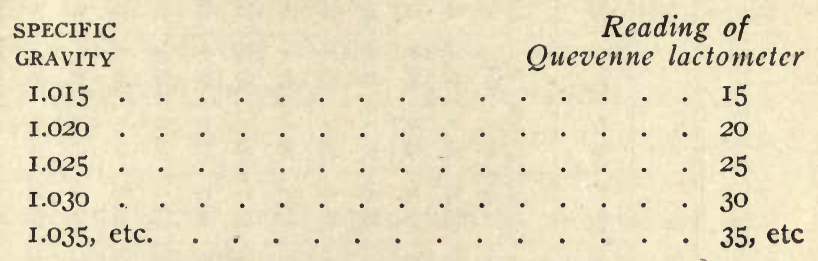

Corrections for temperature.-The Quevenne lactometer is graduated to give correct results at $60^{\circ} \mathrm{F}$. When it is used in milk, the milk should be at $60^{\circ} \mathrm{F}$., or, if at some temperature above or below $60^{\circ} \mathrm{F}$., a correction of the lactometer reading must be made. This correction can be closely made by adding to the lactometer reading .I for each degree above $60^{\circ} \mathrm{F}$., or by subtracting.I for each degree below $60^{\circ} \mathrm{F}$. For more exact corrections, consult table on the following page.

The Quevenne lactometer should carry a thermometer, the scale of which is placed for convenience above the lactometer scale.

Process of using Quevenne lactometer.-The sample of milk to be tested for specific gravity is brought to a temperature between $50^{\circ}$ and $70^{\circ} \mathrm{F}$. For convenience the milk is placed in a cylinder (Fig. 49), which is nearly filled. The lactometer is carefully lowered into the milk until it floats and is allowed to remain half a minute or more. Then one reads and records (I) the point at which the lactometer scale comes in contact with the upper surface of the milk; and (2) the temperature. The lactometer reading is. 


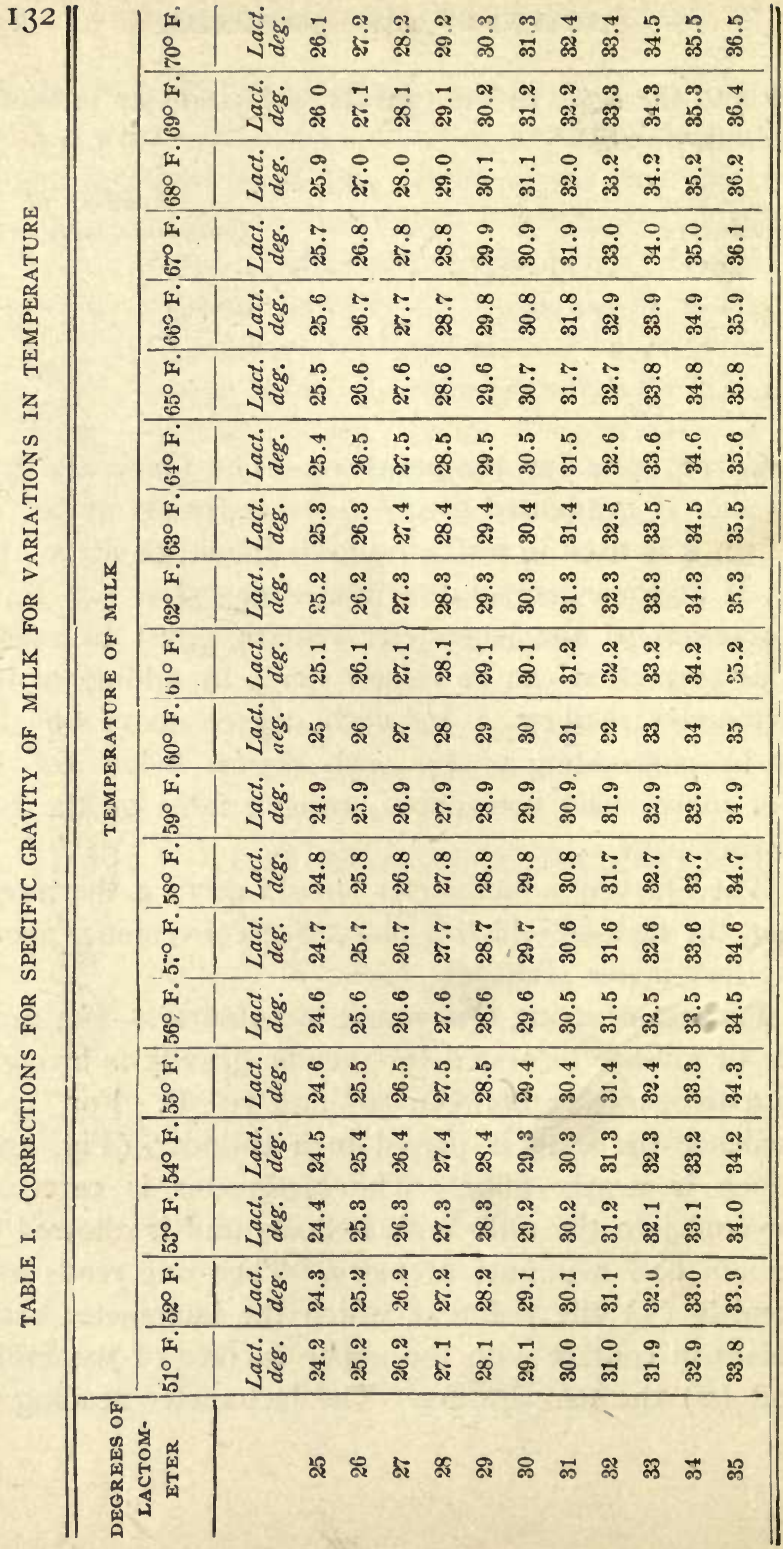


then corrected, if the temperature is above or below $60^{\circ} \mathrm{F}$. For example, the lactometer settles in milk, which is at a temperature of $65^{\circ} \mathrm{F}$, to the point marked 29. Adding to the reading for correction .I for each degree above $60^{\circ} \mathrm{F}$., which in this case is .5 , the reading becomes 29.5 . This means that the specific gravity is 1.0295. If the temperature of the milk were $55^{\circ} \mathrm{F}$., the correction is subtracted and the reading becomes 28.5 , equal to specific gravity 1.0285 .

\section{THE NEW YORK BOARD OF HEALTH LACTOMETER}

Description.-This lactometer has been in common use among milk-inspectors in the eastern and middle states. Its scale is quite different from that of the Quevenne lactometer, since it is divided into $\mathrm{I} 2 \mathrm{O}$ equal parts. Beginning at the top of the instrument, the zero point on the scale is the point to which the lactometer sinks in water; and the point is marked IOO to which it settles in milk of specific gravity $\mathrm{I}, 029$ at $60^{\circ} \mathrm{F}$. (Quevenne reading, 29), the lowest limit supposed to belong to normal milk. The distance between the zero and 100 points is divided into Ioo equal parts and the scale is then prolonged beyond the 100 mark for 20 divisions to I2O. The instrument is used CYLINDER FOR in the same way as the Quevenne lactom- LACTOMETER eter in testing milk.

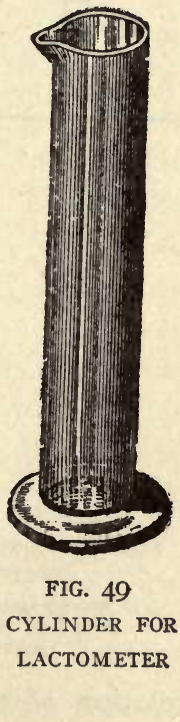




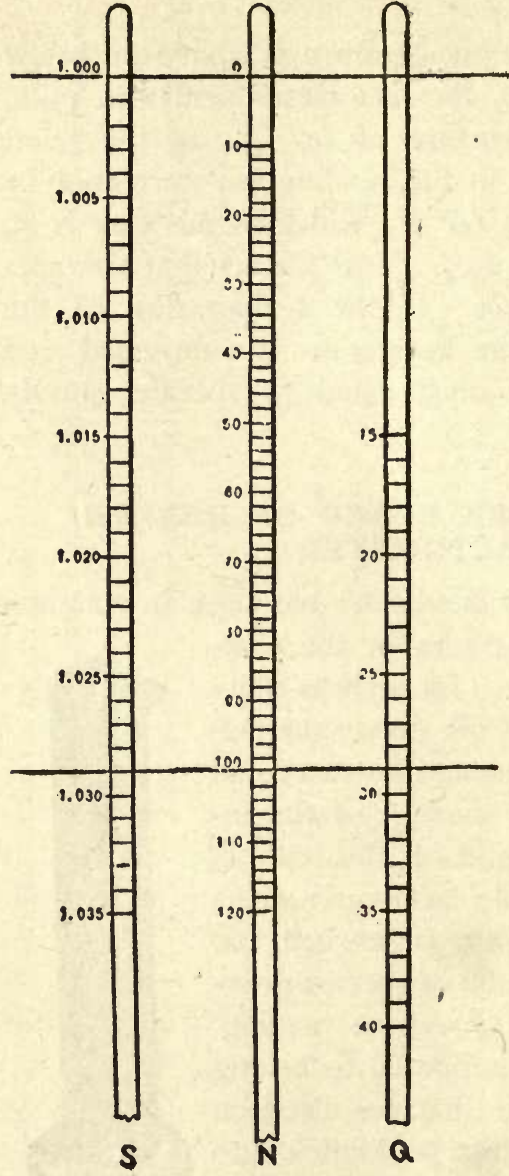

FIG. 50-COMPARISON OF DIFFERENT SPECIFIC GRAVITY SCALES

$S$ is specific gravity scale; $N$ is New York Board of Health lactometer; $Q$ is Quevenne lactometer.
Comparison of the two lactometer scales.-In comparing the scales of the Quevenne and Board of Health lactometers, the following points will make clear their relations: (I) The zero point on both instruments indicates the specific gravity of water, that is, 1.00o. (2) On the B. of H. lactometer, the Ioo divisions or degrees from o to Ioo correspond to 29 divisions on the Quevenne. Therefore one degree on the $\mathrm{B}$. of $\mathrm{H}$. lactometer corresponds to .29 degree on the Quevenne. To convert the $\mathrm{B}$. of $\mathrm{H}$. lactometer reading into $t h a t$ of $t h \epsilon$ Quevenne, multiply the reading of the former by .29. The cale of a hydrometer 
to the scales of the Quevenne and B. of H. lactometer is shown in Fig. 50.

TABLE II.-DEGREES ON QUEVEN NE LACTOMETER CORRESPONDING TO DEGREES ON NEW YORK BOARD OF HEALTH LACTOMETER

\begin{tabular}{|c|c|c|c|c|c|}
\hline $\begin{array}{l}\text { BOARD OF } \\
\text { HEALTH }\end{array}$ & QUEVENNE & $\begin{array}{c}\text { BOARD OF } \\
\text { HEALTH }\end{array}$ & QUEVENNE & $\begin{array}{c}\text { BOARD OF } \\
\text { HEALTH }\end{array}$ & QUEVENNE \\
\hline Degrees & Degrees & Degrees & Degrees & Degrees & Degrees \\
\hline 60 & 17.4 & 81 & 23.5 & 101 & 29.3 \\
\hline 61 & 17.7 & 82 & 23.8 & 102 & 29.6 \\
\hline 62 & 18.0 & 83 & 24.1 & 103 & 29.9 \\
\hline 63 & 18.3 & 81 & 24.4 & 104 & 30.2 \\
\hline 64 & 18.6 & 85 & 24.6 & 105 & 30.5 \\
\hline 65 & 18.8 & 86 & 24.9 & 106 & 30.7 \\
\hline 66 & 19.1 & 87 & 25.2 & 107 & 31.0 \\
\hline 67 & 19.4 & 88 & 25.5 & 108 & 31.3 \\
\hline 68 & 19.7 & 89 & 25.8 & 109 & 31.6 \\
\hline 69 & 20.0 & 90 & 26.1 & 110 & 31.9 \\
\hline 70 & 20.3 & 91 & 26.4 & 111 & 32.2 \\
\hline 71 & 20.6 & 92 & 26.7 & 112 & 32.5 \\
\hline 72 & 20.9 & 98 & 27.0 & 113 & 32.8 \\
\hline 73 & 21.2 & 94 & 27.3 & 114 & 33.1 \\
\hline 74 & 21.5 & 95 & 27.6 & 115 & 33.4 \\
\hline 75 & 21.7 & 96 & 27.8 & 116 & 33.6 \\
\hline$\tau 6$ & 22.0 & 97 & 28.1 & 117 & 33.9 \\
\hline 77 & 22.3 & 98 & 28.4 & 118 & 34.2 \\
\hline 78 & 22.6 & 99 & 28.7 & 119 & 34.5 \\
\hline$\% 9$ & 22.9 & 100 & 29.0 & 120 & 34.8 \\
\hline 80 & 23.2 & $\cdots$ & $\cdots$ & $\therefore$. & $\cdots$ \\
\hline
\end{tabular}


Corrections for temperature.-In using the B. of $\mathrm{H}$. lactometer, correction is made for temperatures above or below $60^{\circ} \mathrm{F}$. For each degree of temperature of milk above $60^{\circ} \mathrm{F}$., add .3 to the lactometer reading, and for each degree below $60^{\circ} \mathrm{F}$. subtract $\cdot 3$ from the reading.

\section{PRECAUTIONS IN TESTING SPECIFIC GRAVITY OF MILK}

I. Milk should, for best results, not be examined until I to 2 hours or more after milking, since the specifie gravity of milk is lower for a while after being drawn than it is later, due chiefly to the presence of gases.

2. The sample of milk must be completely mixed.

3. The lactometer must be kept clean.

4. In milk which has been preserved by potassium bichromate, the specific gravity is about one degree higher than in the normal milk, in case the usual amount of bichromate has been added. (See p. 30).

\section{VALUE OF LACTOMETER IN DETECTING ADUL- TERATED MILK}

The value of the lactometer in detecting adulterated, especially watered, milk was formerly overestimated. Taken alone, the results given by the lactometer may be thoroughly unreliable and misleading. It has come to be quite generally recognized that the proper use of the lactometer in milk inspection is largely to indicate whether a sample is suspicious and to furnish a guide as to whether it is necessary to take a sample for further detailed investigation by chemical anal- 
ysis. As already stated, a milk which is both skimmed and watered may appear to be entirely normal by the lactometer.

\section{METHOD OF TESTING MILK FOR SOLIDS BY LACTOMETER}

As the result of extended studies of the relations existing between the specific gravity of milk, milk-fat and milk-solids, rules have been formulated by means of which it is possible to calculate with a close degree of approximation the total solids of milk, when one knows the percentage of fat and the (Quevenne) lactometer reading.

Babcock's formulas for solids and solids-not-fat. The following formulas were devised by Dr. Babcock :

( I) Formula for determining solids-not-fat.-Solids-not-fat $=1 / 4 \mathrm{~L}+.2 \mathrm{f}$, in which $\mathrm{L}$ is the reading of the Quevenne lactometer and $f$ is the per cent. of fat in the milk.

(2) Formula for determining solids in milk.-Total solids $=\mathrm{T} / 4 \mathrm{~L}+\mathrm{I} .2 \mathrm{f}$.

These formulas can be expressed in the form of rules as follows:

Rule I.-To find the per cent. of solids-not-fat in milk, divide the reading of the Quevenne lactometer by 4 , and to the result add the per cent. of fat in the milk multiplied by .2 .

Rule 2.-To find the per cent. of solids in milk, divide the Quevenne lactometer reading by 4 , and to the result add the per cent. of fat multiplied by I.2.

Examples:-A milk containing 4 per cent. of fat 


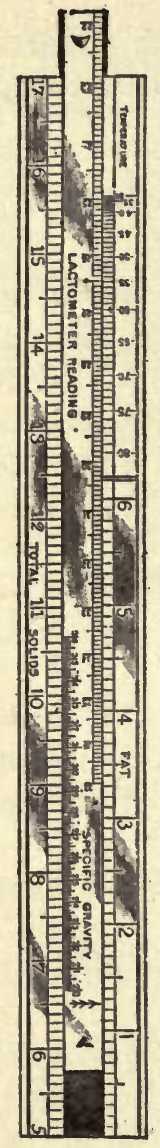

FIG. 5I RICHMOND'S SLIDE-RULE

shows a lactometer reading of 32 . What is the per cent. (a) of solids-not-fat, (b) of total solids?

(a) The lactometer reading (32), divided by 4 , equals 8 . The per cent. of fat (4), multiplied by .2, equals .8. Adding 8 and .8 , we obtain 8.8 as the per cent. of solids-not-fat.

b) The per cent. of total solids in the milk is I2.8 per cent.; for the lactometer reading, divided by 4 , equals 8 , the per cent. of fat (4) multiplied by 1.2 equals 4.8 , and 8 plus 4.8 equals $\mathbf{2} .8$.

Richmond's slide-rule for calculating solids.-Instead of going through the details of calculation to estimate solids in milk, Richmond uses a slide-rule which is a clever mechanical calculating device. (Fig. 5I). The results obtained in this manner agree closely with those given by Babcock's formulas. The method of using the slide-rule is as follows: Determine (I) the Quevenne lactometer reading, (2) the temperature of the milk, and (3) the per cent. of fat in the milk. Then set the central slide of the rule so that the observed lactometer reading is opposite the 60 degree (temperature) mark. The true lactometer reading is found opposite the line indicating the observed temperature of the milk. Having thus corrected the lactometer reading for temperatures 
other than $60^{\circ} \mathrm{F}$., next set the arrow on the sliding portion of the rule opposite the per cent. of fat found in the milk and read the total solids contained in the milk corresponding with the corrected lactometer reading or specific gravity.

To illustrate, suppose the lactometer reading of a sample of milk at $70^{\circ} \mathrm{F}$. is 30 and the per cent. of fat is 4. To correct for temperature and find what the lactometer reading would be at $60^{\circ} \mathrm{F}$., the lactometer reading $(30)$ is placed opposite the little arrow at 60 on the temperature scale. Then, looking at the point of temperature 70 , we find opposite this point 3 I.3, which is the corrected or true reading. Next, we place the arrow opposite the 4 per cent. mark, as the milk contains 4 per cent. of fat, and then notice where the point $3 \mathrm{I} .3$ (specific gravity), comes in contact with the solids scale. It corresponds closely to 12.8 , which is the per cent. of total solids in the sample of milk examined. Some practice with this slide-rule enables one to work rapidly.

Specific gravity of milk-solids.-The following rule has been proposed by Fleischmann for calculating the specific gravity of milk-solids: Multiply the specific gravity of the milk by Ioo, from the result subtract IOO and divide this result by the specific gravity of the milk. Subtract the last result from the per cent. of total solids in the milk and then divide by this result the per cent of total solids of the milk. This may also be expressed by the following formula:

$$
\text { Sp. gr. milk-solids }=\frac{\text { milk-solids }}{\text { milk-solids- } \frac{\text { (roo } \times \text { sp. gr. })- \text { Ioo }}{\text { sp. gr. }}}
$$


Example: A sample of milk contains 12.5 per cent. of solids and has a specific gravity of 1.03I; -what is the specific gravity of the milk-solids?

$$
\frac{100 \times 1.031-100}{1.031}=3.006 ; \quad 12.5-3.006=9.494: \frac{12.5}{9.494}-1.32
$$

This calculation may assist in determining whether a sample of suspected milk has been adulterated. The variations of the specific gravity of milk-solids is slight, ranging between 1.25 and 1.34 . Milks richer in fat have solids of lower specific gravity. The specific gravity of milk-solids is not changed by watering milk, but is increased by removing fat or by addition of skimméd milk. Hence, milk whose solids have a specific gravity above $\mathrm{I} .34$ is suspected of being skimmed, while a specific gravity above 1.40 is regarded as clear evidence of skimming. 


\section{CHAPTER XI}

\section{Methods of Testing Milk and Milk Products for Adulterations}

Milk is commonly adulterated in one of the following ways: ( I) By addition of water, (2) by removal of fat (skimming) or addition of skim-milk, (3) by addition of substances not normally found in milk, such as preservatives and coloring matter. All these forms of adulteration may occur in the same milk.

\section{DETECTION OF ADDED WATER IN MILK}

Since water in milk is the same chemical compound as the water found everywhere else, it is impossible to identify added water in milk by any direct test for special properties. The presence of added water in milk can be learned with certainty only by indirect means and even then not with certainty in all suspected cases. An examination of milk direct from the cow or herd, when this is possible, may settle the question of watering. The lactometer, while unreliable as a sure means of detecting added water in milk, may give a helpful suggestion, used as a preliminary test. Thus, if a milk shows a specific gravity under I.028, it is open to the suspicion of being watered, and should then be carefully examined in other ways.

Most states fix legal standards for the per cent. of water, solids, fat, and solids-not-fat in milk, and any 
milk falling below the fixed limit in composition is regarded as adulterated. "Thus, a standard common to several states is 12 per cent. of solids and 3 per cent. of fat. This means also that such legal-standard milk must not contain more than 88 per cent. of water or less than 9 per cent. of solids-not-fat.

The relations of the different constituents of milk have been studied and formulas have been devised which enable one in an approximate way to tell how much water has been added to a sample of milk beyond the amount allowed by the standards. These formulas are based on the assumption that the limits fixed by the legal standard represent the lowest amounts of solids and fat found in normal milk, and they are correct only when the original milk contains the lowest percentages given in the legal standard.

In calculating the amount of added water in milk, the amount of solids-not-fat (total solids minus fat) is used as a basis. The procedure is as follows:

(I) Determine the per cent. of fat in the suspected sample.

(2) Take the lactometer (Quevenne) test.

(3) Determine the amount of solids-not-fat according to the formula, $1 / 4 \mathrm{~L}+.2 \mathrm{f}$. (p. I 37 ).

(4) Apply the following rule: Multiply the per cent. of solids-not-fat by 100 and divide the result by the legal standard for solids-not-fat. Subtract the last result from 100 and the result is the per cent. of added water in the sample of suspected milk. This rule is expressed in the form of the following formula:

Per cent. of added water $=100-\frac{\text { per cent. of solids-not-fat } \times \text { Ioo. }}{\text { legal standard for solids-not-fat. }}$ 
This formula gives only the amount of water added beyond the limit fixed by the legal standard and is correct only if the original milk contained the amount of solids-not-fat prescribed by the standard (usually 9 per cent.). Hence, in cases of watered milk, the calculated amount of water added is generally less than the real amount added.

Example: A milk is found to contain 3 per cent. of fat and to show a lactometer reading of 27. Applying the formula for finding the amount of solids-not-fat, the per cent. is $7 \cdot 35$. If the legal standard for solidsnot-fat is 9 , then the formula becomes

$$
100-\frac{7.35 \times 100}{9}=18.3 \text {, }
$$

the per cent. of added water that is contained in the milk, assuming that it contained 9 per cent. of solidsnot-fat before being watered.

The following rule can also be used: Add together the lactometer reading and the per cent. of fat present in the milk, divide the sum by 36 , multiply the result by 100 and subtract the last result from roo. Expressed as a formula, this becomes

$\left.\begin{array}{l}\text { Per cent. of } \\ \text { added water }\end{array}\right\}$ in milk $=100-\frac{\text { lactometer reading }+ \text { per cent. of fat }}{3^{6}} \times 100$.

An examination of the serum of milk by means of a refractometer gives, probably, the most reliable means of detecting added water in milk, but this method is available only for special workers. For its details see "Food Inspection and Analysis," by Leach, (p. I39). 


\section{DETECTION OF SKIMMED MILK}

The percentage of fat in milk in relation to the other milk-solids is reduced either (I) by direct removal of fat through some process of skimming or (2) by the addition of separator skim-milk to normal milk. Milk containing less than 3 per cent. of fat is generally skimmed. Watering milk does not disturb the relations of the constituents of milk to one another, since it reduces the percentages of all uniformly, but the removal of fat does very seriously affect the amounts of the constituents in respect to their relative percentages. In skimming milk, the solid constituent most largely removed is fat, comparatively little casein, sugar, etc., being taken with the fat. The removal of fat therefore leaves the milk containing less fat but with most of its casein, sugar, etc., still remaining. In normal herd milk, containing over 3 per cent. of fat, the percentage of fat is rarely as low as the percentage of casein and albumin. In 5,500 analyses of samples of American milks, compiled by the author, with a fat content lying between 3 and 5 per cent., the fat averages 3.92 per cent., and the casein and albumin together, 3.20 per cent.; that is, for I part of casein and albumin there is an average of I.225 parts of fat. In skimming such milk, the fat may be decreased to I per cent. or .I per cent., but the remaining milk still contains about 3.20 per cent. of casein and albumin. Milk is open to the suspicion of being skimmed, when the percentage of fat falls below that of the casein and albumin.

The percentage of fat removed, based on the legal 
standard, may be calculated by the following rule: Multiply the per cent. of fat in the milk by Ioo, divide the result by the legal standard for fat and subtract this from IOO; or expressed as a formula:

The per cent. of fat removed $=100-\frac{F \times 100}{3 .}$ This formula is true only for milks originally containing 3 per cent. of fat and so its results are generally much below the truth. For example, in a milk containing originally 5 per cent. of fat, which has been skimmed to 2.50 per cent., thus removing 50 per cent. of the fat in the milk, the above formula would indicate that only I6.6 per cent. of the fat had been removed. In most cases results nearer the actual truth are given by substituting 3.75 for 3 in the formula.

\section{GENERAL METHOD FOR JUDGING WATERED AND SKIMMED MILK}

Having found in a sample of milk (I) the per cent. of fat, (2) the specific gravity of the milk and (3) of the milk-solids, (4) the per cent. of solids, and (5) of solids-not-fat, one may arrive at fairly safe conclusions in regard to the watering and skimming by making comparison with the percentages of constituents present in average normal milk. In forming such conclusions, the following facts should be kept in mind:

I. Water has a lower specific gravity than milk.

2. Watering milk decreases (a) the lactometer reading, (b) the fat, (c) total solids, and (d) solids-not-fat.

3. Water has a higher specific gravity than milk-fat. 
4. Skimming milk (a) increases the lactometer reading, (b) decreases the fat and total solids, (c) slightly increases the solids-not-fat, and (d) increases the specific gravity of the milk-solids.

5. Skimming and watering decrease all constituents, but lower the fat more in proportion than the solids and solids-not-fat.

6. Skimming and watering may produce the same specific gravity as in normal milk.

7. The amount of fat in milk is more variable than the amount of solids-not-fat.

8. Herd milk which shows a lactometer reading above 33.5 , along with a low percentage of fat, and a specific gravity of solids above I.40, can be regarded as skimmed.

9. Herd milk showing a lactometer reading below 28 may be regarded as watered, especially with low fat, solids and solids-not-fat.

Milk is watered when (I) the specific gravity of the milk is low, (2) the percentage of fat and solidsnot-fat is low and (3) the specific gravity of the milksolids is between 1.25 and 1.35 .

Milk is skimmed when (I) the specific gravity of the milk and of the milk-solids is high; when (2) the per cent. of solids-not-fat is high, and when (3) the per cent. of fat and solids is low.

Milk is watered and skimmed when (I) the specific gravity of the milk is normal or otherwise, (2) the specific gravity of the milk-solids is normal or high, and (3) the per cent. of fat and solids-not-fat is low. 
DETECTION OF FOREIGN SUBSTANCES IN MILK

The foreign substances most frequently found in milk are preservatives and coloring matters. The preservatives in common use are formalin, boric acid, borax and sodium bicarbonate. The coloring matters generally used are annatto and coal-tar dyes (azocolors), which are added to milk to make it look rich, and, especially in case of skimmed and watered milk, to cover up the signs of such adulterations.

Test for annatto.-To Io cc. of milk in a test-tube add Io cc. of ether, shake vigorously and let stand until the ether separates on top of the milk. If annatto is present, the layer of ether will be yellow, the depth of color depending on the amount of annatto present.

Test for Coal-Tar Dyes.-The azo-colors, which are the ones most commonly used in coloring milk, may be detected by adding Io cc. of milk to Io cc. of strong hydrochloric acid and mixing, when a pink coloration appears.

Tests for Formalin.-Formalin, which is a 40 per cent. solution of formaldehyde, is commonly diluted and sold under such names as "Freezine," "Iceline," etc., which contain from 2 to 6 per cent. of formaldehyde. In making the Babcock test in milk, the presence of formalin may be shown when a marked violet layer forms at the junction of the acid and milk just after pouring the acid into the test-bottle. The test may also be performed by taking Io cc. of milk in a test-tube or Babcock test-bottle, and adding about 5 cc. of sulphuric acid, such as is used in the Babcock test, pouring the acid down the side of the tube so that it does not mix with the milk. 
Leach's test, which is more delicate, is performed as follows: Make a solution of hydrochloric acid (specific gravity I.2) containing $2 \mathrm{cc}$. of Io per cent. ferric chloride per liter. Add Io cc. of this solution to Io cc. of milk in a white teacup and heat slowly over a flame to boiling, giving the cup a rotary motion. If formalin is present, a violet coloration appears, varying in depth with the amount present.

Test for borax and boric acid.-To $25 \mathrm{cc}$. of milk add lime water, until the milk is alkaline, evaporate to dryness and burn to an ash in a small porcelain or platinum dish. To the ash add a few drops of dilute hydrochloric acid, not too much; then add a few drops of water and place in this water solution a strip of turmeric-paper (obtainable at drug-stores). Then dry the paper, when a cherry-red color will appear on the paper if either borax or boric acid is present. This test is made still more certain by moistening the reddened paper with a drop of an alkali solution, when the paper turns to a dark-olive color in the presence of borax or boric acid.

Test for sodium carbonate.-To Io cc. of milk add Io cc. of alcohol and a few drops of a I per cent. solution of rosolic acid. Carbonates are present if a rose-red color appears, while pure milk shows a brownish-yellow color.

\section{ADULTERATIONS OF CREAM}

The adulterants of cream are the same as those for milk and are detected in the same manner. Gelatine and sucrate of lime are used to some extent to give crèam a greater consistency. 


\section{ADULTERATIONS OF BUTTER}

The most common adulteration of butter is substitution, in part or in whole, of fat other than butterfat, such as products from beef-fat and lard. Occasionally preservatives are found, such as occur in milk. "Renovated" or "process" butter is made from refuse . butter that can not be disposed of otherwise on the market. Excessive water or casein should be regarded as an adulteration. Harmless coloring matter has been universally allowed. The absolute identification of such adulterants as oleomargarin requires somewhat elaborate chemical methods. Only simple tests can be given here.

Foam-test for oleomargarin and "renovated" butter.-Melt in an ordinary tablespoon a piece of the suspected butter about the size of a small chestnut, holding it over a small flame,- a candle flame will do. Stir the fat, while melting, with a match or similar stirrer. Then lower the spoon into the flame and let the fat boil vigorously, stirring thoroughly several times during the boiling and not neglecting the outer edges. Oleomargarin and "renovated" butter boil with marked noise, sputtering more or less and producing little or no foam. Genuine butter generally boils with much less noise and foams up vigorously.

Milk-Test for oleomargarin.-In a tin measuringcup take about one gill of sweet milk or water, heat to about $140^{\circ} \mathrm{F}$. and then add a slightly rounded teaspoonful of the suspected sample. Stir with a small piece of wood, about the size of a match or smaller, until the fat is melted. Then immerse the cup to about one-third of its height in a pan of water in which there 
are several large pieces of ice. Stir the liquid continuously, alternating a circular and crosswise motion, until the fat hardens, when it can be easily collected into one lump by means of the wooden stirrer, if it is oleomargarin; but, if butter, the fat will form little granules and can not be collected in one lump. When milk is used in the test, it should contain as little fat as possible. In this test "renovated" butter behaves like genuine butter.

\section{ADULTERATIONS OF CHEESE}

Only two kinds of adulteration are common in American cheddar cheese: (I) The removal of fat in varying degrees producing so-called skim-cheese, and (2) the use of fat other than milk-fat, producing the so-called filled cheese. Harmless coloring matter is allowed. Cheese containing less than 32 per cent. of fat can be regarded as having been made from milk containing less than its normal amount of fat. The per cent. of fat in filled cheese is generally lower than in cheese made from normal milk. 


\section{CHAPTER XII}

\section{The Babcock Test Applied to Farm Conditions}

The Babcock test finds application on the farm of every dairyman in one or more of the following ways:

I) In testing the quality of milk in respect to fat produced by individual cows and by the herd.

(2) In testing cream.

(3) In testing skim-milk.

(4) In testing buttermilk.

(5) In testing milk and cream as a means of selfprotection.

\section{TESTING COWS}

The most effective test of the value of a dairy cow is the production of milk and of milk-fat. Evidence has been carefully collected showing that many cows in this country are kept at an actual loss. The owners of such cows may be conscious of the fact that they are not prospering, but without having any idea of the cause. The amount of fat in milk required for various purposes differs somewhat. For ordinary market purposes, where consumers take as a matter of course any kind of milk delivered to them, the most profitable cow is the one producing a large yield of milk, which generally means a low percentage of fat, frequently just enough to keep above the legal standard. The statement applies to milk sold by bulk 
or by weight alone, whether sold for direct consumption or taken to a cheese-factory or creamery. But whenever milk is paid for according to its percentage of fat, as in certain forms of market milk, at creameries, at condenseries, and at progressive cheese-factories, the cow producing the largest amount of milkfat will nearly always be found the most profitable. As a rule, a pound of milk-fat can be produced at less cost in rich milk than in poor milk. The only method of ascertaining accurately the value of a cow or of a herd for the production of milk-fat is by testing the milk. The real object of a test is to find the total number of pounds of fat produced in the milk for a definite period of time, the most satisfactory unit being one period of lactation, that is, from the time of calving to the time of becoming dry.

In testing the value of a cow for the production of milk-fat, two factors must be considered: (I) The amount of milk produced and (2) the per cent. of fat in the milk. The first amount is obtained by weighing the milk, and the second by testing the milk by the Babcock test. From these data the amount of milk-fat produced is easily found.

In applying the Babcock test on the farm to individual cows, certain details need to be considered, such as (I) the duration of the testing, (2) the frequency of testing, (3) the method of sampling, (4) weighing the milk, (5) keeping records, and (6) calculating results. In carrying out the work of the milk-test, all necessary details are given in Chapter IV, p. 53 .

Duration of testing.-For best results, the tests 
should be made at intervals for a whole period of lactation.

Frequency of testing.-It is not practicable to test the milk of every milking for fat and it is not necessary. On the other hand, the testing of a single milking or of a day's milk or even of a week's milk is insufficient, since, for many reasons, the percentage of fat may vary greatly from one time to another. The following plan combines a high degree of accuracy with the least amount of labor: Make the first fattest in about two weeks after the cow calves and then repeat it regularly once in two weeks during the period of lactation. Even a monthly testing will, however, give fairly accurate results.

Method of sampling.-When a single cow's milk is to be tested, the following precautions should be observed in taking the sample:

(I) The cow must be milked dry at the milking previous to the one to be tested. (2) On the day of milking for the test, the cow is milked as completely as possible each time. (3) After the morning's milking, the milk is well mixed by pouring from one pail to another or by stirring with a dipper, and about a gill is at once dipped out and poured into a pint fruitjar, which has been thoroughly cleaned and scalded. The sample is kept in a cool place. Repeat the sampling with the evening's milk or with each milking, if the cow is milked more than twice a day, adding a sample of each to the jar containing the morning's milk. (4) Make a test before the milk can sour, mixing well before taking samples for the test by pouring back and forth a few times from one vessel to another. If 
it is impossible to make the test promptly, add bichromate of potash to preserve the sample, as directed on p. 3o. (5) In testing the milk of several cows at the same time, label each sample-jar with the number or name of the cow furnishing the milk. (6) If the milk is to be tested also for solids by the lactometer, take about a half-pint sample from each milking.

More strictly accurate results are secured if each milking is sampled by a tube, as stated on p. 27.

Weighing milk.-In testing a cow, the milk must always be weighed on the testing day immediately after the milking is completed. As it is so easy to weigh milk, it is desirable to weigh the milk at every milking, or, at least, on two or three days each week. Accurate spring scales of moderate cost are available.

Keeping records.-Records of each cow tested should be carefully kept, the following facts being recorded: (I) Date, (2) name of cow, (3) pounds of milk given, (4) per cent. of fat in milk, (5) lactometer reading, if desired.

Calculating results.-The following data can be derived by calculation from the facts recorded above: ( I) Pounds of fat produced on day of test, (2) pounds of fat and milk produced each month, (3) pounds of fat and milk produced for one period of lactation.

The amount of fat on the day of the test is found by multiplying the total number of pounds of milk given by the per cent. of fat found and dividing by Ioo. For example, if the day's yield of milk is 25 pounds and the per cent. of fat is 4, the day's milk contains I pound of milk-fat. (See p. I93).

The amount of milk and fat produced each month 
is found as follows, when the test is made once in two weeks: Add the daily yields of milk for the day of the test and for one week before and one week after the test, thus obtaining the milk yield for 15 days. Multiply this sum by the per cent. of fat found on the day of the test and the result is the fat yield for half a month. This added to the next half month gives the yield of fat for the month.

The monthly yields of milk and fat, added together at the end of the period of lactation, give the total yields for the period.

\section{APPLICATION OF RESULTS OF TESTING INDI- VIDUAL COWS}

A progressive dairyman will discard from his herd any animal that can not produce, at least, 200 pounds of milk-fat in a year, especially if the milk is sold on the basis of its fat content; and he will aim, by means of intelligent breeding, feeding and care, to increase the annual yield of milk-fat to 250 or 300 pounds for each cow.

\section{TESTING CREAM ON THE FARM}

There are several conditions under which it is of advantage to test cream on the farm in order to know its fat content.

When a dairyman is producing cream to sell directly to consumers, it is important to know its percentage of fat, in order that it may be uniform from day to day, whatever the desired percentage may be. The work of the cream-separator may be controlled ad- 
vantageously only by knowing the percentage of fat in the cream produced. In states where a certain percentage of fat in cream is required by law, it is important for the dairyman to know that his product is up to standard before he sells it.

In making butter on the farm, better results can be secured by having the cream of a uniform richness in fat, and the percentage of fat in cream can be accurately known and regulated only by testing.

\section{TESTING SKIM-MILK AND BUTTERMILK ON THE FARM}

The completeness with which fat is removed from milk by different methods of creaming, whether by separator or by gravity processes, can be known accurately only by testing the skim-milk for its fat content. With the knowledge furnished by testing, one is in position to prevent further losses when they are known to exist. Similarly, the efficiency of churning may be found by testing the buttermilk for its fat content.

\section{TESTING MILK AND CREAM FOR SELF- PROTECTION}

When dairymen sell milk or cream to milk-dealers, creameries, cheese-factories, shipping-stations, condenseries, etc., on the basis of the per cent. of fat in milk, it is often a matter of satisfaction to know that the tests which serve as a basis of payment are correct. If a dairyman will take pains to acquire the skill necessary to perform the operations of the Babcock test, he can satisfy himself easily in regard to the ac- 
curacy of the tests of his milk made by others. In cases where a purchaser reports the test lower than it is, his dishonesty can be detected by means of home testing.

It is also important for the dairyman who sells milk directly to consumers to know that his milk is above the legal standard. Much annoyance and expense may sometimes be saved by knowing the percentage of fat and solids in the milk one sells. 


\section{CHAPTER XIII}

\section{Methods of Commercial Testing and Scoring of Butter and Cheese}

In commercial transactions in butter and cheese, certain points or qualities have been adopted as a basis or standard in judging the commercial value of these products. The terms used in expressing the different qualities vary considerably in different market centers, and the same expression is used with different meanings by different persons. Frequently individuals use terms that are strictly local or personal. It is desirable that there should be a uniform usage and a common understanding in respect to the terms used in judging dairy products. The attempt is made here to discuss the terms in common use and to define them as well as may be, in the hope that it may serve as a beginning in bringing about a general agreement in respect to the use and understanding of the expressions employed in testing and scoring dairy products. The definitions here given can hardly be expected to be in full agreement with the usage of everyone, since individuals differ from one another so much in their use of these terms.

\section{SAMPLING AND TESTING BUTTER}

In obtaining a sample of butter from a package for examination, a butter-trier (Fig. $5^{2}$ ) is used. 'This is inserted its whole length, if possible, into the but- 
ter, turned around once and then drawn out, bringing with it a long, round plug as a sample. The plug, as soon as drawn, is examined for flavor by smelling and next by tasting. It is then broken across to examine the grain or texture, and then other qualities are examined in turn.

\section{TERMS USED IN DESCRIBING QUALITIES OF BUTTER}

The qualities that have been selected to serve as a basis or standard in the commercial testing and scoring of butter are as follows: (I) Flavor, (2) texture, (3) body, (4) moisture, (5) color, (6) salt and (7) appearance.

Flavor.-By flavor is meant the quality that is perceptible to the senses of smell and taste. The sense of smell is, as a rule, capable of being developed so as to be more highly sensitive than the sense of taste in detecting variations of flavor. The flavor in normal butter is due to the formation of certain organic compounds in minute quantities during the cream-ripening process. What specific compounds these are has not yet

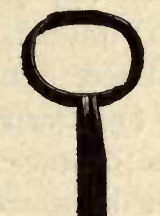
been learned. The odor is not that of lactic acid, since that is odorless.

Testing Flavor.-The flavor is obtained by placing the plug of butter under the nose as soon as possible after the plug is drawn. A portion of the butter is also tasted. 
Terms describing flavors.-The following terms are selected from the great variety of names that are applied to various flavors found in butter: (I) Perfect, (2) quick, (3) clean, (4) light, (5) buttermilk, (6) rancid, (7) tallowy, (8) cowy, (9) fishy, (I0) tainted, (II) stable, (I2) weedy, (I3) cheesy.

(I) Perfect flavor applies to butter which possesses the characteristic aroma and taste of high-grade butter in a well-marked degree. It is difficult to describe this flavor adequately, but it is commonly characterized as nutty, clean, pleasantly aromatic, delicate and sweet. Perhaps the best description of it is to liken it to the flavor of clean, well-ripened cream. It should be entirely free from rancidity or any unusual flavor.

(2) Quick flavor is so delicate and volatile that it disappears quickly; "high" is also applied to the same condition.

(3) Clean flavor is free from every trace of unpleasant aroma or taste.

(4) Light or flat flavor in butter indicates absence of marked flavor, due to lack of cream-ripening, to excessive washing of granules and to other concitions.

(5) Buttermilk flavor is somewhat sour in taste and like buttermilk in aroma. It is due to the presence of an excessive amount of buttermilk in the butter.

(6) Rancid flavor is that of butyric acid, the presence of which is due to the use of over-aged cream or milk or to age of butter, in which butyric acid fermentation has occurred. When the flavor is strong, it produces an unpleasant, strangling or choking sensation in a sensitive throat. The odor is very penetrating and lasting. 
(7) Tallowy flavor is like that of tallow.

(8) Cowy flavor refers to the animal odor, particularly as noticed in the breath of a cow. It appears to be especially prominent in cows freshly turned into pasture.

(9) Fishy odor is rather suggestive of salted codfish. It is usually due to a special form of fermentation appearing in the milk and cream.

(Io) Tainted flavor covers a variety of odors and tastes that are offensive in varying degrees.

(II) Stable flavor is the one characteristic of cow manure.

(12) Weedy flavor includes such abnormal flavors as may come from onions, leeks, cabbages, turnips, etc.

(13) Cheesy flavor suggests the flavor of cheese and is due to fermentation changes in the proteid of butter; it is more common in unsalted butter.

Texture.-The texture of butter refers to what is called the grain and depends upon the condition of the butter-granules. In its first formation in churning, butter appears in very small, irregular grains or granules. These grains retain their individuality in large measure throughout the rest of the process of buttermaking and even in the finished product. The more distinct the individuality of the granules can be kept in making the butter into a solid mass, the better is the texture.

Testing texture.-The granular texture of butter is seen when a plug or chunk of butter is broken into parts transversely, giving somewhat the fractured appearance seen in broken steel and free from a smooth, greasy appearance. Another method of testing tex- 
ture is to pass a knife-blade or butter-trier through the butter; when it is withdrawn, the trier is clean and free from any greasy appearance, if the texture is good.

Terms describing texture.-The terms used to describe texture are (I) perfect, (2) poor grain, and (3) salvy.

(I) Perfect texture in butter is shown by the granular formation, as described above.

(2) Poor grain texture in butter is shown by less marked grain and a more or less smooth, greasy appearance on the broken surfaces.

(3) Salvy texture applies to butter in which the grain is more or less destroyed and the smooth, greasy appearance of the broken surface is very marked.

Defective texture in butter is caused by allowing the butter-granules in the churn to become too large and by working too much or at too high a temperature. The granular texture of butter is completely destroyed by warming butter to near its melting point.

Body.-By this term is meant the quality of consistency, firmness or hardness, as shown by not melting or softening too easily.

Testing body.-The body of a sample of butter can be ascertained by pressing a portion of the plug between the thumb and fingers, and also by pressing between the tongue and roof of the mouth.

Terms describing body.-The terms used to describe the body of butter are: (I) perfect, firm or solid, (2) hard or tallowy, (3) weak-bodied, (4) sticky. 
(I) Perfect body in butter is shown by firmness or solidity under proper conditions of temperature. When pressed between the fingers or on the tongue it shows a certain amount of resistance.

(2) Hard or tallowy body is shown by excessive solidity, being characteristic of butter made from cows far along in lactation, or in the case of cows heavily fed on cotton-seed meal.

(3) Weak-bodied butter is lacking in firmness, more or less soft, melting more easily on warming than a perfect-bodied butter. Weak-bodied butters are usually salvy in texture and high in moisture. Certain feeds, such as gluten meal, tend to increase the softness of butter.

(4) Sticky body in butter is shown by extreme softness amounting to stickiness.

Moisture.-The water in butter should be so thoroughly incorporated with the fat that it does not appear in the form of free beads of water visible to the eye. Water should not run off the trier when a sample is drawn. The water should also be clear and transparent.

Testing moisture.-The sample of butter is examined for the appearance of moisture or brine in respect to the completeness of its incorporation and its clearness.

Terms describing moisture.-The following terms are used to describe the condition of moisture in butter: (I) Perfect, (2) excessive, (3) milky or turbid.

(I) Perfect moisture in butter is shown by the absence of any visible moisture in the form of drops. (2) Excessive moisture is shown by the presence of 
water easily apparent to the eye. Butter may sometimes contain so much water as to be called "mushy."

(3) Milky or turbid moisture or brine appears more or less milky, being due to the presence of too much buttermilk.

Relation of texture, body and moisture.-Considerable confusion prevails in the use of the terms texture, body and moisture. Some use the term texture to include also body and moisture; others use the term body to include texture, while others use the expression "body and grain" to cover all three qualities. Texture and body and moisture may be influenced by the same conditions and may be, to some extent, interdependent, but in reality they are distinct properties and, if they were treated as such, needless confusion would be avoided.

Color.-The color of butter varies in different markets according to requirements, but most of the butter made in the United States has, as its standard, an even, bright, straw-yellow. Most butter in commerce is colored artificially, so as to maintain a uniform appearance at all seasons of the year. Somewhat different shades of color are demanded by different markets.

Testing color.-The quality of color is tested simply by inspection with the eye. The thumb-nail is run along the surface of the plug near the edge of the trier, and the fresh surface thus made is examined. The examiner carries in his mind the shade of what he regards as an ideal color and judges the sample under examination by its comparison with his ideal. It would lead to easier methods of comparison and 
more uniform results if there could be agreed upon a certain shade of color which should serve as a national standard as far as possible. Such a color standard could be furnished butter-makers and examiners of butter. Along with such a standard color, there could be prepared a scale of shades which could serve as a basis for scoring color.

Terms describing color.-The terms used in describing the color of butter are: (I) perfect, (2) light, (3) high, (4) reddish, (5) mottled, and (6) whitespecked.

(I) Perfect color in butter is a straw-yellow, bright, and uniform throughout the mass. A plug of butter held between the light and the eye should be evenly translucent and not opaque or cloudy.

(2) Light color is shown by insufficient color, the yellow being too pale.

(3) High color is deeper yellow than called for by perfect color.

(4) Reddish color is self-explanatory and is due to excessive use of coloring material.

(5) Mottled color in butter is shown by the appearance of light-colored portions, which may be in spots or streaks or waves. The term wavy is often used to indicate a variation of color that is just perceptible. They are not seen as readily on a sample plug drawn by a trier as they can be by cutting a lump of butter across so as to show a smooth, broad surface. Slight mottling is apt to escape observation when the examination is made only of a plug. Mottling is due to the action of salt upon buttermilk retained in the butter. The light portions owe their color to the pres- 
ence of the casein lactate of buttermilk. Removal of buttermilk from the butter-granules prevents mottling. (Bulletin No. 263, N. Y. Agr. Exp. Sta. 1905).

(6) White-specked color in butter appears in white specks of varying size, but usually small. They are due to particles of coagulated casein lactate produced in cream by over-ripening, and also to dried cream particles, caused by lack of stirring during the process of ripening.

Salt.-The amount of salt in butter varies with different markets; but, whatever the amount used, it should be completely dissolved and evenly distributed through the mass of butter.

Testing butter for salt.-The quality of butter as affected by salt is examined by tasting, sight and feeling. Undissolved particles of salt, when they can not be felt on the tongue or seen, can be detected by rubbing some of the butter between the fingers.

Terms describing salt.-The terms used in describing the quality of butter in relation to salt are the following: (I) Perfect, (2) too salty, (3) flat, (4) gritty, (5) uneven.

(I) Perfect quality in respect to salt in butter is shown as follows: The salt must be in the proportion demanded by the market; it must be entirely dissolved and evenly distributed.

(2) Too salty butter contains more salt than the market demands.

(3) Flat butter is lacking in salt for the market requirements.

(4) Gritty butter contains undissolved salt. 
(5) Uneven salt in butter is lack of uniformity, some portions of butter being more salty than others.

Appearance.-Under this head are included the manner of packing, the attractive appearance of the package, cleanliness, etc.

Testing appearance.-When the cover of the package is removed for sampling the butter, the appearance of the surface of the butter is noticed. The outside of the package is also examined. The two general qualities that must be kept in mind in this connection are cleanliness and neatness.

Terms describing appearance.-The quality of appearance of butter may be considered under two heads, (I) finish and (2) package.

(I) Finish in appearance, in connection with examining butter, refers to the manner of packing. The finish is perfect when the package is lined with paraffin or with a good quality of parchment paper, neatly placed, and the package well filled, the surface being even and bright. The package should be just evenly full. The top should be neatly covered with cheesecloth saturated with brine.

(2) Package.-The package is regarded as perfect when of good material, well-made, clean, and neat in appearance. In the same lot of butter the packages should all be alike in size and shape.

\section{SCORING BUTTER}

The different qualities indicated above are used in a specific manner for judging and fixing the commercial value of butter. 
Scale of points.-To each quality is assigned a definite numerical value and these numbers are called a scale of points. The following scale of points is in common use in many markets of this country, the numbers indicating perfect quality in each case, and the totals aggregating I00:

Flavor, 45 points.

Texture, ( I0)

Body, ( Io)

Moisture, (5) $\}^{25}$ points.
Color, 15 points.

Salt, Io points.

Appearance, 5 points.

Total, Ioo points.

Method of scoring.-In scoring a sample of butter, an examination is made with reference to each of the qualities mentioned. In those qualities in which it is perfect, it is given the values or points assigned above. If the butter is defective in any quality, that is, short of perfect, then a smaller value is given than the one indicated above in the scale of points; the more defective the butter is in any quality, the lower is the value or number of points given it. When all the qualities have been scored, the numbers of points assigned to them are added and the total is the score of the butter under examination.

It can readily be seen that judgment, trained by experience, is required to assign to each quality its proper number of points. The sense of smell and of taste must be highly developed by training in the field of experience. The eye and touch must also be trained by special experience.

Score-cards.-For convenience, score-cards are used in keeping records of the results of scoring where many samples are examined. The following form illustrates a commercial score-card: 
NAME OR NUMBER IDENTIFYING SAMPLE........

JUDGE. . . . . . . . .

\begin{tabular}{|c|c|c|c|c|c|}
\hline QUALITY & SCORE-POINTS & $\begin{array}{c}\text { Sample } \\
1\end{array}$ & $\begin{array}{c}\text { Sample } \\
2\end{array}$ & $\begin{array}{c}\text { Sample } \\
\mathbf{3}\end{array}$ & $\begin{array}{c}\text { Sample } \\
4\end{array}$ \\
\hline Flavor............... & 45 & 45 & 40 & 36 & 32 \\
\hline Texture.............. & 10 & 8 & 10 & 8 & 7 \\
\hline Body................ & 10 & 10 & 8 & 8 & 7 \\
\hline Moisture........... & 5 & 5 & 3 & 4 & 4 \\
\hline Color................ & 15 & 13 & 14 & 13 & 12 \\
\hline Salt................ & 10 & 10 & 10 & 10 & 8 \\
\hline Appearance........ & 5 & 4 & 5 & 4 & 5 \\
\hline & & 95 & 90 & 83 & 75 \\
\hline
\end{tabular}

These scores, under the system of grading described below, would be graded as follows: Sample I, "extras;" sample 2, "firsts;" sample 3, "seconds;" and sample 4, "thirds."

In commerical scoring, reasons for the number of points given are not stated; but in dairy schools and competitive public exhibitions, where educational purposes are in view, the reason for each score should be given. The following form of score-card for such purposes is a suggestion, which may be modified to suit any special conditions:

\section{Butter-Scoring-Numerical and Descriptive Card} Date ........... Judge ..........

Name or number identifying butter ........ 
NUMERICAL SCORE.

Perfection-Flavor, Texture, Body, Moisture, Color, Salt, Appearance (45) (10) (10) (5) (15) (10) (5)

Score given

DESCRIPTIVE sCORE (check defects below).

\begin{tabular}{|c|c|c|c|c|c|c|}
\hline Flavor & Texture & Body & Moisture & Color & Salt & $\begin{array}{c}\text { Appear } \\
\text { ance }\end{array}$ \\
\hline Perfect Quick & Perfect & Perfect & Perfect & Perfect & Perfect & Finish \\
\hline Clean Light & Poor - & & & & & \\
\hline Buttermilk & grain & Firm & $\begin{array}{r}\text { Exces- } \\
\text { sive }\end{array}$ & I,ight & Too salty & Package \\
\hline Rancid & Salvy & Hard & Milky & High & Flat & \\
\hline Tallowy cowy & & $\begin{array}{l}\text { Weak- } \\
\text { bodied }\end{array}$ & & Reddish & Gritty & \\
\hline Fishy Tainted & & Sticky & & Mottled & Uneven & \\
\hline $\begin{array}{l}\text { Stable Weedy } \\
\text { Cheesy }\end{array}$ & & & & $\begin{array}{l}\text { Wavy } \\
\text { Specks }\end{array}$ & & \\
\hline
\end{tabular}

\section{CLASSES AND GRADES OF BUTTER}

The following system for classifying and grading butter is taken from the regulations of the New York Mercantile Exchange:

\section{Classification :-}

I. Creamery Butter includes butter made in a creamery from cream obtained by the separator system, or from gathered cream.

2. Imitation Creamery Butter includes butter churned by the dairyman, collected in its unsalted, unworked condition, and worked, salted and packed by the dealer or shipper.

3. Dairy Butter includes such as is made, salted and packed by the dairyman and offered in its original packagé.

4. Factory Butter is butter collected in rolls, lumps, 
or in whole packages, and reworked by the dealer or shipper.

5. Renovated Butter is that made by taking pure butter and melting the same and rechurning with fresh milk, cream or skim-milk, or other equivalent process.

6. Grease consists of all gradës of butter below Fourths free from adulteration.

7. Known Marks is a term used to include such butter as is known to the trade under some particular mark or designation and must grade as Extras, if creamery, and as Firsts, if reworked butter, in the season in which it is offered, unless otherwise specified.

Grades:-Grades of butter must conform to all the following requirements and are not determined by score alone.

I. Extras must be of the highest grades of butter made in the season when offered under the different classifications; 90 per cent. shall be up to the following standard and the balance must not grade below Firsts :

(I) Flavor must be fine, sweet, clean and fresh, if of current make; and fine, sweet and clean, if held. (2) Body must be firm, smooth and uniform. Color should be a light straw shade, even and uniform. (4) Salt should be medium. (5) Package should be good, uniform and clean. (6) Score must average 93 points or higher.

2. Firsts is a grade just below Extras and must be fine butter for the season when made and offered, under the different classifications, and up to the following standard: 
(I) Flavor must be good, sweet, clean and fresh, if of current make; and good, sweet and clean, if held. (2) Body must be good and uniform. (3) Color must be reasonably uniform, neither too high nor too light. (4) Salt should be medium. (5) Packages should be good and uniform. (6) Score must average 87 points or higher.

3. Seconds is a grade just below Firsts and must be good for the season when offered under the different classifications, and up to the following standard:

(I) Flavor must be reasonably good and sweet. (2) Body, if creamery or dairy, must be solid-boring. If factory or renovated, must be 90 per cent. solid-boring. (3) Color must be fairly uniform. (4) Salt may be high, medium or light. (5) Package should be good and uniform. (6) Score must average 80 points or higher.

4. Thirds is a grade just below Seconds.

(I) Flavor must be reasonably good; may be strong on top and sides. (2) Body should be fair-boring, if creamery or dairy, and at least 50 per cent. boring a full trier, if factory or renovated. (3) Color may be irregular. (4) Salt may be high, light or irregular. (5) Packages should be fairly uniform. (6) Score must average 75 points or higher.

5. Fourths is a grade just below Thirds and may consist of promiscuous lots.

(I) Flavor may be off and strong on tops and sides. (2) Body is not required to draw a full trier. (3) Color may be irregular. (4) Salt may be high, light, or irregular. (5) Package may be of any kind mentioned at time of sale. 


\section{SAMPLING AND TESTING CHEESE}

Only the ordinary American cheese, usually made by the cheddar system, is here considered. For commercial testing, cheese is sampled by a cheese-trier in much the same manner as butter. The plug should always be drawn from the top and not from the side in order to avoid injuring the protective power of the bandage. The plug drawn is examined by smelling, feeling, appearance, etc., in reference to the various qualities mentioned below.

\section{TERMS USED IN DESCRIBING QUALITIES OF CHEESE}

The following qualities have been selected to serve as a basis in the commercial testing and scoring of cheese: (1) Flavor, (2) texture, (3) body, (4) color, (5) salt, and (6) appearance.

Flavor.-By flavor is meant the quality that is perceptible to the smell and taste. The sense of smell is depended upon in testing flavor in cheese much more largely than is the sense of taste, because, in examining a large number of samples of cheese in succession, constant tasting soon dulls not only the sense of taste but also that of smell. Flavor in cheese is due to the formation of some unknown compound or compounds during the ripening process.

Testing flavor in cheese.-The flavor is best obtained by direct smelling of the plug as soon as it is drawn and, in addition, by crushing and warming some of the cheese in the hand and then smelling.

Terms used in describing cheese flavors.-From a great variety of names applied to various flavors 
found in cheese, the following terms are selected for consideration: (I) Perfect, (2) high or quick, (3) clean, (4) low or flat, (5) strong, (6) too much acid, (7) too little acid, (8) sour, (9) sweet or fruity, (I0) rancid, (II) tallowy, (I2) tainted, (I3) stable, (I4) weedy, (I5) bitter, (I6) cowy.

(I) Perfect flavor applies to cheese when it somewhat resembles that of first-class butter with an added quality of its own that is characteristic but cannot be described further than to call it cheese-like. It is sometimes described as "nutty." This flavor should be marked, but not strong. It should be free from all other flavors, particularly the more or less offensive products of undesirable fermentations. The taste should be mild and somewhat lasting, but should not be so sharp as to "bite" the tongue.

(2) High or quick flavor is a delicate flavor that disappears quickly.

(3) Clean flavor is free from every trace of unpleasant aroma or taste.

(4) Low or flat flavor applies to slight traces, or absence, of flavor; it is insipid.

(5) Strong flavor is a good flavor very pronounced but free from everything offensive; it is a good flavor strongly developed.

(6) Too much acid applies to flavor that smells somewhat sour but does not taste sour.

(7) Too little acid applies to a mild flavor, lacking in character.

(8) Sour flavor is characterized by a sour taste when the cheese is fresh, owing to the presence of too much whey. 
(9) Sweet or fruity flavor is suggestive of artificial pineapple odor and is somewhat "sickish."

(I0) Rancid flavor is that of butyric acid, more common in old cheese than in young. When very strong, it affects a delicate throat with a slight sensation of choking or strangling.

(II) Tallowy flavor is like that of tallow.

(I2) Tainted flavor includes a variety of odors, mildly to strongly offensive.

(I3) Stable flavor suggests the smell of cow. manure.

(I4) Weedy flavor applies to such abnormal flavors as come from onions, leeks, cabbages, ragweed, etc.

( I5) Bitter flavor is self-descriptive. It is often due to certain fermentations that develop when a cheese is undersalted.

(16) Cowy flavor is suggestive of the breath of a cow and may develop in cheese from some form of fermentation.

Texture.-Texture, as applied to cheese, refers chiefly to compactness or appearance of solidity, and has a meaning quite different from what it has when used with reference to butter. It is quite common to regard the "body" as a part of the texture, but the two qualities are clearly distinct.

Testing texture in cheese.-The texture of cheese is tested by an examination of the plug with reference to the presence of holes. The plug is broken in two and the broken ends examined for the characteristic flinty appearance.

Terms describing texture.-The following terms are among those most commonly used in describing 
texture: (I) Perfect, (2) close, (3) loose, (4) mechanical holes, (5) gas or pin-holes, (6) Swiss holes.

(I) Perfect texture in cheese is shown when a plug or a cut surface of the inside of the cheese presents to the eye a solid, compact, continuous appearance, free from breaks, holes and chunks. When a plug is broken in two, it should show a flaky appearance, termed a "flinty" break, resembling the surface of broken flint or steel.

(2) Close texture describes the appearance of a cut surface of cheese when free from all kinds of holes.

(3) Loose or porous texture is indicated by lack of solid compactness, being more or less full of holes, which vary from a few to enough to make a spongy appearance.

(4) Mechanical holes in cheese are irregular, open spaces, caused by the incomplete cementing of the pieces of curd in the press.

(5) Gas-holes or pin-holes are small holes, produced by gaseous products of fermentation.

(6) Swiss holes are fairly large, round holes, such as are present in Emmenthaler cheese.

Body.-This term, used in connection with cheese, refers to the consistency, firmness or substance of cheese. It is largely influenced by the amount of fat and moisture in cheese.

Testing body.-This quality is found by pressing a piece of cheese between the thumb and fingers.

Terms describing body.-The following terms are among those used in describing the body of cheese: (1) Perfect, (2) solid or firm, (3) smooth, (4) silky, (5) waxy, (6) pasty or salvy, (7) stiff, corky, or 
curdy, (8) weak-bodied, (9) mealy, (Io) gritty, (II) watery, (I2) over-dry.

(I) Perfect body in cheese is indicated when it feels solid, firm and smooth in its consistency or substance. It does not crumble under pressure. A plug drawn from a cheese of perfect body should be smooth in appearance and not "fuzzy."

(2) Solid or firm body is indicated when cheese offers a certain amount of resistance under pressure, somewhat like that shown by a piece of fat pork or cold butter. The term meaty is also used.

(3) Smooth-bodied cheese, when pressed between the thumb and fingers, feels smooth and velvet-like, as distinct from harsh, gritty or mealy.

(4) Silky-bodied cheese is smooth in feeling but not over-solid in consistency.

(5) Waxy-bodied cheese is much the same as silky but possessing more firmness or solidity.

(6) Pasty or salvy cheese is very soft, usually from an excess of moisture. When pressed, it sticks to the fingers.

(7) Stiff, corky or curdy cheese is hard, tough, overfirm; it does not crush down readily when pressed in the hand.

(8) Weak-bodied cheese is very soft, lacking in firmness but not necessarily sticky like pasty cheese.

(9) Mealy cheese breaks down in fine crumbs when pressed.

(I0) Gritty-bodied cheese feels harsh and gritty under pressure.

( I I ) Watery-bodied cheese is excessively soft, pasty and sticky. 
(12) In an over-dry cheese the body is very hard or mealy.

Color.-The color of cheese varies considerably, whether artificially colored or not. There appears to be an increasing demand for uncolored cheese. The coloring varies from a pale yellow to a reddish yellow, according to the demands of special markets.

Testing color.-The color is tested by inspection with the eye, the examiner noticing particularly unevenness and any extreme condition of color.

Terms describing color.-Color in cheese is described by the following terms: (I) Perfect, (2) straight, (3) translucent, (4) white specks, (5) streaked, (6) wavy, (7) mottled, (8) acid-cut, (9) high, ( Io) light, (II) uncolored.

(I) Perfect color in cheese is indicated by evenness of color throughout the mass. A plug held between the eye and light should appear somewhat translucent.

(2) Straight color is an even, uniform color through the whole cheese.

(3) Translucent applies to color in cheese which appears slightly translucent when the plug is held between the eye and the light.

(4) White specks is a term that describes itself. Such specks in cheese are a defect. They may appear in cheese cured at low temperature.

(5) Streaked color indicates that there are lightcolored portions in the form of streaks.

(6) Wavy color applies to lighter portions appearing in the form of waves.

(7) Mottled color shows in cheese in lighter-colored spots of fairly large size, more or less irregular. 
(8) Acid-cut color is shown in cheese when considerable portions of the cheese have been made lighter in color by the presence of too much acid (whey).

(9) High color is indicated by a reddish color, caused by using too much coloring matter. However, the question of color is a relative one, because the demand in different markets varies from uncolored to extremely high color.

(10) Light color is the term usually used in describing cheese that has been made uniformly dead white by the action of too much acid (whey).

(II) Uncolored cheddar cheese is not white but of a light amber shade.

Salt.-The amount of salt in cheese varies somewhat with different markets. There is seldom experienced difficulty of uneven salting in cheese, because the salt slowly permeates the cheese in the ripening process. Little variations usually occur in different parts of the same cheese, but are so slight as to be incapable of being noticed by ordinary methods of examination.

Testing cheese for salt.-The quality of cheese as influenced by the salt is found simply by tasting.

Terms used in describing salt.-In describing the relation of salt to cheese, the following terms are used: (1) Perfect, (2) too much, (3) too little.

(I) Perfect applies to salt in cheese when just enough has been used to impart a sufficient taste of salt.

(2) Too much salt is indicated by salty taste. Too much salt in cheese causes a dry, mealy texture, overfirm body and imperfect flavor.

(3) Too little salt is shown by insipidity of taste. 
It is usually accompanied by bitter flavor and porous texture.

Appearance.-This term refers to the general appearance of the cheese to the eye in respect to uniformity, neatness and cleanliness. It may also include the boxing. One system, as in the case of butter, describes under "finish" the appearance of the cheese, and under "packages" the boxing; and we will follow this method here.

Testing appearance.-When the cover of the box is removed for sampling, in the case of boxed cheese, the appearance of the cheese is noticed and the box itself is examined. Cleanliness and neatness are the points to observe in judging appearance.

Terms describing appearance.-The general terms used in describing appearance are (I) finish and (2) package.

(I) Finish in appearance, in order to be perfect, must meet the following requirements: The rind must be smooth, even in color, free from cracks and fairly hard. The bandage must be without wrinkles and must be neatly rounded over the edges about an inch and a half on each end of the cheese. The sides of the cheese should be straight and of uniform height all around.

The faults of appearance in finish are as follows, the terms being self-descriptive: (I) Cracks, (2) light spots, (3) roughness in rind, (4) uneven edges, (5) wrinkles in bandage, (6) lack of uniformity in ends and in height, (7) bulging out at sides or ends.

(2) Packagc.-The packages or boxes are regarded as perfect when of good material, well made, strong, 
clean, close-fitting, uniform in size and in undamaged condition.

\section{SCORING CHEESE}

The qualities described in the preceding pages are used for judging and fixing the commercial value of cheese.

Scale of points.-The following scale of points is in use in many places, the numbers indicating perfect quality in each case and the totals aggregating Ioo:
Flavor, 50
Body, 15
Salt, 5
Texture, 15
Color, 10
Appearance, 5

In the practice of many markets, salt is omitted and appearance is given Io points.

Method of scoring.-The general procedure is essentially the same as that already described in connection with butter (p. 160).

Method of grading cheese.-The same general principles apply as in grading butter (p. I7 I). One classification is into (I) "fancy," (2) "firsts," and (3) "seconds." In the Canadian market, there are first, second and third grades.

Score-cards for cheese can be prepared in a manner similar to those previously suggested for butter (p. I70).

As in the case of butter, the testing, scoring and grading of cheese demand good judgment trained by experience. The sense of smell and touch must be well developed.

No formal classification or grading of cheese is made by the New York Mercantile Exchange, as is done in the case of butter. 


\section{CHAPTER XIV}

\section{Methods of Commercial Testing and Scoring of Milk and Cream}

In the past few years, there has been a growing sentiment that some method of testing the commercial value of milk and cream, similar to that used in judging butter and cheese, is much needed. Some helpful work has been done in this direction by the Dairy Division of the U. S. Department of Agriculture. The writer believes an efficient system will be developed in the near future, and, as a basis for such a system, the present discussion is offered.

For convenience of treatment, we will classify milk and cream according to the purposes for which they are used, as follows: (I) Market milk and cream, when sold for direct consumption as such. (2) Creamery milk and cream, when used for butter-making. (3) Cheese-factory milk, when used for cheese-making. (4) Certified and standardized milk, when produced under specific sanitary conditions and reaching a guaranteed standard of composition.

\section{TERMS USED IN DESCRIBING QUALITIES OF MARKET MILK}

The qualities that are selected as a basis in the commercial testing and scoring of milk are the following: (I) Composition, (2) keeping-power, (3) flavor, and, we may add, though of minor importance, (4) color, 
and (5) appearance. For all practical purposes color and package can be omitted. In educational competitions they may be included.

Composition.-By composition is meant the per cent. of fat and of solids-not-fat in milk. The composition of milk, other things being equal, is the direct and only practicable measure of value as food, and this must constitute an important factor in judging the value of market milk.

Testing composition.-The percentages of fat and of solids-not-fat are found in the manner described on p. 53 and p. I 37 .

Terms describing composition.-Only two terms need to be used in describing the composition of milk: (I) perfect and (2) defective.

( I) Perfect, as applied to testing and scoring milk, means milk containing not less than 4 per cent. of fat and not less than 9 per cent. of solids-not-fat.

(2) Defective applies to milk containing less fat or solids-not-fat than required for milk of "perfect" composition.

The figures selected to indicate milk "perfect" in composition represent as nearly as possible normal milk of average composition. Injustice would obviously be done by selecting 4.5 or 5 per cent. as the amount of fat to represent milk perfect in composition. It would, on the other hand, be very unsatisfactory to take a so-called legal standard as representing perfect composition, because it is not a standard at all but simply, a method of prescribing the lowest permissible amounts of fat and solids that will be legally tolerated in milk. 
Keeping-power is an expression used to indicate in a general way the length of time milk remains sweet and palatable for direct consumption. In estimating the commercial value of milk, this is an important factor; since milk that is sour or otherwise unpalatable, or milk containing the products of any form of undesirable fermentation, is comparatively valueless for direct consumption, however rich it may be in fat and other solids. Keeping-power is a matter of much importance in warm weather, especially in the case of milk that is transported long distances before reaching the consumer.

Testing keeping-power.-The keeping-power of milk is tested by making determinations of (I) the acidity (p. 96), (2) the dirt in suspension (p. II ), (3) the fermentation test (p. I I4), and (4) the number of bacteria (when practicable).

Terms describing keeping-power.-The terms used in describing the keeping-power of milk are (I) perfect, (2) acidity, (3) dirt ir suspension, (4) undesirable fermentations, and (5) number of bacteria per cubic centimeter.

(I) Perfect.-Milk is called perfect in keepingpower (a) when its acidity is not above 0.18 per cent., (b) when it contains no dirt in suspension, (c) when the fermentation test reveals nothing abnormal, and (d) when the number of bacteria does not exceed IOO,000 per cubic centimeter.

(2) Acidity is used to mean the amount of apparent total acid calculated as lactic, as shown by the amount of alkali neutralized. For discussion of the relation of acidity to the temperature and cleanliness of milk, see pp. II3-II4. 
(3) Dirt in suspension. The amount of dirt suspended in milk may usually be regarded as a rough measure of the germ content or cleanliness of milk, since the visible dirt we find in milk is generally the same in source and kind.

(4) Undesirable fermentations refer to the results of the fermentation test. They may reveal themselves in causing porous, spongy curd and in producing offensive odors.

(5) Number of bacteria per cubic centimeter is a self-descriptive term.

Flavor, applied to milk, is used to mean the odor and taste. The abnormal odors and tastes noticeable in market milk, otherwise good, come from three sources: (I) From certain things eaten by the cow, as leeks, onions, rag-weed, cabbage, etc. (2) From the direct absorption of strong-smelling substances present in the air surrounding the milk, such as manure, tobacco smoke, ensilage, etc. (3) From stable filth dropping bodily into the milk.

Testing flavor.-This is done by tasting and smelling the milk. The presence of abnormal odors can be more readily perceived by heating the milk for a few minutes to $100^{\circ} \mathrm{F}$. in a closed bottle or jar and then smelling at once on opening the vessel.

Terms describing flavor.-The following terms may be used in describing the flavor of market milk: (I) Perfect, (2) stable or cow manure, (3) cowy or animal, (4) weedy, caused by leeks, rag-weed, etc., (5) vegetable, such as cabbage, turnip, ensilage, etc., (6) bitter, (7) fishy, (8) sour, (9) tainted.

(I) Perfect flavor in market milk is indicated by 
freedom from all traces of abnormal odor and taste. There should be no marked odor and no trace of any offensive smell. The taste should be palatable, slightly saline and rich, without any unpalatable after-taste. It should not be flat or insipid.

The other terms are mostly self-descriptive. Their number could be extended to cover more minute details. The term tainted is used to cover miscellaneous offensive flavors not included under other terms.

Color in relation to the testing and scoring of market milk explains itself. It is in itself of little practical importance and may usually be omitted except in case of educational competitions.

Testing color.-The milk is examined for color by direct inspection in a clear light.

Terms describing color.-In describing the color of market milk, the following terms may be used: (I) Perfect, (2) white, (3) bluish, (4) high color, (5) reddish.

(I) Perfect as applied to color in milk indicates a yellowish color, not too pronounced, strikingly different from the white or bluish color of skim-milk, but not as deep as the color of cream.

The other terms explain themselves. High color may be caused by artificial coloring, usually producing a reddish tint.

Appearance.-This term refers to the appearance of the can, bottle or other vessel containing the milk and applies to these in respect to uniformity, neatness and cleanliness. This is of relatively small practical importance and may usually be omitted in commercial work. It finds a use in educational competitions. 


\section{SCORING MARKET MILK}

The qualities described above are intended for use in the commercial judging and scoring of market milk. For practical purposes it will be sufficient ordinarily to make use of the first three qualities mentioned, viz: (I) composition, (2) keeping-power, and (3) flavor.

Scale of points.-In fixing a scale of points, we have a score of 100 to distribute among the three qualities last mentioned. How many points of the roo shall be assigned to each? Here is a chance for wide variation of opinion. In actual experience, flavor does not hold the same important relation to market milk that it does to cheese and butter. A flavor that is imperceptible in the ordinary consumption of milk usually becomes concentrated in the process of butter-making or cheese-making and seriously affects the quality of the final product. A flavor must be very bad to render milk useless for cooking or for purposes other than direct drinking. Hence, flavor should not receive so high a score in the case of market milk as in the case of butter or cheese. On the other hand, composition should receive a relatively high score, since, other things being equal, it alone governs the relative values of different milks. The importance of keeping-power has already been considered. For the various reasons given, the following scale of points is suggested as a desirable one for practical use:

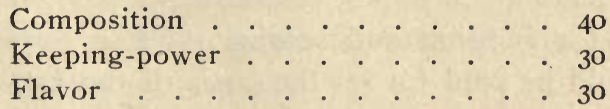


The numbers indicate perfect quality in each case and the totals aggregate Ioo. The numbers assigned could be varied considerably and still give equally satisfactory results in practise.

Method of scoring.-The milk is examined in the manner previously described and defects are indicated by making deductions from the perfect score in the following manner:

(I) Composition.-The perfect score of 40 points is reduced one point for each O.I per cent. below 4 per cent. of fat and one point for each o.I per cent. below 9 per cent. of solids-not-fat.

(2) Kecping-power.-The perfect score of 30 is to be reduced (a) one point for each o.or per cent. of acidity above 0.18 ; (b) a certain number of points, according to the judgment of the examiner, for dirt in suspension; (c) a certain number of points for any abnormal results shown by the fermentation test; and (d) one point for each 100,000 bacteria above 100,000 in I cubic centimeter of milk, when this determination is made.

(3) Flavor.-The perfect score of 30 is reduced by the presence of abnormal odors or tastes, the examiner using his judgment as to the amount of reduction.

\section{JUDGING MILK FOR MANUFACTURE OF BUTTER AND CHEESE}

For milk that is to be used for butter-making or cheese-making, a somewhat different method is suggested for judging and scoring. Since such milk is or should be paid for on the basis of the fat, the sys- 
tem of judging and scoring should be such as to affect the value or the amount of the fat for which payment is received. Such a method is given in the following statements :

(I) Score the milk directly for two qualities only, (a) keeping-power and (b) flavor. For perfection, allow 50 points for keeping-power and 50 points for flavor.

(2) From the total amount (pounds) of fat contained in the milk furnished by each patron, deduct, according to the results of scoring, a certain amount of fat, which is found by multiplying the total amount of fat in the milk by 0.25 per cent. and this result by the number of points scored below IOO.

(3) Use the number of pounds of fat thus found as the actual amount of fat on which to base dividends. To illustrate, a patron furnishes $\mathrm{I}, 000$ pounds of milk, containing 4 per cent. of fat, which scores 90 in keeping-power and flavor. What deduction shall be made from the fat for the score of 90 ? The amount ( 1,000 pounds) of milk furnished contains 40 pounds of fat. This number (40) multiplied by 0.25 per cent. (Rule I, p. 193) equals o.I pound of fat, which multiplied by Io, the number of points scored below Ioo, equals I pound. The total amount (40 pounds) of fat, diminished by the subtraction of $\mathrm{I}$, leaves 39 pounds, which amount would be used as a basis in making this patron's dividend.

The judging of flavor and keeping-power is carried out as previously described for market milk. In cheese-making, it is important to make full use of the fermentation test (p. I I4). 


\section{COMMERCIAL TESTING AND SCORING OF CER- TIFIED AND STANDARDIZED MILK}

Certified milk usually guarantees (I) the per cent. of fat, (2) the per cent. of total solids or solids-notfat, and (3) bacteria below a specified number., Standardized milk usually guarantees only the per cent. of fat.

The examination and scoring of certified or of standardized milk are conducted in the same manner as in the case of market milk, except that the scoring is based upon the guarantees, so far as these are given. The guaranteed per cent. of fat and of solids-not-fat and the number of bacteria are to be taken as representing the perfect score in place of the figures given above for market milk, and deductions from the perfect score for defects are made on the basis of the guarantees. For example, if a certified milk is guaranteed to contain 5 per cent. of fat, then, in order to score 40 in composition, the milk must contain 5 per cent. of fat and, in case of any shortage, a proportionate deduction should be made from the perfect score of 40 .

\section{COMMERCIAL TESTING AND SCORING OF CREAM}

Market cream is that which is sold for direct consumption. The method of examining and scoring market cream is essentially the same as in the case of market milk. In composition, cream is not examined or scored for solids but for fat only. Another quality might be added in case of cream, that of body, 
by which is meant the consistency of the cream, especially with reference to the presence or absence of lumps, complete evenness of consistency being required for perfection of body.

In composition, not less than 20 per cent. of fat should be used as a basis for perfection and from the perfect score of 40 is deducted one point for each 0.5 per cent. of fat below 20. Acidity and flavor are of special importance in market cream. The acidity should not be allowed to be above 0.2 per cent. for perfect cream.

Creamery cream is that which is intended for butter-making. The same general procedure is employed as in the case of milk that is to be used for buttermaking, which, adapted to cream, is as follows :

(I) Score the cream directly for two qualities only, (a) keeping-power and (b) flavor. For perfection allow 50 points for each quality.

(2) From the total amount (pounds) of fat contained in the cream furnished by each patron deduct, according to the results of scoring, a certain amount of fat, which is found by multiplying the total amount of fat in the cream by 0.25 per cent. and this result by the number of points scored below roo.

(3) Use the number of pounds of fat thus found as a basis for making dividends.

To illustrate, a patron furnishes 500 pounds of cream, containing 20 per cent. of fat, which scores 90 in keeping-power and flavor. What deduction shall be made from the fat for the score of 90 ? The amount (500 pounds) of cream furnished contains Ioo pounds of fat. This number (IOO) multiplied by 0.25 per 
cent. (Rule I, p. I93) equals 0.25 pound of fat, which multiplied by Io, the number of points scored below IoO, equals 2.5 pounds. The total amount ( IOO pounds) of fat, diminished by the subtraction of 2.5 , leaves 97.5 pounds of fat, which amount would be used as a basis in making this patron's dividend. 


\section{CHAPTER XV}

\section{Arithmetic of Milk and Milk Products}

In connection with the testing of milk and milk products, especially in some of the practical applications, various arithmetical calculations are often necessary. Special attention may need to be given to the methods employed in solving such problems as are presented, and a few pages are here devoted to the treatment of some of the more common problems in a systematic, comprehensive form, convenient for ready reference. In creameries, cheese-factories, etc., where - much arithmetical work is involved in making dividends, saving of time is effected by using calculations or tables, which are published in book form.

\section{FINDING WEIGHT OF ANY CONSTITUENT}

Rule.-To find the weight of any constituent in milk or milk products, when the weight of the milk or its product and the per cent. of the constituent are known, multiply the weight by the number indicating the per cent. of the constituent and divide the result by 100. Example: How many pounds of fat in 675 pounds of milk testing 4.6 per cent. of fat? $\frac{675 \times 4.6}{100}=31.05$, the number of pounds of fat. 


\section{EXAMPLES FOR PRACTICE}

( I) How many pounds of fat in 2,000 pounds of cheese containing 35 per cent. of fat?

(2) How much water in 1,000 pounds of butter containing 14.5 per cent. of water?

(3) How many grams of milk-sugar are there in 500 grams of milk containing 5 per cent. of milksugar?

(4) How much fat is there in 1,200 pounds of cream testing 44 per cent. of fat?

(5) How much fat is there in 5,000 pounds of skimmilk testing .15 per cent. of fat?

\section{FINDING PER CENT. OF ANY CONSTITUENT}

Rule.-To find the per cent. of any constituent in milk, etc., when the weight of the milk, etc., and the weight of the constituent are known, multiply the weight of the constituent by 100 and divide the.result by the weight of the milk, etc. Example: What is the per cent. of fat in 675 pounds of milk containing 31.05 pounds of fat? $\frac{31.05 \times 100}{675}=4.6$ per cent.

\section{EXAMPLES FOR PRACTICE}

(I) What is the per cent. of fat in 120 pounds of butter containing 96 pounds of fat?

(2) What is the per cent. of water in 600 pounds of cheese containing 210 pounds of water? 


\section{FINDING PER CENT. OF SOLIDS IN MILK}

Rule.-To find the per cent. of solids in milk when the Quevenne lactometer reading and the per cent. of fat are known, divide the lactometer reading by 4, and to the result add the per cent. of fat multiplied by I.2. (See p. I37.)

\section{FINDING PER CENT. OF SOLIDS-NOT-FAT IN MILK}

Rule.-To find the per cent. of solids-not-fat in milk when the Quevenne lactometer reading and the per cent. of fat are known, divide the lactometer reading by 4, and to the result add the per cent. of fat multiplied by .2. (See p. I37.)

\section{EXAMPLES FOR PRACTICE UNDER RULES 3 AND 4}

(I) What is the per cent. of solids in milk testing 4 per cent. of fat and showing a lactometer reading of 32 ?

(2) What is the per cent. of solids-not-fat in the same milk as in ( $\mathrm{I})$ ?

(3) What is the per cent. (a) of solids and (b) of solids-not-fat in a milk testing 2.5 per cent. of fat and showing a lactometer reading of 27 ?

(4) What is the per cent. (a) of solids and (b) of solids-not-fat in milk testing .2 per cent. of fat and showing a lactometer reading of 36 ? 


\section{FINDING THE “OVERRUN" IN BUTTER- MAKING}

The weight of butter produced is greater than the amount of fat in the milk or cream from which the butter is obtained, because butter, in addition to its fat, contains water, salt and curd. Such excess is called the "overrun" and may be readily ascertained by finding the yield of butter for one pound of fat. While some milk-fat is lost in the skim-milk and buttermilk and in handling during butter-making, enough water, salt and curd are added to the fat to make up these losses and something more. The amount of butter yield for a pound of fat in milk or cream necessarily varies with the variation of losses of fat in skimmilk and in butter-making and the amount of water, salt, etc., retained in the butter. Hence the "overrun" varies. When the operations of skimming milk and butter-making are properly managed, one pound of fat in milk produces about I.I7 (about I I-6) pounds of butter. Hence, the "overrun" is .17 or one-sixth, (I7 per cent). The "overrun" in case of cream averages about .03 higher than in case of milk, according to Hills.

Rule.-To find the "overrun" when the weight of butter made from a given amount of milk or cream and the per cent. of fat in the milk or cream are known, find the number of pounds of fat in the milk or cream by Rule I, and divide the weight of butter by the weight of fat. From the result subtract $\mathbf{I}$. Example: What is the "overrun" in case of milk testing 4 per cent. of 
fat, when we make I 35 pounds of butter from 3,000 pounds of milk? Applying Rule $\mathrm{I}, \frac{3000 \times 4}{100}=120$, pounds of fat in milk; and $135 \div 120=1.125$ ( $\mathrm{I} / 8$ ) pounds. $I . I 25-I=.125$ ( 12.5 per cent.) or $I / 8$. Therefore, the "overrun" is .I25 or $1 / 8$ pound, that is, for each pound of fat in milk there will be made $1 / 8$ pounds of butter.

\section{FINDING THE YIELD OF BUTTER}

Rule.-To find the yield of butter when the per cent. of fat in milk and the weight of milk are known, find the number of pounds of fat in milk by Rule I and multiply this result by I.I7 or I I-6. Example: How much butter is made from $\mathrm{I}, 000$ pounds of milk containing 4 per cent. of fat? Applying Rule I, $\frac{1000 \times 4}{100}=40$, pounds of fat in milk; and $40 \times 1.17=$ 46.8 , pounds of butter yield.

In the case of cream apply the foregoing rule, except to multiply by I.2O instead of I.I7.

The application of this rule finds use in checking creamery work. If the yield, in case of milk, is not in proportion to an "overrun" of 15 to 17 per cent, and in case of cream, 20 per cent., one should ascertain why and then correct such faults as are found to exist in the form of losses of fat or retaining too little water. When the proportion of butter to fat greatly exceeds I.I7 in the case of milk, too much water is retained in the butter, or else the fat-test is improperly made or the results purposely read too low. 


\section{EXAMPLES FOR PRACTICE UNDER RULES 5 AND 6}

(I) How much butter should be made from 5,000 pounds of milk testing 5 per cent. of fat?

(2) What is the "overrun" when 4,000 pounds of milk, testing 4 per cent. of fat, yield 180 pounds of butter?

(3) A butter-maker has I0,000 pounds of milk, testing 4 per cent. of fat; in skimming this, he produces 8,000 pounds of skim-milk, testing .15 per cent. of fat. After churning, he has 1,600 pounds of buttermilk testing .2 per cent. of fat. The loss of fat in handling the cream and making the butter amounts to 4 pounds. (a) How much fat is left in the butter? (b) How many pounds of butter should be made? (c) What is the "overrun" if he produces 450 pounds of butter?

(4) How much butter should be made from 1,000 pounds of cream testing 35 per cent. of fat?

\section{FINDING YIELD OF CHEESE FOR MILK-FAT}

Rule.-To find the yield of green cheese for a pound of fat in milk when the weight of the cheese made from a given amount of milk and the per cent. of fat in milk are known, find the number of pounds of fat in milk by Rule I, and divide the weight of cheese by the weight of fat. Example: How much cheese is made for one pound of fat in milk, testing 4 per cent. of fat, when we make 63 pounds of cheese from 600 pounds of milk? Applying Rule I, $\frac{600 \times 4}{100}=24$ pounds of fat in milk; $63 \div 24=2.67$ pounds of cheese 
made for one pound of fat in milk. In connection with cheese, this is the same kind of relation as the "overrun" in butter. In cheese-making a pound of fat in milk has added to it enough casein, water, salt, etc., to increase the weight from I of fat to 2.7 (more or less) pounds of cheese.

\section{FINDING YIELD OF CHEESE FROM FAT IN MILK}

Rule.-To find the yield of green cheese from 100 pounds of milk when the per cent. of fat in milk is known, multiply the per cent. of fat in milk by 2.7. Example: How much cheese should be made from 100 pounds of milk testing 3.7 per cent. of fat? $3.7 \times 2.7=$ 9.99 pounds.

This rule applies only to normal milk containing 3.6 to 3.8 per cent of fat. For milk containing fat above 3.8 per cent., the results are usually too high; and for milks containing less than 3.6 per cent. of fat, the results are usually too low.

\section{FINDING YIELD OF CHEESE FROM FAT AND CASEIN IN MILK}

Rule.-To find the yield of green cheese from Ioo pounds of milk when the per cent. of fat and of casein in milk is known, multiply the per cent. of casein by 2.5 and to this result add the per cent. of fat multiplied by 1.I. Example: How much cheese can be made from 100 pounds of milk containing 4 per cent. of fat and 2.6 per cent. of casein? $(2.6 \times 2.5)+(4 \times 1.1)=$ I0.90 pounds of green cheese. 


\section{FINDING PER CENT. OF CASEIN IN MILK FROM FAT}

Rule.-To find the per cent. of casein in milk when the per cent. of fat is known, subtract 3 from the per cent of fat in milk, multiply the result by .4 and add this result to 2.1. Example: How much casein is there in milk containing 4.5 per cent. of fat? $(4.5-3) \times .4+$ 2. $1=2.70$ per cent of casein.

This rule is based upon the writer's work, showing that milk testing 3 per cent of fat contains an average of about 2.I per cent of casein, and that the casein increases, on an average, 4 per cent. when the per cent. of milk increases I per cent. above 3. This is especially true of milks ranging from 3 to 4.5 per cent. of fat when the milk is produced at the same stage of lactation. In the later stages of lactation the ratio of casein to fat is greater than is indicated by this rule. (See p. 12.)

In applying Rule 9, Rule ro can be used to find the per cent. of casein in milk when only the per cent. of fat is known. For example, how much cheese can be made from 100 pounds of milk containing 4.25 per cent. of fat? By Rule Io, $(4.25-3) \times .4+2.1=2.6$, the per cent. of casein in the milk. Then by Rule 9, (2.6 $\times 2.5)+(4.25 \times 1.1)=I 1.18$ pounds.

The above rule can be used in finding the amount of casein and albumin together, the factor 2.9 being added instead of 2.I. 


\section{FINDING YIELD OF CHEESE FROM FAT AND LACTOMETER}

Rule.-To find how much green cheese can be made from Ioo pounds of milk when the per cent. of fat in milk and the lactometer reading are known, find the per cent. of solids-not-fat by Rule 4, divide the result by 3 and to this add the per cent. of fat multiplied by .9I, and finally multiply the result by 1.58 .

This rule was devised by Dr. Babcock and gives good results. It may be expressed also in the following form: $\left(\frac{\text { solids-not-fat }}{3}+\right.$ fat $\left.\times .9 I\right) \times 1.58$.

\section{EXAMPLES FOR PRACTICE UNDER RULES} 8 TO 11

( I) What is the per cent. of casein in milk containing (a) 3.50 , (b) 3.60 , (c) 4 , (d) 4.4 per cent. of fat?

(2) How much green cheese should be made from Ioo pounds of the different milks mentioned in the preceding example? (Apply Rule 9 and Rule Io).

(3) How much green cheese should be made from I8,ooo pounds of milk testing 3.75 per cent. of fat?

(4) How much green cheese should be made from Ioo pounds of milk testing 4 per cent. of fat and showing a lactometer reading of 33 ?

(5) What is the per cent. of casein and albumin in milk containing (a) 3.50 , (b) 3.80 , (c) 4.30 , (d) 5 per cent. of fat?

\section{FINDING DIVIDENDS ON FAT BASIS AT CREAMERIES}

Rule.-To calculate the amount of each patron's dividend at creameries on the basis of the fat in the milk, multiply the amount of the milk-fat delivered by each patron by the price of one pound of fat. 
This rule can be made more clear by considering the process in three separate steps, assuming that the creamery is operated on the co-operative plan.

Step I. By Rule I find the amount of milk-fat furnished by each patron during the dividend period.

Step 2. Find the net value of one pound of milkfat by dividing the total net receipts by the total number of pounds of fat delivered by all the patrons during the dividend period.

Step 3. Multiply the number of pounds of fat delivered by each patron by the net price received for one pound of fat.

Example: Step I. The data and results are indicated in tabular form as follows:

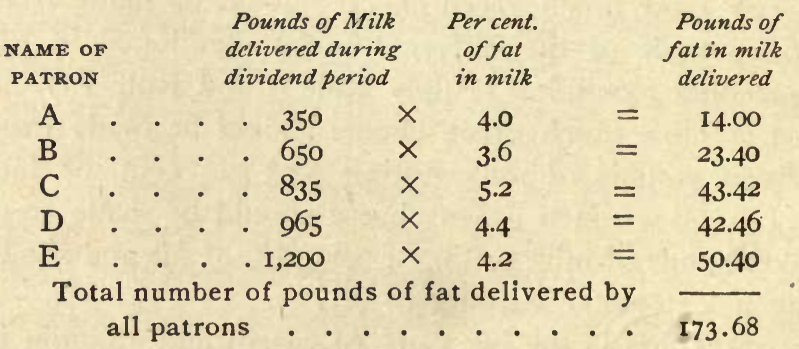

Step 2. From the amount of fat indicated above, the amount of butter made was 195 pounds, which realized 18 cents a pound after deducting all expenses, making a total of $\$ 35$.ro. This sum divided by 173.68 , the total pounds of fat delivered, gives 20.2 cents as the net price received for each pound of fat. 
Step 3. The data and results are indicated in tabular form, as follows:

\begin{tabular}{|c|c|c|c|c|c|c|c|}
\hline $\begin{array}{l}\text { NAME OF } \\
\text { PATRON }\end{array}$ & $\begin{array}{l}\text { Pounds } \\
\text { of fat } \\
\text { delivered }\end{array}$ & & & $\begin{array}{r}\text { Net } \\
\text { received } \\
\text { per po }\end{array}$ & $\begin{array}{l}\text { price } \\
\text { for fat } \\
\text { und }\end{array}$ & & $\begin{array}{l}\text { Amount of } \\
\text { dividend due } \\
\text { each patron }\end{array}$ \\
\hline A. & . 14.00 & $x$ & & 20.2 & cents & $=$ & $\$ 2.83$ \\
\hline B & - 23.40 & $x$ & & " & “ & $=$ & 4.73 \\
\hline $\mathrm{C}$ & 43.42 & $x$ & & $"$ & $"$ & $=$ & 8.77 \\
\hline D & 42.46 & $x$ & & “ & “ & $=$ & 8.58 \\
\hline $\mathrm{E}$ & 50.40 & $x$ & & " & “ & $=$ & 10. 18 \\
\hline
\end{tabular}

When both milk and cream are used in a creamery, the pounds of fat delivered in the form of cream are found by applying Step I above and then multiplying the result by I.O2. From this point on, the process of calculating dividends is the same as above described.

\section{FINDING DIVIDENDS ON FAT BASIS AT CHEESE-FACTORIES}

Rule.-To calculate the amount of each patron's dividend at cheese-factories on the basis of the fat in the milk, proceed as under Rule $\mathbf{I} 2$.

\section{FINDING AMOUNTS OF MILK, ETC., TO USE IN MODIFYING NORMAL MILK}

The practice of modifying or-standardizing milk for special market purposes is constantly increasing. This consists in increasing or decreasing the per cent. of fat in a normal milk. The per cent. of fat in a normal milk may be increased (I) by adding cream, (2) by adding milk richer in fat, or (3) by skimming part of the normal milk with a separator and then putting the cream thus obtained back into the rest of the normal milk. The per cent. of fat in a normal milk 
may be decreased without adding water, (I) by adding skim-milk, (2) by adding milk poorer in fat, or (3) by skimming part of the milk and then putting the skin-milk thus obtained back into the rest of the normal milk.

Prof. R. A. Pearson, of Cornell University, has devised an ingenious method by which one can accurately, quickly and easily find the amounts of milk, cream and skim-milk to be used in modifying or standardizing milk in order to produce a milk containing a desired per cent. of milk-fat. The following diagram and explanation may serve to make clearer the working of the method:

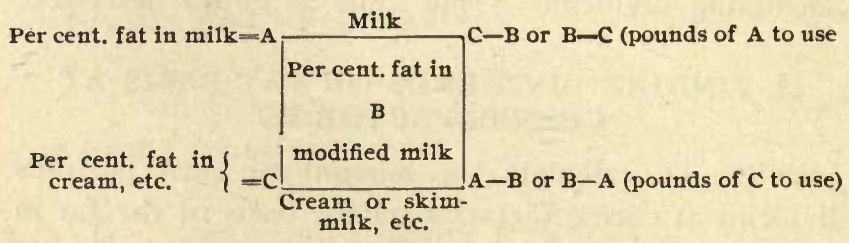

Let A represent the per cent. of fat in the milk to be modified.

Let $B$ represent the per cent. of fat desired in the modified milk.

Let $\mathrm{C}$ represent the per cent. of fat in the milk, cream or skim-milk which is to be used in increasing or decreasing the per cent. of fat.

The problem is to find in what proportions we shall use the milk, etc., containing $\mathrm{A}$ and $\mathrm{C}$, in order to obtain a product containing $\mathrm{B}$.

When the per cent. of fat in the normal milk is to be increased, $A$ is less than $B$, while $C$ is greater than B. In this case, B minus $A$ gives the pounds of 
the product containing $\mathrm{C}$ to be used, while $\mathrm{C}$ minus $\mathrm{B}$ gives the pounds of milk (A) to be used or, expressed in another way, the procedure becomes, $\mathrm{B}-\mathrm{A}=$ pounds of product containing $\mathrm{C}$ to be used, and $\mathrm{C}-\mathrm{B}=$ pounds of milk (A) to use.

When the per cent. of fat in the normal milk is to be decreased in the modified milk, the procedure is thus indicated: $\mathrm{A}-\mathrm{B}=$ pounds of product containing $\mathrm{C}$ to be used and $\mathrm{B}-\mathrm{C}=$ pounds of milk (A) to be used.

The simplicity of the method becomes readily apparent when practically illustrated.

(I) When the per cent. of fat in milk is to be increased by addition of cream or richer milk. Rule.From the per cent. of fat desired in the modified milk subtract the per cent. of fat in the milk to be modified, and the result is the number of pounds of cream or richer milk to be used. From the per cent. of fat in the cream or richer milk subtract the per cent. of fat desired in the modified milk, and the result is the number of pounds to use of the milk to be modified. Example: What relative amounts of normal milk and cream must be used to produce milk containing 4.5 (B) per cent. of fat, when the normal milk contains 3.5 (A) per cent. of fat and the cream 25 (C) per cent.?

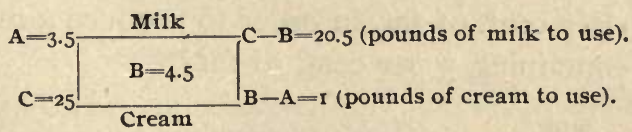

The results mean that 20.5 pounds of milk containing 3.5 per cent. of fat, mixed with I pound of cream containing 25 per cent. of fat, will produce a modified 
milk containing 4.5 per cent. of fat. If, in place of cream, a milk containing more than 3.5 per cent. of fat were used, the process would be the same.

(a) If it is desired to know how much such cream must be used in standardizing 1,000 pounds of such milk, divide $\mathrm{I}, 000$ by 20.5 ( $\mathrm{C}-\mathrm{B}$ ) and multiply by I $(\mathrm{B}-\mathrm{A}$,$) which will give 48.8$ pounds of cream to be added and ro 48.8 pounds of the modified milk.

(b) If it is desired to know how much such cream and milk to use to make 1,000 pounds of the modified milk, divide $\mathrm{I}, 000$ by $2 \mathrm{I} .5(\mathrm{C}-\mathrm{B})+(\mathrm{B}-\mathrm{A})$, which is 46.5 , and multiply this amount by $20.5(\mathrm{C}-\mathrm{B})$ and by I (B-A), which will give 953.5 pounds of 3.5 per cent. milk and 46.5 pounds of 25 per cent. cream.

(2) When the per cent. of fat in milk is to be increased by removing a portion of the milk-serum (skim-milk). Rule.-From the per cent. of fat desired in the modified milk subtract the per cent. of fat in the milk to be modified, and the result is the number of pounds of skim-milk to be removed. The per cent. of fat in the modified milk is the number of pounds to use of the milk to be modified. This is done by separating the cream from a portion of the milk and then adding it to the normal milk. The skim-milk can be assumed to contain practically no fat. Example: How much skim-milk should be removed from milk containing 3.9 per cent. of fat, in order to produce a modified milk containing 5 per cent. of fat?

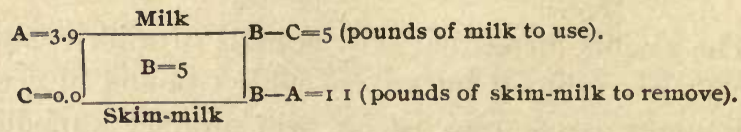


In this case we add nothing, so that $\mathrm{C}$ equals $\mathrm{o}$ and $\mathrm{B}-\mathrm{C}=5-\mathrm{O}=5$. The results mean that for 5 pounds of the milk, we should remove I.I pounds of skimmilk, thus reducing 5 pounds of milk containing 3.9 per cent. of fat to 3.9 pounds of modified milk containing 5 per cent. of fat.

Applying these results to a specific case, how much skim-milk should be removed from 980 pounds of 3.9 per cent. milk to increase the fat to 5 per cent? Divide 980 by 5 (B-C), which gives 196 , and multiply this by I.I (B-A) which gives 215.6 pounds of milk-serum or skim-milk to be removed, leaving 764.4 pounds of modified 5 per cent. milk.

(3) When the per cent. of fat is to be decreased by adding skim-milk. Rule-From the per cent. of fat in the milk to be modified subtract the per cent. of fat desired in the modified milk, and the result is the number of pounds of skim-milk to be used. From the per cent. of fat desired in the modified milk, subtract the per cent. of fat in the skim-milk, and the result is the number of pounds to use of the milk to be modified. Example: How much skim-milk containing .I per cent of fat should be added to milk containing 5 per cent. of fat to reduce the fat to 3.9 per cent.?

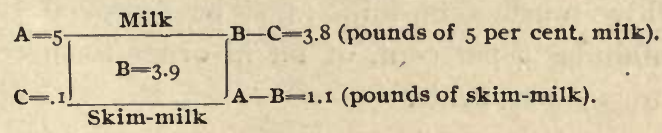

(a) How much skim-milk should be added to 1,000 pounds of 5 per cent. milk to produce 3.9 per cent. milk? Divide 1,000 by 3.8 , giving 263 , and multiply the result by I.I, which gives 289 , the number of 
pounds of skim-milk. There would be 1,289 pounds of 3.9 per cent. milk.

(b) How much skim-milk is needed to produce I,000 pounds of modified 3.9 per cent. milk? Divide I,000 by 4.9 , which gives 204.08 . This, multiplied by 3.8 , gives 775.5 pounds of 5 per cent. milk to use and, multiplied by I.I, gives 224.5 pounds of skim-milk.

\section{EXAMPLES FOR PRACTICE}

(I) What amount of milk containing 4.7 per cent. of fat, and of cream containing 30 per cent. of fat, should be mixed in order to produce 740 pounds of milk containing 6 per cent. of fat?

(2) Mix milk containing 5.2 per cent. of fat with milk containing 3.3 per cent of fat in such amounts as to produce 950 pounds of milk containing 4 .I per cent. of fat.

(3) How many pounds of separator skim-milk must be mixed with 100 pounds of cream containing 20 per cent. of fat in order to produce a modified milk containing 5 per cent. of fat?

(4) How many pounds of skim-milk must be mixed with two pounds of 4.5 per cent. milk in order to produce a mixture containing 3 per cent. of fat?

(5) How much skim-milk must be removed from milk containing 3 per cent. of fat in order to increase the fat to 3.7 per cent.?

\section{CORRECTING QUEVENNE LACTOMETER READING FOR TEMPERATURE}

Rule.-For each degree F. above $60^{\circ}$ F. add .I, and for each degree below $60^{\circ}$ F. subtract .I (See p. I3I). 
16. CONVERTING QUEVENNE INTO BOARD OF HEALTH LACTOMETER DEGREES.

Rule.-Divide the Quevenne reading by .29. (See p. I34.)

17. CONVERTING BOARD OF HEALTH INTO QUEVENNE LACTOMETER DEGREES

Rule.-Multiply the Board of Health reading by .29. (See p. I34.)

18. CORRECTING BOARD OF HEALTH LACTOMETER READING FOR TEMPERATURE

Rule.-For each degree $\mathrm{F}$. of temperature above $60^{\circ} \mathrm{F}$. add .3 , and for each degree below $60^{\circ} \mathrm{F}$. subtract .3. (See p. I36.)

\section{CHANGING VOLUME INTO WEIGHT}

Rule.-To convert a known volume of a liquid into pounds when the specific gravity is known, multiply' the specific gravity of the liquid by the weight of an equal volume of water. Example: One gallon of water weighs 8.33 pounds; what is the weight of a gallon of milk whose specific gravity is 1.032? Multiplying 8.33 by 1,032 , we have as the answer 8.6 pounds.

20. CHANGING POUNDS OF MILK INTO QUARTS

Rule.-Divide the number of pounds of milk by 2.15 . Example: How many quarts of milk in 100 pounds? $100 \div 215 .=46.5$ quarts. 


\section{CHANGING QUARTS OF MILK INTO POUNDS}

Rule.-Multiply the number of quarts by 2.I5. Example: How many pounds in 40 quarts of milk? 40 $\times 2.15=86$ pounds.

\section{CHANGING DEGREES FAHRENHEIT INTO DEGREES CENTIGRADE}

Rule.-From the degrees $F$. subtract 32 and multiply the result by 5-9. Example: $162^{\circ} \mathrm{F} .=(162-32)$ $\times 5-9=72^{\circ} \mathrm{C}$.

\section{CHANGING DEGREES CENTIGRADE INTO DEGREES FAHRENHEIT}

Rule.-Multiply the degrees $C$. by 9-5 and add 32 . Example: $72^{\circ} \mathrm{C} .=(72 \times 9-5)+32=162^{\circ} \mathrm{F}$.

\section{FINDING THE TRUE AVERAGE}

Rule.-To find the true average per cent. of fat in different lots of milk or milk products, find the weight of fat in each separate lot by Rule I, add these amounts and divide the sum by the total weight of milk or milk products. Example: What is the average per cent. of fat in the following lots of milk?

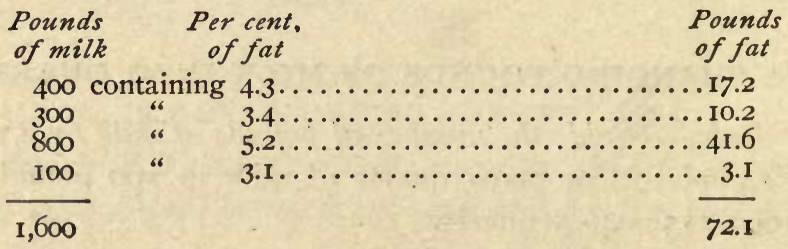


Applying Rule I, we find the weight of fat in each lot of milk, the results being indicated in the third column above. The total amount of fat in all of the milks is 72.1 pounds, which, divided by 1,600 (the total weight of milk), gives 4.5 as the real average per cent. of fat in all the milk.

It is wrong to regard as the average per cent. the result obtained by adding the per cents. directly and then dividing this sum by the number of lots represented, unless the amounts of milk or milk products are equal. Thus, in the foregoing example, the result of such a wrong method would make the average 4 per cent., when it is really 4.5 .

The same principle explains why we do not get a true average composite sample, when we take the same amount of milk from different lots that vary considerably in weight and per cent. of fat.

\section{EXAMPLES FOR PRACTICE}

(I) Find the average per cent. of fat in the following lots of milk: I,200 pounds, 3 per cent. of fat; 2,000 pounds, 5 per cent. of fat; 6,000 pounds, 4 per cent. of fat; and $\mathrm{I}, 800$ pounds, 3.5 per cent. of fat.

(2) Find the average per cent. of fat in 1,000 pounds of cream, 40 per cent. of fat ; 1,600 pounds, 30 per cent. of fat; and 400 pounds, 20 per cent. of fat.

\section{FINDING AMOUNT OF CREAM}

Rule.-To find the amount of cream produced for Ioo pounds of milk when the per cent. of fat in milk and in cream is known, divide the per cent. of fat in 
milk by the per cent. of fat in cream and multiply the result by Ioo. Example: How many pounds of cream containing 25 . per cent. of fat are produced from too pounds of milk containing 5 per cent. of fat? $5 \div 25=.2$. $.2 \times 100=20$, number of pounds of cream with 25 per cent. of fat.

\section{FINDING AMOUNT OF SKIM-MILK}

Rule.-To find the amount of skim-milk for $\mathrm{IOO}$ pounds of milk when the per cent. of fat in milk and in cream is known, find the amount of cream by Rule 25 and then subtract this from Ioo. Example: How much skim-milk is produced from too pounds of milk containing 4 per cent. of fat when the cream contains 25 per cent of fat? $4 \div 25=.16 ; .16 \times 100=16 ; 100-$ $16=84$, number of pounds of skim-milk.

\section{FINDING AMOUNT OF BUTTERMILK}

Rule.-To find the amount of buttermilk for Ioo pounds of milk when the per cent. of fat in milk and in cream is known, multiply the amount of fat in 100 pounds of milk by I.I7 and subtract the result from the amount of cream. Example: How many pounds of buttermilk are produced for Ioo pounds of milk containing 4 per cent. of fat, when the cream used contains 25 per cent. of fat? $4 \times 1.17=4.68$ (pounds of butter made) ; $4 \div 25 \times 100=16$ (pounds of 25 per cent. cream) $; \mathrm{I} 6-4.68=\mathrm{II} .32$ (pounds of buttermilk). 


\section{FINDING SPECIFIC GRAVITY OF MILK-SOLIDS}

Rule.-To find the specific gravity of milk-solids, when the specific gravity of the milk and per cent. of milk-solids are known, multiply the specific gravity of the milk by 100 , from the result subtract IOO and divide this result by the specific gravity of the milk. Subtract the last result from the per cent. of milk-solids and then divide this result by the per cent. of milksolids. (See p. I39.)

\section{FINDING AMOUNT OF ADDED WATER IN MILK}

See page $\mathbf{1 4 2}$.

\section{FINDING AMOUNT OF MOISTURE IN BUTTER}

Rule.-To find the approximate amount of moisture in butter, add 3 to the per cent. of fat (obtained by the method described on p. 85) and subtract the sum from Ioo. In adding 3, allowance is made for I per cent. of casein and 2 per cent. of salt in the butter. The results by this method should in most cases be within I or 2 per cent. of the correct figures. Example: How much moisture in butter containing 83.7 per cent. of fat? $83.7+3=86.7$; 100-86.7 $=\mathrm{I} 3.3$, the per cent. of moisture.

\section{TABLE SHOWING APPROXIMATE EQUIVA- LENTS OF METRIC SYSTEM
I fluid ounce $=29.60$ cubic centimeters (cc.)
I quart $=0.95$ liter (1.)
I gallon $\quad 3.8$ liters.
I grain $=65$. miligrams (mg.)
I ounce $(\mathrm{av})=$.28.35 grams $(\mathrm{gm}$. $)$
I pound $\quad .45$ kilogram (kg.) 



\section{N D E X}

PAGE

Acid, lactic, from milk-sugar .. 13

Estimation of ......996-108

Acid, sulphuric, action in Bab-

cock test ......... 33

Adding to milk ...... 56

Care in handling ...... 44

Effect of strong and weak acid ......... 42

Measuring for test ..... 56

Mixing with milk ..... 58

Strength of ....... 42

Temperature when used ... 57

Testing strength of .....44

Acid-hydrometer ....... 43

Acid-measures ...... 36, 37

Testing accuracy of .... 49

Acid solution ........ 98

Acid tester .......... 43

Acid tests, Mann's ...... 101

Spillman's ......... 105

Acids, action on alkalis .... 97

In milk-fat ......... 3

Volatile acids ....... 4

Acidity, indicators for . .... 98

In milk, causes and kinds of 96

In milk in relation to bacteria 113

In rich and poor cream :... 110

Principles of testing .... 97

Rapid estimation of ..... 106

Testing of, in cheese .... 110

In cream and milk .. 101-108

In whey ......... 109

Acidometer ........ 43

Adulterations of butter .... 149

Cheese .......... 150

Cream ........... 148

Milk ............ 141
PAGE

Age of composite samples when tested ........... 31

Of milk, testing by rennet .. 126

Albumin in milk ....... 11

In relation to casein .... 12

Alkalis, action on acids .... 97

Alkali test, Purdue ..... 107

Alkaline solution ....... 98

Alkaline-tablet test ...... 103

Analysis. See Composition.

Annatto, detection of, in milk .147

Apparatus in Babcock test ... 34

Testing accuracy of ..... 45

Appearance in judging and scor-

ing butter ....... 167

Cheese ........... 180

Arithmetic of milk and products

193-212

Ash in milk ........ 13

Average, true, how to find . . 210

Babcock test ........ 32

Acid measure :...... 36

Acid used in ........ 42

Action of acid ...... 33

Apparatus .......... 34

Benefits of use ...... 32

Bottles ...... 34, 70,82

Centrifugal machines ... 38-40

For butter ........ 85

For buttermilk ....... 83

For cheese ........ 83

For condensed milk ..... 91

For cream ......... 69

For milk ......... 53

For milk powder ....... 94

For skim-milk ....... 81 
Babcock test for whey PAGE

Modifications of ...... 66

Operation of ....... 53

Pipette ............ 35

Principles underlying .... 33

Reading results ....... 61

Testers ........... 38

Testing accuracy of apparatus 45

Use of centrifugal force... 33

Water used in ...... 60

Bacteria and acidity of milk . 113

Bacterial condition of milk, test-

ing $\ldots \ldots \ldots \ldots \ldots$

Bichromate of potash as preservative ......... 29

Board of Health lactometer . . 133

Body of butter ....... 162

of cheese .......... 176

Borax in milk, detection of . . 148

Bottles, Babcock test, for cream 70,71

For milk .......... 34

For skim-milk, whey, etc. .. 82

Butter, appearance in judging .167

Body of .......... 162

Calculating dividends for ...201

Calculating water in .....213

Classes of ........ 170

Color of .......... 164

Commercial testing, judging, and scoring ............. 158

Composition of ...... 16

Definition of ....... 18

Finish of ........ 167

Flavor of ......... 159

Grades of ......... 171

Gray's test for water in ... 86

Judging . . . . . . . 158

Moisture in ......86, 163

"Overrun," how to calculate 196

Package .......... 167

Qualities of ....... 159

Renovated ....... 18, 149

Salt in ............ 166
PAGE

Butter, sampling for fat-test . 85

For $\mathrm{judging}$ and scoring .. 158

Scale of points...... 168

Score-cards ......... 168

Scoring ......... 167

Standard of ....... 18

Texture of ......... 161

Yield of, how to calculate .. 197

Butter-fat. See Milk-fat.

Buttermilk, composition of ... 16

Testing fat in ....... 83

Yield of, calculating .... 212

Butter-trier ........ 159

Butyrometer, Gerber's ..... 67

By-products of milk, composition of .............. 16

Calcium casein ........ 9

Calibration of glassware ....4 45

Casein in milk, action of acids

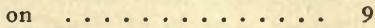

Of alkalis......... 10

of heat ........... 10

Of rennet......... 10

Calculating amount of, from fat in milk ...... 200

Composition of ....... 9

Lactate ........... 10

Per cent. in milk ...... 12

Products formed from .... 11

Proportion to albumin .... 12

Centigrade degrees calculating to Fahrenheit ...... 210

Centrifugal force in Babcock test ........... 33

Machines .......... 38

Centrifuges ..... 38, 40, 118

Cheddar cheese, American, composition of ...... 16

Commercial testing, judging, and scoring .....173, 181

Cheese, adulterations of ... 150

Appearance and finish of ... 180

Body of ........ 176 
PAGE

Cheese, calculating yield of,

from fat ......... 198

From fat and casein ... 199

Classes of ............... 181

Color of .......... 178

Commercial judging, testing, and scoring of ..... 173

Commercial qualities of ...173

Composition of ...... 16

Definition of ....... 19

Dividends from, calculating .203

Finish of ........ 180

Flavor of ....................... 173

Judging of ......... 173

Package .......... 180

Salt in ......... 179

Sampling for fat-testing ... 84

For judging and scoring .173

Score-cards ........ 181

Scoring .......... 181

Standard ......... 19

Testing acidity in ..... 110

Testing commercial qualities .173

Testing fat in ...... 83

Texture .......... 175

Trier for sampling ..... 173

Yield of, calculating ... 198

Cheese-factory, calculating divi-

dends of ........203

Chemistry of cow's milk .... 1

Churned samples of milk ... 21

Prevention of ...... 22

Sampling of ....... 21

Cleaning greasy glassware ... 49

Collecting sediment in milk. . 117

Coloring matter in milk, detec-

tion of ......... 147

Commercial testing, judging, and scoring of butter.... 158

Of certified milk..... 190

Of cheese ........... 173

Of cream ......... 190

Of milk.......... 187

Of standardized milk. .... 190
Composite samples, age for testing ................... 31

Care of ............. 30

Description ......... 24

Method of taking. ..... 26

Preserving ........ 28

Sampling for test..... 54

Sample-jars. ....... 25

Composition of butter .... 16

Buttermilk ........ 16

Casein ............ 9

Composition of cheese .... 16

Milk ........... 15

Milk-fat ......... 3

Skim-milk ........ 16

Whey ........... 16

Condensed milk, testing fat of. . 91

Corrosive sublimate as preserva-

tive .......... 28

Cows, testing on farm .... 151

Cows' milk, analyses of. .... 15

Chemistry of ........ 1

Composition of ...... 15

Definition of ....... 16

Standard of ......... 17

Cream, acidity of, testing . 96, 112

Adulterations of ...... 148

Bottles, bulb-necked ..... 70

Straight-necked ...... 71

Calculating yield of .....211

Color of fat-column ..... 64

Commercial testing, scoring and judging ....... 190

Definition of ...... 18

Keeping samples of .....73

Method of sampling ..... 72

Poor and rich, acidity in .. 110

Preparing sample for testing .73

Standard ......... 18

Testing fat in .....69-76

Weighing sample of ....75

Cream scales......... 72

Creamery dividends, calculation

of ...........201

Curd-test, Wisconsin .... 114 
Cylinder, for lactometer ... 133

Spillman's, acid-test . . . . 105

Definitions of milk and milk products ........ 16-19

Detection in milk, of annatto . 147

Borax........... 148

Coloring matter ...... 147

Formalin ......... 147

Of skimmed milk.... 144, 146

Of watered milk .,.. 141, 146

Dipper, sampling ....... 27

Dirt in nilk, testing . . . . 117

Dividends, calculating, at cream-

eries .......... 201

At cheese-factories .... 203

Double-necked test-bottles ... 82

Draining-rack ....... 51

Farm, testing milk on .... 151

Farrington's alkaline-tablet test 103

Bottle-cleaner ......551,52

Fat in milk. See milk-fat.

Fat-column, black particles in . 64

Gas-bubbles in ...... 65

Measuring, in cream-testing . 77

White particles in ..... 65

Fat-globules, in milk, number . 4

Size ........... 4

Influences affecting .... 5

In cheese, etc........ 5

Fermentation test of milk, Wisconsin ............ 114

Gerber's ......... 117

Finish of butter ...... 167

Of cheese ........ 180

Flavor of butter...... 159

Cheese .......... 173

Milk, cream, etc. ..... 185

Formalin in milk, as preserva-

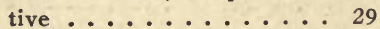

Detection of ....... 147

Frozen milk, sampling of ... 23

Galactase in milk ...... 11

Gerber's butyrometer ..... 67

Fermentation test ..... 117
Gerber's "Sal" test ........ 68

Glassware in Babcock test, calibration of ......4 45

Cleaning of ....... 49

Testing accuracy of ....45

Globulin in milk ....... 11

Glycerin in milk-fat ...... 3

Grades of butter ....... 171

Of cheese ......... 181

Gray's test for water in butter 86

Greiner's automatic pipette . . 36

Hand-testers ....... 39, 118

Hydrometer for testing specific gravity ........ 130

Testing strength of acid ...44

Infant foods, testing fat in .. 93

Indicator in testing acidity ...998

Jars, waste, for emptying testbottles ........ 50

Jars, for composite samples . . 25

Judging butter ...... 158-167

Cheese ......... 173-181

Cream .......... 190

Milk ......... 182-190

Kumiss, definition of ..... 19

Lactate, casein ........ 10

Lactate acid in milk .... 13, 96

Estimation of ..... 96-108

From milk sugar ....... 13

Lactose ... . . . . . . 13

Lactometer, application. . . 127-140

Board of Health ....... 133

Bi-chromate, effect on .... 136

Cylinder for ........ 133

Method of using ...... 131

Quevenne ......... 130

Temperature, effect on $.129,131$

Mann's acid test ....... 101

Marschall rennet test ..... 123

Measures for acid ...... 36

Measuring, acid ...... 56

Fat-column in testing cream. 77

In testing milk ..... 63 
Metric system, equivalents of . 213 Milk, acidity of ...... 96

Adding acid to ...... 56

Adulteration of ....... 141

Age of, testing . . . . . 126

Albumin in ........ 11

Analyses of ........ 15

Arithmetic of . . . . . 193

Ash in ......... 13

Chemistry of ........ 1

Churned, sampling of . . . 21

Color of ........ 186

Certified, judging . . . . . 190

Composite sampling of .... 24

Composition of . . . . 15

Condensed . . . . 17, 91

Definition of ........ 16

Detection of adulterations in 141

Flavor of . . . . . . . 185

Frozen, sampling of ..... 23

Gases in .......... 14

Judging and scoring . . . 187

Keeping power of . . . . 184

Mixing with acid ...... 58

Modified, to prepare ....203

Nitrogen, compounds of ... 8

Salts in .......... 13

Sampling of ......20-31

Sampling with pipette.... 54

Scale of points in judging . . 187

Scoring of . . . . . 187

Skimmed, detection of . 144, 146

Sour, sampling of ..... 23

Souring of ....... 13

Specific gravity of . . . . 127

Standard of . . . . . 17

Standardized, to prepare ...203

Standardized, judging and scoring . . . . . . . 190

Temperature for testing . . . 57

Terms used in judging and scoring ......... 182

Testing acidity of . . 96-108

Total solids of . . . 3, 137

Watered, detection of . .141, 146

Milk-albumin ........11
Milk-bottle, use of in cream-testing ............ 69

Milk, Casein. See Casein.

Milk-fat, color of in Babcock test 64

Composition of ...... 3

Definition of ....... 18

Glycerin in ........ 4

Influenced by various conditions ........ 5-8

In relation to butter yield $\ldots 197$

In relation to Casein . . . 200

In relation to cheese . . . 198

Method of testing, in butter . 85

In buttermilk ...... 83

In cheese $\ldots \ldots \ldots .83$

In condensed milk..... 91

In cream . . . . . 6 69-77

In milk ...... 53-66

In milk powders . . . . 99 94

In skim-milk ....... 81

In whey $\ldots \ldots \ldots \ldots 83$

Per cent. in foremilk ... 8

In strippings $\ldots \ldots \ldots 8$

Standard of ....... 18

Variation of, in milk .... 5

Volatile acids in ...... 4

Milk-globulin ........ 11

Milk, measuring with pipette.. 54

Milk powders, testing of . . . 994

Milk products, arithmetic of . 193

Composition of ....... 16

Judging and scoring . . 158-192

Milk serum ......... 15

Milk-solids, composition of . . 3, 14

Estimating by lactometer . . 137

Specific gravity of . . . . 139

Milk-sugar . . . . . . 13

Milk testing, Babcock test . . 32, 53

On the farm ........ 151

Mixing milk and acid ..... 58

Moisture. See water.

Monrad reniet-test . . . . 121

Neutral solutions . . . . . . . 98 98

Neutralization .......997 
Nitrogen compounds of milk PAGE In relation to fat .....12, 144

New York Board of Health lactometer .......... 133

Oleomargarin, test for .... 149

"Overrun" in butter, how to find ..................

Package, judging and scoring of, in butter........ 167

In cheese ........... 180

Per cent. of any constituent of milk and products, how to find ............. 194

Percentages, average, how to find ......... 210

Phenolphthalein as indicator .. 98

Pipette, in Babcock test .... 35

Accuracy of, testing ..... 49

Correct way to use ..... 55

Greiner's ......... 36

In cream testing ...... 75

Sampling milk with .... 54

Wagner's ......... 36

Potassium-bichromate .... 29

Pounds, to change to quarts . 209

Powdered milk, testing of ... 94

Preservatives for composite samples........... 28

Detection of, in milk. ... 147

Purdue alkali test ...... 107

Qualities, commercial, of butter 159

Cheese .......... 173

Milk ........... 182

Cream .......... 190

Quarts to change to pounds . 210

Quevenne lactometer, description of ........ 130

Correcting for temperature . 131

How to use ........ 131

Compared with Board of

Health lactometer ..... 135

Rack, draining for test-bottles . 51

For composite samples .... 26

Rennet-test, Marschall's .... 123
Rennet-test, Monrad's ..... 121

Renovated butter, definition of 18

How to detect....... 149

Standard of ........ 19

Richmond's slide-rule for finding milk-solids ...... 138

Russian test for fat in milk and products ........66 66

"Sal" test for fat in milk, etc., Gerber's ......... 68

Salt in butter, commercial judg. ing and scoring ..... 166

In cheese .......... 179

Salts in milk........ 13

Samples, See Composite samples.

Sampling butter ..... 85, 158

Cheese ........ 83, 173

Cream ......... 72

Milk, composite ...... 24

Frozen ........ 23

Partially churned ..... 21

Partially creamed ..... 20

Sour ......... 23

With pipette ......... 54

Sampling-dipper ...... 27

Sampling-tubes ....... 27

Scales for weighing cheese,

cream, etc ..... 72

Score-cards for butter .... 168

Cheese ........... 181

Scoring butter ....... 167

Cheese ........... 181

Cream ........... 190

Milk ........... 187

Standardized milk ...... 190

Sediment in milk, how to test for ............ 117

Serum of milk ....... 15

Solids of ........ 15

Sinacid test for fat in milk, etc. 67 ,

Skim-milk, composition of ... 16

Detection of ..... 144, 146

How to calculate yield of .. 212

Test-bottles ......... 82

Testing for fat in ..... 81 
Slide-rule, Richmond's for calculating solids ...... 138

Sodium carbonate in milk, detection of ....... 148

Solids-not-fat in milk .... 15

How to find amount of ... 137

Solids, total, in milk. See Milksolids.

Sour milk, cause of ...... 13

Sampling of ....... 23

Specific gravity of milk .... 127

Cylinder ............ 133

Effect of fat on ...... 128

Effect of temperature on ... 129

Effect of water on .... 128

How to find ........ 129

Specific gravity, of milk solids . 139

Table for temperature correc-

tion ............ 132

Speed of testers ....... 40

Spillman's acid-test cylinder .. 105

Standard of butter ...... 18

Butter-fat ......... 18

Cheese .......... 19

Condensed milk ...... 17

Cream .......... 18

Milk-fat ......... 18

Standard of Renovated butter . 19

Skim-milk ......... 17

Steam-turbine tester ..... 38

Sugar of milk ........ 13

Sulphuric acid. See acid.

Sweetened condensed milk ... 17

Table of correction of specific gravity for temperatures . 132

Equivalents of metric systems 213

Of degrees of Board of Health and Quevenne lactometers .......... 135

remperature of acid in testing milk ......... 57

Of fat-column when read ... 62

In relation to specific gravity 129

Of milk when tested .... 57
Terms describing commercial qualities of butter .... 159

Of cheese ......... 173

Of cream and milk ..... 182

Test, Babcock. See Babcock Test.

Curd, Wisconsin ....... 114

Fermentation, Gerber's ... 117

Rennet, Marschall ...... 123

Monrad .......... 121

"Sal," Gerber's ....... 68

Russian ......... 66

Sinacid .........6 67

Test-bottles, accuracy of, testing 45

Bulb-necked, cream ..... 70

Calibration ......... 45

Cleaning ............ 49

Cream .......... 70

Double-necked ....... 79

Drain-rack ........ 51

Test, Milk ........ 34

Rinser......... 50

Skim-milk ........ 82

Straight-necked cream .... 71

Tester .......... 46

Whirling ........ 59

Testers, Babcock ...... 37

Bottle ......... 46

Electrical ......... 40

Estimating speed of ..... 40

Hand ............ 39

Steam-turbine ....... 38

Testing, accuracy of test bottles,

etc. .......... 45

Acidity of cream, milk, etc. 96-108

Age of milk ....... 126

Butter .......... 85

Cheese .......... 83

Condensed milk ...... 91

Cows on farm ....... 151

Dirt in milk ........ 117

Infant foods........ 93

Milk powders ........ 94

Pepsin ......... 125

Rennet .......... 121

Fexture, commercial, of butter .161 
Texture, commercial, of cheese $\begin{array}{r}\text { PAGE } \\ 175\end{array}$

Titration ........... 100

Total solids of milk. See milksolids.

Trier for testing butter . . . 159

Cheese ......... 173

Tube, sampling $\ldots \ldots \ldots 27$

Turbine testers $\ldots \ldots \ldots \ldots 38$

Volatile acids in milk-fat .... 4

Volume of liquid, changing to weight ........209

Wagner's pipette ...... 36

Skim-milk bottle . . . . 82

Waste acid jar....... 50

Water, in milk, amount of ... 1

Causes of variation ..... 2

Detection of, in adulterated . 141

In butter, calculation of $\ldots 213$

In butter-testing . . . . 86

In commercial testing and judging of butter ..... 163

In milk and milk products 15,16
PAGE

Water used in Babcock test . . 60

Watered milk, detection of ... 141

Weighing samples of cream ... 75

Weight of any constituent of milk and products, how to find ............... 193

Changing to volume ..... 209

Weights and measures, equivalents of metric system ...213

Whey, composition of .... 16

Definition of ....... 19

Testing of ....... 81

Whirling test-bottles ..... 59

Wisconsin curd-test ..... 114

Yield of butter, how to calculate 197

Buttermilk ........ 212

Cheese, for fat ...... 198

Cheese, from fat ...... 199

Cheese, from fat and casein . 199

Cheese, from fat and lacto-

meter ...........201

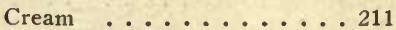

Skim-milk ........ 212

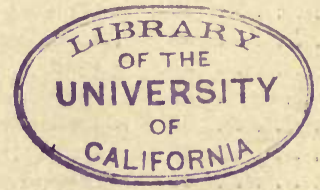




\section{The Quality \\ Cream Separator}

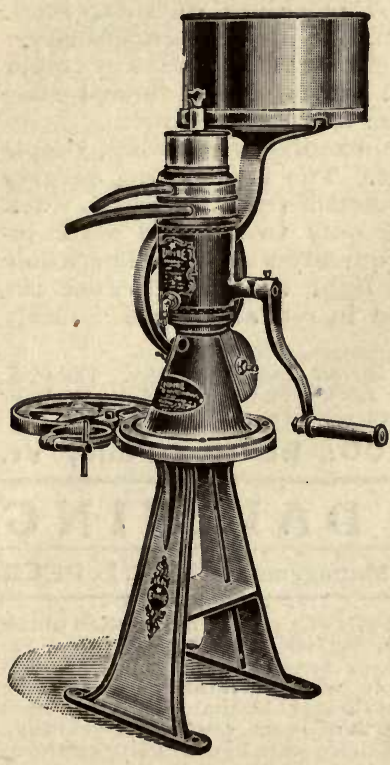

Do GET the best results from your cows, to make the most money from their milk, you must obtain the highest quality of cream. There is a way to do this, and only one way, and that is by using an

\section{Improved Frictionless}

\section{Empire}

\section{Eream separator}

The Separator of "Quality"

The reasons are simple and plain. No matter how fine your cows are, their milk contains impurities. Impurities mean second or third grade cream. The Empirs removes all the impurities from the milk and cream.

A separator to get pure first quality cream must be cleaned after every separation and thoroughly cleaned. The Empire is the simplest separator on the market, of few, simple parts. It is the most easily and quickly cleaned, and kept clean.

There are a hundred other reasons why an Empire Cream Separator will give you the best results in dollars made. Write for our catalog and free dairy booklets, and investigate them for yourself.

\section{EMPIRE CREAM SEPARATOR CO.,} BLOOMFIELD, N. J. 


\section{THE IMPROVED \\ U. S. SEPARATOR}

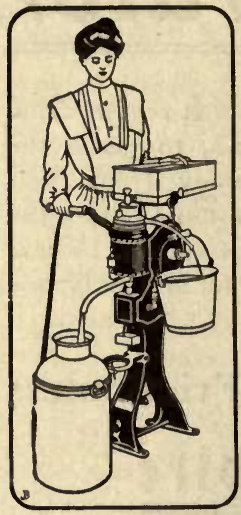

For many years the U. S. Separators have been tested under all conditions, and have proved to thousands of satisfied users that they are the best machines of their kind. There are good reasons for their superiority.

The U. S. skims cleaner than any other separator because the milk is skimmed three distinct times before leaving the bowl.

All parts of the machine are strong, simple and easy to get at. The gears being entirely enclosed are protected from dirt and dust. The bowl having only two simple parts inside is easily and quickly washed. The whole machine is very light running because the working parts run in oil, and are accurately made and fitted.

No other separator has all these advantages. The U.S. is the cream separator for you to buy. Send for catalogue and name of nearest local selling agent. Address,

VERMONT FARM MACHINE CO., Bellows Falls, Vt. PROFITABLE DAIR YING

A Practical Guide to Successful Dairy Management. By C. L. PECK

The introductory chapter of this book consists of a minute description of the far-famed model dairy farm of Rev. J. D. Detrich, near Philadelphia, Pa. Never perhaps has the description of any farm caused a more profound sensation in the agricultural world. This article, which originally appeared in American Agriculturist, is out of print and nolonger obtainable; it is reprinted herewith by numerous requests. On this farm of 15 acres, which 20 years ago could not maintain one horse and two cows, there were kept 27 dairy cattle, in addition to two horses. All the roughage, litter, bedding, etc., necessary for these animals was grown on these 15 acres, more than most farmers could ac. complish on roo acres. A description of this plain, unpretentious little farm sounds almost like a fairy tale, and yet it is nothing but plain, clear facts, of the truth of which anyone can convince themselves.

The author of this volume is a well known, practical dairyman, who has made dairying a marked success, and who, in this volume, gives such practical hints on dairying as will enable the reader to improve his methods, better his conditions and more clearly attain that poiut in business known as success. The treatment of the entire subject is thoroughly practical in every detail, being principally a description of the methods practiced by the author, and which after a lifetime of experience and study he has found most advantageous. Yet the scientific bearing on the subject has not been neglected, as the author has availed himself of all the most recent discoveries and advancements in science, thus making the work authoritative, practically as well as scientifically.

Separate chapters are devoted to the importance of the dairy, physiology, and secretion of milk, future of dairying, dairy breeds, selection of a breed, the dairy cow and the dairy sire, dairy standard, care and feed of the dairy cow, care of the calf, milking, when to have cows come fresh, feeds and their value, care of the milk, device for ripening cream, churning, marketing dairy butter, the dairy barn, silo and silage, miscellaneous topics, necessary appliances, general hints, dairy remedies.

Illustrated. $5 \times 7$ inches. 174 Pages. Cloth. Price, 75 cents 


\section{STANDARD BOOKS}

.. PUBLISHED BY..

\section{ORANGE JUDD GOMPANY}

NEW YORK

52 \& 54 Lafayette Place
CHICAGO

Marquette Building

BOOKS sent to all parts of the zuorld for catalog price. Discounts for large quantitzes on application. Correspondence invited. Brief descriptive catalog free. Large illustrated catalog, six cents : $:$

\section{The Cereals in America}

By Thomas F. Hunt, M.S., D. Agr. If you raise five acres of any kind of grain you cannot afford to be without this book. It is in every way the best book on the subject that has ever been written. It treats of the cultivation and improvement of every grain crop raised in America in a thoroughly practical and accurate manner. The subject matter includes a comprehensive and succinct treatise of wheat, maize, oats, barley, rye, rice, sorghum (kafir corn), and buckwheat, as related particularly to American conditions. Fi i t-hand knowledge has been the policy of the author in his work, and every crop treated is presented in the light of individual study of the plant. If you have this book you have the latest and best that has been written upon the subject. IHlustrated. 450 pages. $5 \mathrm{I}-2 \times 8$ inches. Cloth. . . . . $\$ 1.75$

\section{The Potato}

By Samuel Frazer. A reliable guide on the cultivation of the potato, its development, manuring and fertilizing, planting, tillage, sprays and spraying, breeding new varieties, harvesting, storing, marketing, etc., etc. Taken all in all it is the most zomplete, reliable and authoritative work on the potato ever published in America. Illustrated. 200 pages. $5 \times 7$ inches. Cloth. 


\section{Farm Grasses of the United States of America}

By William. Jasper Spillman. A practical treatise on the grass crop, seeding and management of meadows and pastures, description of the best varieties, the seed and its impurities, grasses for special conditions, lawns and lawn grasses, etc., etc. In preparing this volume the author's object has been to present, in connected form, the main facts concerning the grasses grown on American farms. Every phase of the subject is viewed from the farmer's standpoint. Illustrated. 248 pages. $5 \times 7$ inches. Cloth. . . \$1.00

\section{The Book of Corn}

By Herbert Myrick, assisted by A. D. Shamel, E. A. Burnett, Albert W. Fulton, B. W. Snow, and other most capable specialists. A complete treatise on the culture, marketing and uses of maize in America and elsewhere, for farmers, dealers and others. Illustrated. 372 pages. $5 \times 7$ inches. Cloth.

\section{The Hop-Its Culture and Care, Marketing and Manufacture}

By Herbert Myrick. A practical handbook on the most approved methods in growing, harvesting, curing and selling hops, and on the use and manufacture of hops. The result of years of research and observation, it is a volume destined to be an authority on this crop for many years to come. It takes up every detail from preparing the soil and laying out the yard, to curing and selling the crop. Every line represents the ripest judgment and experience of experts. Size, $5 \times 8$; pages, 300 ; illustrations, nearly 150; bound in cloth and gold; price, postpaid,

\section{Tobacco Leaf}

By J. B. Killebrew and Herbert Myrick. Its Culture and Cure, Marketing and Manufacture. A practical handbook on the most approved methods in growing, harvesting, curing, packing and selling tobacco, with an account of the operations in every department of tobacco manufacture. The contents of this book are based on actual experiments in field, curing barn, packing house, factory and laboratory. It is the only work of the kind in existence, and is destined to be the standard practical and scientific authority on the whole subject of tobacco for many years. 506 pages and 150 original engravings. $5 \times 7$ inches. 


\section{Land Draining}

A handbook for farmers on the principles and practice of draining, by MANLY MiLES, giving the results of his extended experience in laying tile drains. The directions for the laying out and the construction of tile drains will enable the farmer to avoid the errors of imperfect construction, and the disappointment that must necessarily follow. This manual for practical farmers will also be found convenient for reference in regard to many questions that may arise in crop growing, aside from the special subjects of drainage of which it treats. Illustrated. 200 pages. $5 \times 7$ inches. Cloth. . . \$1.00

\section{Barn Plans and Outbuildings}

Two hundred and fifty-seven illustrations. A most valuable work, full of ideas, hints, suggestions, plans, etc., for the construction of barns and outbuildings, by practical writers. Chapters are devoted to the economic erection and use of barns, grain barns, horse barns, cattle barns, sheep barns, cornhouses, smokehouses, icehouses, pig pens, granaries, etc. There are likewise chapters on birdhouses, doghouses, tool sheds, ventilators, roofs and roofing, doors and fastenings, workshops, poultry houses, manuse sheds, barnyards, root pits, etc. 235 pages. $5 \times 7$ inches. Cloth. . . . \$1.00

\section{Irrigation Farming}

By LUTE Wilcox. A handbook for the practical application of water in the production of crops. A complete treatise on water supply, canal construction, reservoirs and ponds, pipes for irrigation purposes, flumes and their structure, methods of applying water, irrigation of field crops, the garden, the orchard and vineyard, windmills and pumps, appliances and contrivances. New edition, revised, enlarged and rewritten. Profusely illustrated. Over 500 pages. $5 \times 7$ inches. Cloth.

\section{Forest Planting}

By H. Nicholas Jarchow, LL. D. A treatise on the care of woodlands and the restoration of the denuded timberlands on plains and mountains. The author has fully described those European methods which have proved to be most useful in maintaining the superb forests of the old world. This experience has been adapted to the different climates and trees of America, full instructions being given for forest planting of our various kinds of soil and subsoil, whether on mountain or valley. Illustrated. 250 pages, $5 \times 7$ inches. Cloth. \$1.50 


\section{Animal Breeding}

By Thomas Shaw. This book is the most complete and comprehensive work ever published on the subject of which it treats. It is the first book which has systematized the subject of animal breeding. The leading laws which govern this most intricate question the author has boldly defined and authoritatively arranged. The chapters which he has written on the more involved features of the subject, as sex and the relative influence of parents, should go far toward setting at rest the wildly speculative views cherished with reference to these questions. The striking originality in the treatment of the subject is no less conspicuous than the superb order and regular sequence of thought from the beginning to the end of the book. The book is intended to meet the needs of all persons interested in the breeding and rearing of live stock. Illustrated. 405 pages. $5 \times 7$ inches. Cloth. . . \$1.50

\section{Forage Crops Other Than Grasses}

By Thомas Shaw. How to cultivate, harvest and use them. Indian corn, sorghum, clover, leguminous plants, crops of the brassica genus, the cereals, millet, field roots, etc. Intensely practical and reliable. Illustrated. 287 pages. $5 \times 7$ inches. Cloth. . . . . . . . . \$1.00

\section{Soiling Crops and the Silo}

By Thомas Shaw. The growing and feeding of all kinds of soiling crops, conditions to which they are adapted, their plan in the rotation, etc. Not a line is repeated from the Forage Crops book. Best methods of building the silo, filling it and feeding ensilage. Illustrated. 364 pages. $5 \times 7$ inches. Cloth.

$\$ 1.50$

\section{The Study of Breeds}

By Thomas Shaw. Origin, history, distribution, characteristics, adaptability, uses, and standards of excellence of all pedigreed breeds of cattle, sheep and swine in America. The accepted text book in colleges, and the authority for farmers and breeders. Illustrated. $37 \mathrm{I}$ pages. $5 \times 7$ inches. Cloth.

\section{Profits in Poultry}

Useful and ornamental breeds and their profitable management. This excellent work contains the combined experience of a number of practical men in all departments of poultry raising. It forms a unique and important addition to our poultry literature. Profusely illustrated. 352 pages. $5 \times 7$ inches. Cloth. 

THIS BOOK IS DUE ON THE LAST DATE STAMPED BELOW

AN INITIAL FINE OF 25 CENTS WILL BE ASSESSED FOR FAILURE TO RETURN THIS BOOK ON THE DATE DUE. THE PENALTY WILL INCREASE TO 50 CENTS ON THE FOURTH DAY AND TO \$1.00 ON THE SEVENTH DAY OVERDUE.

\section{SEP 101932 \\ SEP 251932}

NOV 111937 
minn te nert

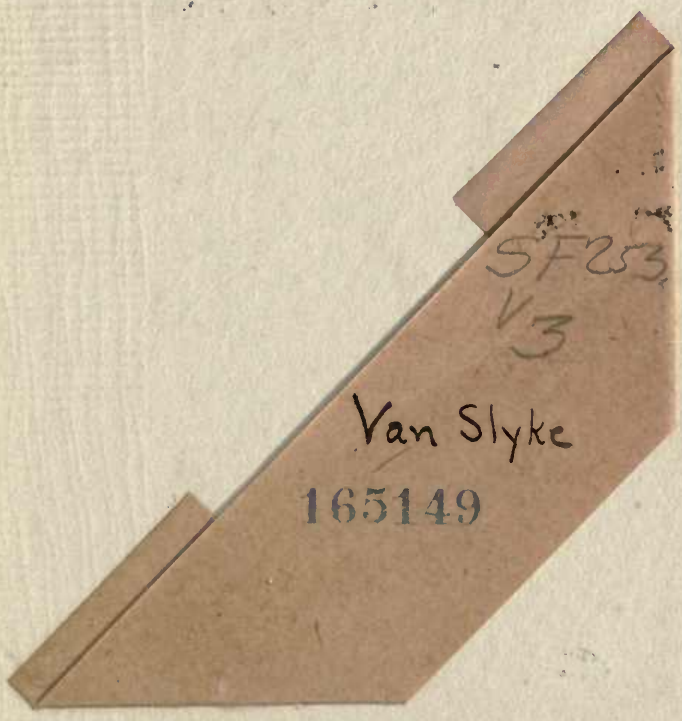


